\title{
Comparison of pure line cultivars with synthetic cultivars in local breeding of faba bean (Vicia faba L.) for organic farming
}

\author{
Dissertation \\ to obtain the Ph. D. degree \\ in the Faculty of Agricultural Sciences, \\ Georg-August-University Göttingen, Germany
}

presented by

Lamiae Ghaouti

born in Rabat, Morocco

Göttingen, 05.2007 
D7

1. Name of referee: Prof. Dr. Wolfgang Link

2. Name of co-referee: Prof. Mohammed Sadiki

Date of dissertation: 24.05 .2007 
To my dear family 
Table of contents

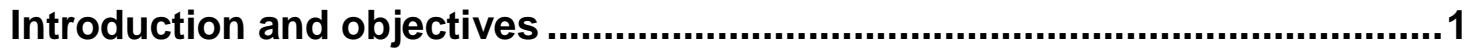

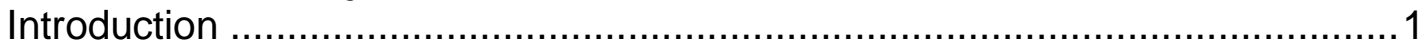

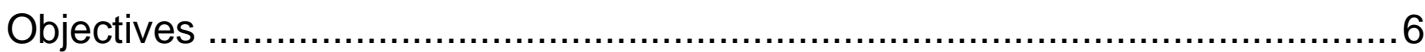

Chapter I. Development of locally-adapted faba bean cultivars for organic conditions in Germany through a participatory breeding approach .............10

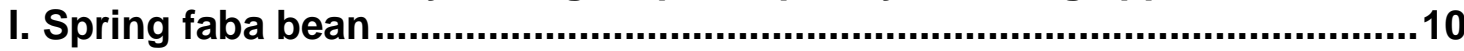

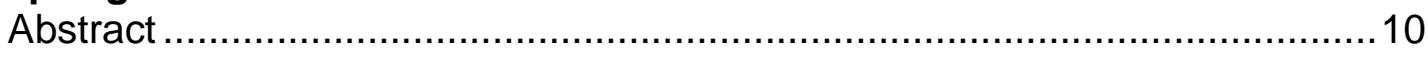

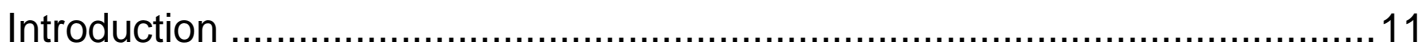

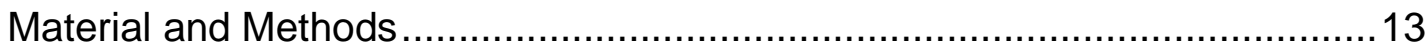

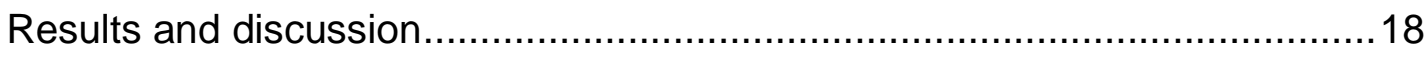

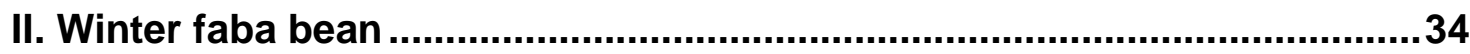

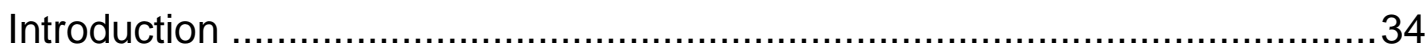

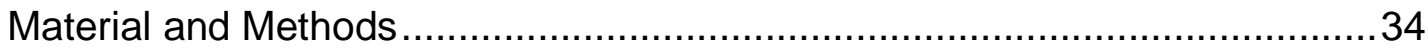

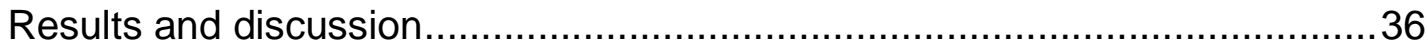

Chapter II. Comparison between local vs. formal breeding and inbred line vs. synthetic cultivars for organic farming. Case of Vicia faba L.................48

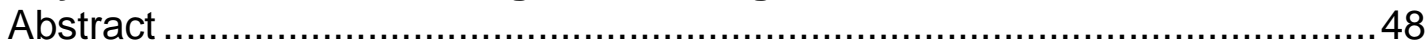

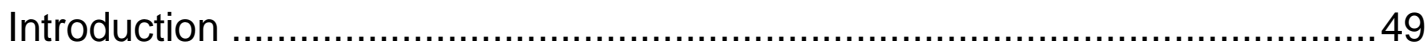

Material and Methods............................................................................ 51

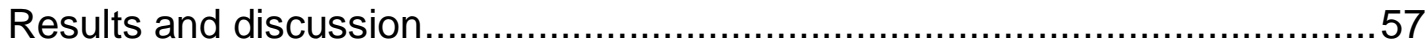

Chapter III. Relevance of competition effects among genotypes in breeding

faba bean (Vicia faba L.) ................................................................................ 78

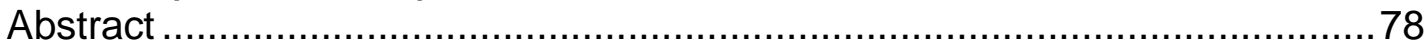

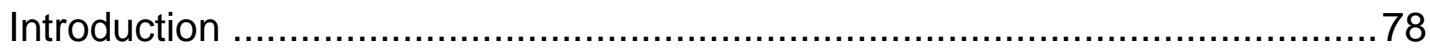

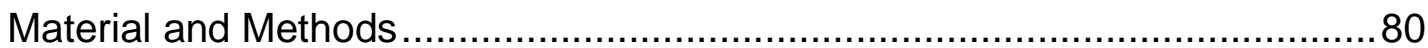

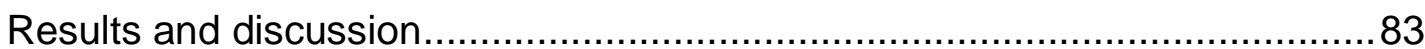

Chapter IV. Effect of competition between Vicia faba L. and Camelina sativa

as a model weed in breeding for organic conditions .................................100

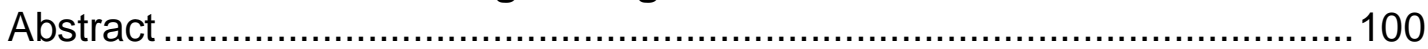

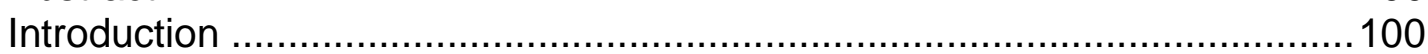

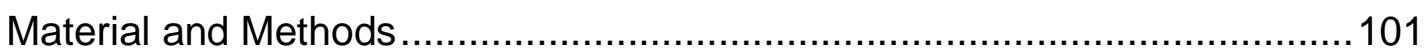

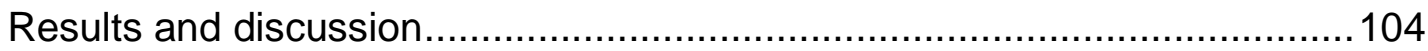

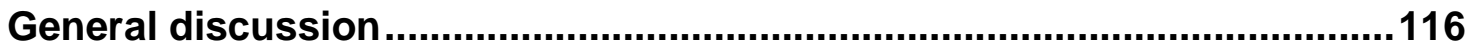

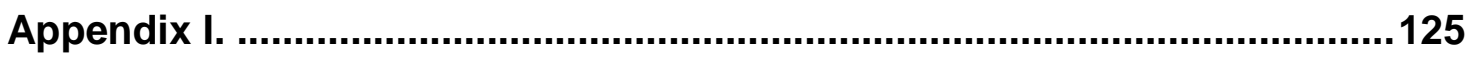

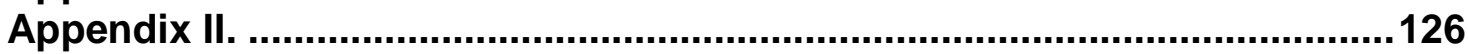

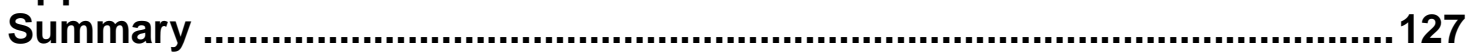

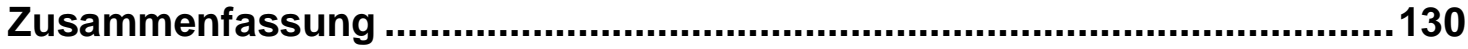

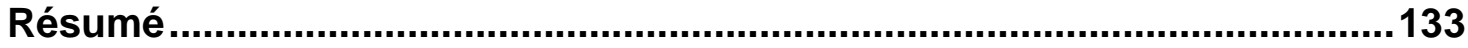

136

Acknowledgment f........................................................................................... 138 


\section{Introduction and objectives}

\section{Introduction}

\section{Vicia faba L.: an overview}

Faba bean (Vicia faba L.), formerly known as broad bean, is among the oldest crops in the world. Vicia faba is a diploid species with $2 n=12$ chromosomes. Its center of origin is believed to be between the oriental Mediterranean countries and Afghanistan (De Candolle, 1882; Cubero, 1974; Ladizinsky, 1975; Zohary, 1977; Abdalla, 1979). According to Muratova (1931), three distinct groups in faba bean were established based on seed size; minor (0.2-0.5 g per seed), equina and major (more than $2.0 \mathrm{~g}$ per seed). Faba bean with its about $30 \%$ of seed protein content constitutes a valuable source of protein for food in developing countries such as Asia, Central America and Africa where a large deficiency of animal protein is recorded. In developed countries, faba bean is mainly used for animal feeding. At the worldwide scale, faba bean occupies about 2.6 millions hectares which represents $4 \%$ of the total area consecrated to pulses. The cultivation of faba bean is mainly concentrated in Asia and Africa. From the worldwide area occupied by faba bean, $41 \%$ is concentrated in Asia, $33 \%$ in Africa, $12 \%$ in Europe and $7 \%$ in Oceania as well as in America. China is the largest grower (39\%) and producer (43\%) of faba bean at the world scale (FAO, 2005).

In Europe, the production of protein-rich crops is insufficient and the providing of such products is mainly relying on the import of soybean (22 millions t/year), mainly from North and South America (FAO, 2005). The promotion of faba bean in Europe will be of benefit to decrease dependency of Europe on imported soybean.

Although faba beans are high in protein content, carbohydrates and fiber, low in fat and provide vitamins and minerals, the breeding of faba is hampered by two main obstacles. Traditional faba bean seeds encompass a variable amount of anti-nutritional compounds (tannins and vicine - convicine) that reduce faba bean 
protein digestibility (Duc, 1997). Besides, yield instability is a major problem in faba bean which arises from its sensitivity to biotic and abiotic stresses faced over time and space.

In Germany, faba bean is after lupine (38.000 ha) and sunflower (27.000 ha) one of the smallest crop. The acreage of faba bean in 2005 was 16.000 ha whereas peas occupied 111.000 ha. As the infestation of peas with the root rot "Aphanomyces euteiches" has been detrimental for their yield (up to 90\% yield loss; Lacampagne, 2001), a recent regain of interest for faba bean has been seen, especially in France.

\section{Importance of faba bean in organic farming}

In Germany, faba bean occupied 6100 ha of the area devoted to organic faming in 2004 which constituted $39 \%$ of total area devoted to faba bean. The contribution of faba bean in the organic cropping system was twice as much its contribution in the conventional cropping system. The area of arable land sown to faba bean was $0.08 \%$ on conventional farms and $1.69 \%$ on organic farms (ZMP, 2004). Schmidtke and Rauber (2000) reported that grain legumes play a more important role in organic farming than in the conventional cropping systems. Faba bean as a legume crop serves as a break for cereal systems. It improves the productivity of the soil in cropping system based on cereal-legume rotations. Yield of cereals grown subsequently after faba bean is improved; one reason is nitrogen residues left by faba bean. Studies on the fixation of atmospheric nitrogen through symbiosis in organic farming (Schmidtke and Rauber, 2000) showed that faba bean surpasses peas in the amount of nitrogen fixed and in a positive $\mathrm{N}$-balance.

\section{Breeding in faba bean}

Breeding methods are classified into four distinct categories according to the reproduction type of the resulting cultivars (Schnell, 1982): breeding lineal cultivars with self fertilization, population cultivars with cross fertilization, hybrid 
cultivars with controlled crossing between the parents, and clonal cultivars with vegetative propagation. A special type of reproductive mode is the partial allogamy found, amongst others, in faba bean (Bond and Poulsen, 1983; Link, 1990), cotton (Lee, 1987), rapeseed (Becker et al., 1992) and pepper (Pochard et al., 1992).

Because of this intermediate mode of reproduction, the choice of the optimal breeding category in faba bean is difficult. The genetic structure of open pollinated populations in faba bean is complicated since plants with extremely different inbreeding coefficient $(F)$ are occurring. The variance of the individual inbreeding coefficient in faba bean populations depends on the degree of cross fertilization which varies greatly. Natural cross fertilization was reported to average $30 \%$ to $60 \%$ (Bond and Poulsen, 1983; Link, 1990) and to depend strongly on the genotype and the environmental conditions (Suso and Moreno, 1999). Ebmeyer (1988) pointed out that non inbred plants tend to self pollinate, whereas inbred plants tend to cross pollinate. Heterosis in faba bean, defined as the superiority of the F1 hybrid over the mean of its homozygous parents (Schnell, 1961), was found to attain high values. In winter beans, heterosis for grain yield averaged 30\% (Bond 1966), whereas in spring beans, it was reported to be from $50 \%$ to $70 \%$ (Link and Ruckenbauer, 1988; Ebmeyer, 1988; Link et al., 1994). Full use of heterosis in faba bean is only possible through hybrid breeding. However, the full commercial exploitation of heterosis is not possible, due to the insufficient stability of the two existing systems of cytoplasmic male sterility (CMS; Bond, 1989; Duc et al., 1992; Link; 2001). Ten years ago, Link et al. (1997) found a further CMS system and studies regarding it are still in progress (Martsch et al., 2001).

Until the achievement of the commercial production of hybrids, an alternative strategy to exploit a part of the heterosis is the production of synthetic cultivars. Synthetic cultivars are a specific kind of population cultivars, typically produced through random mating of a limited number of components selected based on their per se performance and their combining ability (Becker, 1988). The parental components are collectively called Syn-0 and their offspring collectively Syn- 1 . 
The amount of seeds of a synthetic cultivar is multiplied by successive generations of random mating without selection; these generations are called Syn-2, Syn-3, and so on (Busbice, 1969). In partially allogamous crops, the most comprehensive approach to account for the combining abilities of parental components in a synthetic is achieved through the use of the "varietal ability" (Wright, 1973; Wright, 1974; Link and Ederer, 1993). The size of the synthetic (specifying the number of components) influences two aspects. The first aspect is the inbreeding in the synthetic which can be reduced by the increase of the number of parental components. The second aspect is the intensity of selection which can be increased by the decrease of the number of the parental components (Becker, 1988). The number of parental components in a synthetic is therefore an optimum number realizing a compromise between these two aspects.

The quantitative genetic theory to predict the performance of synthetic varieties as developed by Busbice (1969), Gallais (1976) and Wright (1981) was based on the assumptions of random mating, no selection during seed multiplication, no epitasis, no competition and diploid inheritance. The assumption of random mating obviously is violated in faba bean. The assumption of the absence of competition between individuals in a synthetic is at least questionable. With partial allogamy, Syn-1 (composed from homozygous unrelated components in Syn-0) consists of fully inbred $(F=1)$ and non-inbred $(F=0)$ individuals. The competition between individuals with extremely contrasting inbreeding coefficient is not a negligible phenomenon and strict linearity between the performance and the inbreeding coefficient cannot be expected (Link and Ederer, 1993).

Breeding of line cultivars in faba bean could be advantageous if the variance available between the inbred lines is very high and if the inbreeding depression is low (Gallais, 1992). Line breeding is of special interest, when uniformity in certain characters is important, as for example in vegetable beans (Ebmeyer, 1988). Recent cultivars of spring faba bean were line cultivars such as Espresso and Marcel (2003), Taxi (2005) and Tattoo (2006). In winter beans, most cultivars are synthetics or populations originating either from France (landrace Côte d'Or, and 
cultivars Karl, Diva, Bourdon), UK (Bulldog, Clipper, Target; bred by D.A. Bond and M. Pope), or Germany (Winter Bean Population of Göttingen; Hiverna, Wibo, bred by H. Littman).

\section{Breeding approaches in organic farming}

In the past, adaptation to organic farming was not in the scope of breeding preoccupations. Organic farming requires varieties that are maximal adapted to organic conditions to improve yield, yield stability and quality (Lammerts van Bueren et al., 2002). Involving farmers more actively in plant breeding was advocated and described as 'Participatory Plant Breeding'. A major reason for involving farmers is to increase the efficiency of breeding (Witcombe et al., 2005). The breeding approaches and type of cultivars to be adopted in organic cropping system are not necessarily identical to those in the conventional system. As the interaction of genotypes with the environmental conditions is not buffered by the use of agro-chemichal inputs in the organic cropping system, genotype $\times$ environment interaction is expected to be higher under organic farming than under conventional farming. Formal plant breeding programs conducted by international agricultural research centers or national programs provide cultivars adapted across a range of environmental conditions (Atlin et al., 2001). Local plant breeding is confined to breeding for specific environments where the genotype $\times$ environment interaction is very large. At the opposite of formal breeding, local breeding is based on breeding for local and specific adaptation (Ceccarelli, 1994). The efficiency of local breeding versus formal breeding is a crucial aspect in breeding for organic conditions. 


\section{Objectives}

The objectives of this study were the following:

- To combine the efforts of farmers and scientists through a participatory breeding approach for the development of locally adapted winter and spring faba bean cultivars for a set of organic farms in Germany.

- To establish the adequate breeding approach and type of cultivar for organic conditions through a comparison of local breeding versus formal breeding, and inbred line cultivar versus synthetic cultivar.

- To assess the effect of competition among faba bean genotypes contrasting in their heterozygosity level and plant height.

- To assess the competitive ability to weed stress of faba bean genotypes contrasting in their heterozygosity level and plant height.

\section{References}

Abdalla, M. M. F., 1979. The origin and evolution of Vicia faba L. Proc. First Meditteranean conf. pp. 714-746.

Atlin, G. N., M. Cooper, and Å. BjØrnstad, 2001. A comparison of formal and participatory breeding approaches using selection theory. Euphytica 122: 463-475.

Becker, H., 1988. Breeding synthetic varieties of crop plants. Plant Genetics Breeding Rev. 1: 31-54.

Becker, H. C., C. Damgaard, and B. Karlsson, 1992. Environmental variation for outcrossing rate in rapeseed (Brassica napus). Theor. Appl. Genet. 84: 303306.

Bond, D. A., 1966. Yield and components of yield in diallel crosses between inbred lines of winter beans (Vicia faba L.). J. Agric. Sci. (Cambridge). 67: 325-336. 
Bond, D. A., 1989. Prospects for commercialization of $\mathrm{F} 1$ hybrid field beans (Vicia faba L.). Euphytica. 41: 81-86.

Bond, D. A., and M. H. Poulsen, 1983. Pollination. In: The Faba Bean (Vicia faba L.), P. D. Hebblethwaite (ed.), pp. 77-101. Butterworths, London.

Busbice, T. H., 1969. Inbreeding in synthetic varieties. Crop Sci. 9: 601-604.

Ceccarelli, S., 1994. Specific adaptation and breeding for marginal conditions. Euphytica, 77: 205-219.

Cubero, J. I., 1974. On the Evolution of Vicia Faba L., Theor. Appl. Genet. 45: 47-51. Cited from: Genetic Ressources and their Exploitation-Chickpeas, Beans and Lentils, J. R. Witcombe, W. Erskine (eds.).

De Candolle, A., 1882. Origin of Cultivated Plants, Second (eds.) Reprint 1967, pp 468. Hafner, New York.

Duc, G., 1997. Faba bean (Vicia faba L.). Field Crops Res. 53: 99-109.

Duc, G., N. Berthaut, J. Le Guen, and J. Picard, 1992. Hybrid breeding in faba bean (Vicia faba L.). In: Proc. $1^{\text {st }}$ Conf. on Grain Legumes, p.45-46. Angers, France. 1-3 June 1992.

Ebmeyer, E., 1988. Heterosis and genetic variances and their implications for breeding improved varieties of spring beans (Vicia faba L.). Plant Breeding. 101: 200-207.

FAO (Food and Agriculture Organization), 2005. http://faostat.fao.org

Gallais, A., 1976. Development and application of prediction formulae for synthetics. Ann. Amelior. Plantes $26: 623-628$.

Gallais, A., 1992. Pourquoi faire des variétés synthétiques? Agronomie.12: 601609.

Lacampagne, J. P. 2001. Grain legume area recover in 2001. Grain Legumes. 34: 24. 
Ladizinsky, G., 1975. On the origin of the broad bean, Vicia faba L., Israel J. Bot. 24: 80-88.

Lammerts van Bueren, E. T., P. C. Struik, and E. Jacobsen, 2002. Ecological concepts in organic farming and their consequences for an organic ideotype. Neth. J. Agric. Sci. 50: 1-26.

Lee, J. A., 1987. Cotton. Principles of Cultivar Development. Vol. 2, W. R. Fehr (ed.), pp 126-160, Macmillian, New york.

Link, W., 1990. Autofertility and rate of cross-fertilization: crucial characters for breeding synthetic varieties in faba bean (Vicia faba L.). Theor. Appl. Genet. 79: 713-717.

Link, W., 2001. Forschung schafft Grundlagen für künftige AckerbohnenHybriden. Agrarzeitung „Ernährungsdienst“, Frankfurt/Main, 2.

Link, W., and P. Ruckenbauer, 1988. Aspekte der Nutzung von Heterosis bei der Pferdbohne (Vicia faba L.), pp. 147-162. In: Ber. 38. Arbeitstagung der Vereinigung österreichischer Pflanzenzüchter, 1987, Gumpenstein, Austria.

Link, W., and W. Ederer, 1993. The concept of varietal ability for partially allogamous crops. Plant Breeding. 110: 1-8.

Link, W., W. Ederer, and E. von Kittilz, 1994. Zuchtmethodische EntwicklungenNutzung von Heterosis bei Fababohnen. Vortr. Pflanzenzüchtung. 30: 201230.

Link, W., W. Ederer, R. K. Gumber and A. E. Melchinger, 1997. Detection and charachterization of two new CMS systems in faba bean (Vicia faba L.). Plant Breeding. 116: 158-162.

Martsch, R., J. Vaupel, C. C. Schön, and W. Link, 2001. Faba bean hybrid breeding: Current results with CMS199. In: Fourth Conference on Grain Legumes. AEP (ed.) pp. 232-233. Cracow, Poland.

Muratova, V., 1931. Common Beans (Vicia faba). Bulletin Appl. Bot., Genetics and Plant Breeding, Supplement 50. In: Genetic Ressources And Their 
Exploitation-Chickpeas, Beans and Lentils, J. R. Witcombe, W. Erskine (eds.).

Pochard, E., Palloix, A., and A. M. Daubeze. 1992. Le Piment. In: Amélioration des Espèces Végétales Cultivées. Gallais, A., and H. Bannerot (eds.), pp. 420-434, NRA, Paris.

Schmidtke, K., and R. Rauber, 2000. Grain legumes and nitrogen cycling in organic crop systems. Grain Legumes. 30: 16-17.

Schnell, F. W., 1961. Heterosis and inbreeding effect. In : Schriftenreihe des MPI für Tierzucht und Tierernährung, Special Vol. 1961, pp.252-272. Mariensee, Germany.

Schnell, F. W., 1982. A synoptic study of methods and categories of plant breeding. Z. Pflanzenzüchtung. 89: 1-18.

Suso, M. J., and M. T. Moreno, 1999. Variation in outcrossing rate and genetic structure on six cultivars of Vicia faba $\mathrm{L}$. as affected by geographic location and year. Plant Breeding. 118: 347-350.

Witcombe, J. R., K. D. Joshi, S. Gyawali, A. M. Musa, C. Johansen, D. S. Virk, and B. R. Sthapit, 2005. Participatory plant breeding is better described as highly client-oriented plant breeding I. Four indicators of client-orientation in plant breeding. Expl. Agric. 41: 299-319.

Wright, A. J.,1981: The quantitative genetics of diploid synthetic varieties. In: Quantitative Genetics and Breeding Methods, A. Gallais (ed.), pp.137-157. I.N.R.A., Versailles.

ZMP (Zentrale Markt- und Preisberichtstelle GmbH), 2004. http://www.Zmp.de/

Zohary, D., 1977. Comment on the origin of cultivated Broad bean (Vicia faba L.), Israel J. Bot. 26: 39-40. 


\title{
Chapter I. Development of locally-adapted faba bean cultivars for organic conditions in Germany through a participatory breeding approach
}

L. Ghaouti, W. Vogt-Kaute and W. Link

\section{Spring faba bean}

Key words: Faba bean, participatory plant breeding, organic and local breeding, inbred lines, synthetics.

\begin{abstract}
Organic farming requires types of cultivars that are not only adapted to a low input cropping system but that are generally fitting to the requirement of the organic farmers. Hence, efforts of organic farmers and scientists were combined in a participatory breeding approach to develop region specific cultivars of spring bean for organic conditions in Germany. Genotypes with different genotypic structures (more or less heterozygous and heterogeneous) were used in field trials across four organic farms and one conventional station in Germany across 2004, 2005 and 2006. The material involved 18 inbred lines, their 18 polycross progenies, one polycross progenies blend, one inbred lines blend, one hybrids blend and checks. Inbred lines are genetically fixed, thus giving the option to be specifically adapted; whereas polycross progenies and synthetics (Syn-1; predicted from the inbred lines and polycross progenies performance) are diverse, partly heterogeneous and heterozygous, thus giving the option to evolve. Agronomic performance was assessed and a score "personal appreciation" of the material was performed by each partner. The personal appreciation was strongly influenced by biotic and abiotic constraints faced by the crop in each location. Yield constituted for all partners an important trait for the evaluation of the genotypes. Uniformity was apparently appreciated by organic farmers. In all locations, the highest yielding inbred line yielded slightly better than the predicted highest yielding synthetic. However, the slight advantage of the inbred lines is very likely to disappear if the synthetic (Syn-1) is propagated during successive generations.
\end{abstract}




\section{Introduction}

Interest and acreage of organic farming is increasingly gaining interest in Europe. In Germany, organic area occupied $2.3 \%$ of the total agricultural area in 1998 and reached $4.8 \%$ in 2002. Comparatively, the share of organic farming area from total agricultural area was $1.7 \%$ in France and $8.7 \%$ in Austria in 2002 (Eurostat, 2002).

According to EU Regulation 2092/91 modified in 2005, organic production refrains from using agrochemical inputs such as mineral fertilizers, pesticides and herbicides. Consequently, diseases, weeds and availability of nitrogen are often major constraints to achieve an adequate productivity in organic farming.

The major crops grown in the organic farming system in Germany are cereals; they occupied $23 \%$ of the organic acreage in 2004 . Faba bean as a grain legume crop has a considerable potential and is well fitting to the organic requirements. It is producing its own nitrogen supply in addition to supplying a nitrogen reserve for the following crops in the rotation. Faba bean was found to have the highest total nitrogen residues among legume crops reaching $100 \mathrm{~kg} / \mathrm{ha}$ (Kaul et al., 1996). Faba bean could as well serve as a major break for cereal rotation systems, decreasing diseases, energy costs and $\mathrm{CO}_{2}$ output. It improves additionally soil physical conditions and soil fertility (Hebblethwaite, 1983). However, faba bean is one of the smallest crops in Germany. Its acreage was 16 000 hectares whereas the acreage of pea was 121500 hectares (FAO, 2005). The assets of faba bean seem to be nevertheless considered in organic farming, since relatively to the other crops faba is rather concentrated in organic farming. In $2004,39 \%$ of the area devoted to faba bean was organic (ZMP, 2004).

Faba bean is a partially allogamous crop with an average degree of cross fertilization averaging 30\% to 60\% (Bond and Poulsen, 1983; Link, 1990; Link et al., 1994b).

Due to its partial allogamy, Bond in 1982 has stated that breeding the partially heterotic and heterogeneous synthetic cultivars is more advantageous than breeding line cultivars. A synthetic variety is a special kind of population varieties. 
It is produced by open pollination of selected components during a limited number of generations. The number of components in a synthetic is restricted and they are usually selected based on their per se performance and their combining ability (Becker, 1988). The mixture of the components is called collectively Syn-0, and the first offsprings from Syn-0 are called collectively Syn1. Breeding synthetic varieties was repeatedly recommended to increase yield and yield stability of faba beans (Ebmeyer, 1987; Link et al. 1994a, Stelling et al., 1994a). In the past decade, superior and important faba bean cultivars like "Scirocco" and "Fuego" were population cultivars or synthetic.

As organic farming follows different principles than conventional farming, it is questionable whether the superiority of synthetics over lines holds true in the organic context. One of these principles aims to use locally bred and locally adapted rather than generally adapted and used cultivars. Indeed, organic production is similar to marginal areas production with heterogeneous environments, large diversity of farmer's needs and lack of specifically adapted cultivars (Desclaux, 2005).

Organic farming principles give high priority not only to local specific adaptation of a cultivar but to genetic diversity offering the option of local evolution as well. However, a contradiction exists between high genetic diversity within a cultivar and its specific local adaptation. From a given germplasm, only one genotype can be best adapted to a given environment. Being a single genotype, it holds no or little genetic diversity and is a too small basis to realize a meaningful local evolution. If diversity is sought, inclusion of further, less well adapted genotypes into the cultivar is inevitable. Thus, an increase of diversity brings a decrease in specificity of adaptation. Inbred lines are single genotypes, thus giving the option to be specifically and locally adapted; whereas synthetics are genetically diverse and giving the option to be adaptable (Tigerstedt, 1994). They can locally adapt and evolve over time. On average in faba bean, inbred lines are expected to be less performing than their corresponding synthetics (Stelling et al., 1994b). Nevertheless, our hypothesis is that, due to the higher genetic variance among 
inbred lines than among the synthetics, the locally best adapted inbred line may outperform the locally best adapted synthetic.

The objective of this study was to combine the efforts of organic farmers, partners in an organic association and scientists in a participatory breeding approach to simultaneously study this contradiction and to develop locally adapted cultivars in faba bean for a set of organic farms in Germany.

\section{Material and Methods}

\section{Breeding material and experimental design}

A set of eighteen inbred lines (IL) were derived from eighteen old and new European cultivars. They were developed via single seed descent for at least six generations. Through open pollination among these eighteen inbred lines, eighteen polycross progenies (PP) were produced as described by Fleck and Ruckenbauer (1989). One inbred lines blend (ILB) was created by blending equal numbers of seed from each inbred line and correspondingly, a polycross progenies blend (PPB) was established. From a set of 54 single hybrids produced (different crossing combinations of the eighteen lines), a blend of F1hybrids (HB) was constituted. The previous five entries (IL, PP, ILB, PPB, HB) are different regarding their genotypic structure but share a common genetic background. Ten checks (CK) composed mainly from new European cultivars were used (Appendix I).

Altogether, the material consisted of 49 genotypes which were tested in five locations in Germany during three years (2004, 2005 and 2006). The trials were laid out as a lattice design with two replicates. The plot size was $7.2 \mathrm{~m}^{2}$ with an average of 40 seeds $/ \mathrm{m}^{2}$. The intra row spacing was $10.7 \mathrm{~cm}$ and the inter row spacing was $37.5 \mathrm{~cm}$. The trials were altogether sown in the end of March and harvested in the end of August. 


\section{The project area}

The testing sites involved four organic locations and a conventional one in Germany. Three organic locations were organic farms, located at: Tröndel, Ramsthal and Willmering and licensed by Naturland association. The remaining two locations belong to our department's experimental stations: Deppoldshausen (organic nursery) and Reinshof (conventional nursery). In Reinshof, one replicate was treated with agrochemical inputs and the second replicate was managed as in an organic location. The variation in the geographical position of the locations from North to South and from coast to continental area was meant to cover a wide diversity of agro-ecological conditions. Tröndel is located in the North of Germany near the coast of the Baltic Sea. It is characterized by a relatively mild climate where the temperatures are rarely below 0 degrees. Its temperature amplitude is the lowest among the studied locations (Table 1). Relatively to the other locations it has the highest summer daylength and a high "Ackerzahl" (Figure 1). "Ackerzahl" is German soil quality index varying within a scale from: $0=$ minimum soil quality to $100=$ maximum soil quality. Although Reinshof and Deppoldshausen have the same geographical position, they are very different for their "Ackerzahl" and their altitude (Figure 1). Deppoldshausen due to its high altitude is colder on average by one degree compared to Reinshof and has a low "Ackerzahl". Reinshof is the most fertile location. Ramsthal and Willmering are located in the Federal State of Baveria in the South East of Germany. These two farms are located in relatively high altitudes and the quality of their soils is poor (Figure 1). Willmering is the location with highest temperature amplitude which may constitute a stress for spring bean growth.

The general pattern of precipitation is similar for all the five locations. Drought stress is rather taking place in June during flowering. Ramsthal is prone to drought stress (Figure 2). In the organic farms as well as in the experimental locations, the crop rotation followed was winter cereal - legume. 


\section{Participatory approach and measurements}

Three organic farmers were involved in this research. Each partner (farmer or scientist) was involved in his location for the following activities:

(a) Trial management. Farmers followed their normal management practices. For the conventional location, herbicides, fungicides and insecticides were used in only one replicate.

(b) Scoring of the agro-morphological traits of all plots: flowering time (FLW, days), plant height ( $\mathrm{HEl}, \mathrm{cm}$ ), disease infestation (DI, score 1-9; 1: healthy and 9: totally infested), lodging (LOD, score 1-9; 1: fully upright, $9=$ totally lodging), biomass (BM, 1: low biomass, 9: high biomass) and maturity (MAT, days).

(c) Visual estimation of yield at maturity (YE, score 1-9; 1: lowest yielding, 9: highest yielding).

(d) Personal appreciation of the material through a visual score (PA, score 1-9; 1: fully disliked, 9: fully appreciated). The development plant stage and the criteria of evaluation were chosen by each partner independently.

The scoring of YE was essential to define whether and to which extent yield contributes to PA.

After combine harvesting, yield ( $\mathrm{Y}, \mathrm{t} / \mathrm{ha}$ ) and thousand grain weight $(\mathrm{TGW}, \mathrm{g})$ were measured and grain status (GS, score 1-9; 1: healthy grains, 9: fully infested grains) was visually estimated for each plot entry. Additionally for the inbred lines entries and two checks (modern cultivars), the protein content (PC, \%) was measured by Near Infrared Reflectance Spectroscopy (NIRS). First, healthy seeds of each plot were sampled and grinded to a size of $0.5 \mathrm{~mm}$. The samples were then scanned by NIRS monochromator model 6500 . Their spectra collected between $400-2500 \mathrm{~nm}$, registering the absorbance values log $(1 / \mathrm{R})$ at 2 $\mathrm{nm}$ intervals for each sample. The standard faba bean calibration available at the Crop Sciences Department of the University of Göttingen was used. 


\section{Statistical analyses}

The statistical analysis was carried out based on PLABSTAT (Utz, 1991) as follows: First, the lattice designs were analyzed separately for each location in each year. According to Cochran and Cox (1992), adjusted entry means were used for the subsequent analysis of variance for each location and finally a combined analysis of variance across locations and years was performed to assess the genotype environment interaction $(G \times E)$. For each data set, a mixed model was used where the years $(Y)$ were random and the factors genotypes $(G)$ and locations (L) were fixed. The seed protein analysis was restricted to the inbred lines entries. Genetic correlations of the trait "personal appreciation" with the other scored traits were established for each location. Besides, the personal appreciations attributed in each location were correlated to compare the rankings established by each partner. Data presented below are averaged across the three years. For statistical significance, ${ }^{*}$ is used to indicate significances at $5 \%$ level of error probability and ${ }^{* *}$ at $1 \%$ level of error probability.

\section{Prediction of the yield performance of synthetics in the first generation:}

In our case the parental components for the prospected synthetic cultivars are inbred lines. From eighteen inbred lines, $2.6 \times 10^{5}$ synthetic cultivars are possible to generate, with synthetics based on two to eighteen parents. It is crucial to determine the optimum size (i.e. optimum number of components) of the synthetics and to predict their performance.

The performance of a synthetic with k components in the first generation Syn$1(\mathrm{k})$ is predicted as follows (Ederer and Link, 1992):

$\operatorname{Syn}_{1}(k) \approx \frac{1}{k} \sum_{i=1}^{k}\left[S_{i}+\frac{k-1}{k} \frac{m}{m-1}\left(P_{i}-S_{i}\right)\right]$, where $k$ is the number of components in a synthetic variety, $m$ is the number of components in the polycross ( $N=18$ in our case), $\mathrm{Si}$ is the performance of the inbred line $\mathrm{i}$ and $\mathrm{Pi}$ is the performance of the polycross-progeny of the inbred line $\mathrm{i}$. This prediction is based on the assumption that (a) the relationship between panmictic index and yield performance is linear 
and (b) the paternally transmitted general combining ability effects are neglected as well as specific combining ability effects.

Based on the yield performance of the inbred lines and their polycross progenies, the performance of the best synthetics in the first generation were predicted for each location. In each location, the highest yielding synthetic was compared to the highest yielding inbred line.

A cross validation test was performed to verify (1) whether the best inbred line is indeed best in a given location, (2) whether the best Syn-1(4) is indeed best in a given location and (3) whether the best inbred line is indeed outyielding the best synthetic in a given location. The data of each of the three years in a given location were partitioned into two subsets; calibration set (mean across two years) and validation set (the residual third year).

(1) Initially, the highest yielding inbred line from the mean of two years data was identified and the third year was retained to test whether the predicted best inbred line was indeed best in the third year. Three validation sets were available in each location and 15 validation sets were available among all five locations. The best inbred line predicted from the calibration set was accepted as indeed best if in the validation test, it was the highest or second highest yielding, i.e. based on a ratio of two out of $18(11.11 \%)$.

(2) The same analysis was done for the best Syn-1(4) but for the validation, the best Syn-1(4) predicted from the calibration set was considered to be indeed best if it ranked in the validation set among the 340 highest yielding Syn-1(4) out of 3060. This represents the same ratio as for the inbred lines (11.11\%). A second, stricter validation threshold 80/3060 (2.61\%) was used.

(3) In each location, the highest yielding inbred line and the highest yielding Syn1(4) from the mean of each two years data were identified and their performance was checked and compared in the residual third year. From the five locations, 15 comparisons were established between the performance in the validation set of the predicted to be best inbred line and the predicted to be best Syn-1(4). 


\section{Results and discussion}

The performance of the genotypes was significantly different among the locations (Table 2) showing that the locations were indeed characterized by different agroecological conditions. Maximum yield was realized in the conventional location Reinshof. This result was expected since Reinshof has a high "Ackerzahl" and the genotypes in this location were relatively free from pests, diseases and weeds competition due to the application of pesticides and herbicides in the first replicate and to the manual weed control in the second replicate. Yield performance in the treated replicate and in the non treated replicates was not significantly different. In Reinshof, the main factor behind the high yield performance is stemming from good climatic conditions and high "Ackerzahl", which were optimum for faba bean growth compared to the other locations. Regarding the "Ackerzahl" and the incidence of diseases, Tröndel appears to be the best organic location. Genotypes in Tröndel were higher yielding than in any other organic locations and with low disease infestation. Although the genotypes grew relatively tall, they were on average the least lodging compared to all other locations. Ramsthal was characterized by low "Ackerzahl", highest disease incidence and drought stress during the flowering time. Genotypes in Ramsthal were on average early flowering with smallest height due to the drought and thus achieving the lowest yield. Willmering is the location with the latest flowering time and with the earliest maturity time. The duration of flowering and the filling pods period were the shortest in this location which may have contributed to low yield. Besides, the highest lodging scores were recorded in Willmering which were additional disadvantages for yield performance. Genotypes in Deppoldshausen showed the latest maturity time which may be due to the low temperature during the spring bean growing season. For yield and other agronomic traits, the performance of the genotypes in Deppoldshausen was average.

The highest protein content in the grains of inbred lines was recorded in Willmering and the lowest protein content was recorded in Tröndel. A covariance analysis showed that there was a significant negative correlation between protein 
content and grain yield which was caused essentially by the locations effects ($0.48^{* *}$ ), but no significant correlation due to the genotypes was found.

The combined analysis of variance across locations, years and genotypes (Table 3) showed that the genotypes are significantly different for grain yield and flowering time. Locations and location $\times$ year interactions were the largest sources of variation for both traits. For grain yield, the variance of the genotype $x$ environment interactions $(G L+G Y+G Y L)$ was larger than the genotypes variance. Genotype $\times$ location interactions were the strongest component of the genotype $x$ environment interactions and contributed more than half as much as the genotypes to the yield variation. Large genotype $\times$ environment interactions for grain yield were as well observed in other crops conducted in low input environments such as barley (Ceccarelli et al., 2003) and rice (Courtois et al., 2001). For all other agronomic traits, all sources of variations were as well significant and genotype $\times$ location interactions were as well the largest component of the genotype $\times$ environment interactions (details not shown).

The location Tröndel was taken as a representative example to illustrate the pattern of the genotypes' grain yield distribution according (Figure 3). The pattern was distinct according to their genotypic structure. Inbred lines were less performing than the polycross progenies in Tröndel as well as on the average across locations. It never occurred that, in Tröndel or in any single location, any inbred line outyielded the best polycross progeny. In Tröndel, the blend of inbred lines yielded higher than the average yield of inbred lines and the blend of polycross progenies yielded lower than the average yield of polycross progenies. On average of all locations, both blends were better yielding than the average yield of their corresponding components (IL or PP). Thus, the effect of heterogeneity was positive across all locations. In each location and on average of all locations, the hybrid blends was the best yielding entry. As stated previously (Stelling et al., 1994b), the level of heterozygosity seems to be the main factor enhancing the yield performance. 
The superiority of the polycross progenies over the inbred lines for yield performance holded true in each single location (Table 4). On average, the polycross progeny yielded $0.67 \mathrm{t} /$ ha higher than the inbred lines which corroborated previous findings on faba bean (Link et al., 1994 b; Stelling et al., 1994 b). The variance among inbred lines in each location and on average of all locations was larger than the variance among the polycross progenies. The extent of the variation among inbred lines compared to the variation of their polycross progenies was variable among the locations. In Deppoldshausen and Willmering, the variance of the inbred lines was more than double the variance of the polycross progenies, whereas in Ramsthal, the variance of inbred lines was barely superior. In each single location and on average of all locations, yield performance of polycross progenies was positively, markedly and significantly correlated with yield of their inbred lines. On average across locations, the correlation between the inbred lines and their polycross progenies for yield performance amounted $r=0.63^{\star *}$. Fleck and Ruckenbauer (1989) found as well that a significant correlation $\left(0.51^{* *}\right)$ existed between the inbred lines and their polycross progenies in faba bean. The inbred lines and their polycross progenies constituted as well two distinct groups according to the interaction pattern of their yield performance with the locations (Figure 4). Interaction effects of the inbred lines with the locations were generally larger than those of the polycross progenies. Genotypes that deviated markedly in their performance over the locations from zero genotype-location effect (GL effect) are highly interacting with the locations; and genotypes that deviate little in their performance over the locations from zero genotype-location effect are little interacting with the locations. For instance, the inbred line (IL 12) interacted highly with the locations; it yielded $0.74 \mathrm{t} / \mathrm{ha}$ more than expected from the local average and from its own mean performance in Reinshof and 0.94 t/ha less than expected in Willmering. Compared to this inbred line, polycross progenies interacted less with the locations. A genotype that shows a high GL effects is specifically adapted to a given location, whereas a genotype with a little or zero GL effect is showing a stable performance across the locations. The inbred lines tend to be more 
specifically adapted and specifically misadapted to single locations, whereas their polycross progenies are more stable, thus confirming our hypothesis. Heterozygous and heterogeneous entries were found to be more stable than inbred lines in faba bean (Link et al., 1994 a) as well as in other crops such as barley (Einfeldt et al., 2005), rapeseed (Becker and Léon, 1988;) and maize (Schnell and Becker, 1986).

The main objective of this study is to compare two categories of cultivars in local organic conditions; inbred line cultivar and synthetic cultivar. The performance of synthetics at the first generation Syn-1, selected and created from 18 potential components (inbred lines) was predicted on the basis of the inbred lines performance and their polycross progenies performance (see material and methods). For all locations, the optimum size of synthetics was found to be $\mathrm{N}=4$ components. This optimum size of synthetic was the result of a compromise between reducing the inbreeding depression by increasing the number of components and increasing gain from selection by decreasing the number of components (Becker, 1988; Gallais, 1992). With 18 inbred lines as potential components to the synthetics of size four, 3060 possible synthetics Syn-1(4) are possible to establish.

\section{Selection based on yield performance}

The analysis of the best inbred lines in each location showed (Table 5) that the inbred line "IL 1" (Maya/2) was specifically adapted to both Tröndel and Ramsthal. The three other locations had each a different specifically adapted inbred line IL 4 (Styria 343), IL 10 (L1_MxCEx/19) and IL 14 (Music/1). In each location, the best inbred line was one of the four components of the best Syn1(4). This result is expected since the yield performance of the inbred lines was positively correlated to the yield performance of their corresponding polycross progenies and thus to their contribution to the best synthetic cultivar. The best synthetics among the locations were established from 12 different components out of the available 18. The best synthetics covered a large diversity of the components available which confirm that the locations were indeed different 
environments. In each location, the Syn-1(4) yielded on average higher than the inbred lines which is in concordance with the theoretical expectations established by Gallais (1992). This superiority of synthetics over inbred lines average performance is mainly due to the partial heterosis expressed in the synthetics. However, the comparison between the best yielding inbred line and the best yielding Syn-1(4) revealed that in each location and across the three years the best inbred line outyielded the best Syn-1(4).

The cross validation analysis showed that (1) in 10 out of 15 cases $(67 \%)$ the predicted to be best inbred line from the calibration set was best (or second best) in the validation set, (2) the predicted best Syn-1(4) was always indeed best in the validation set using the ratio of $11.11 \%$ as for the inbred lines; with a stricter ratio $2.61 \%$, in 10 cases out of 15 the predicted best Syn-1(4) was ranked among the 80 best in the validation set, (3) In 10 cases out of 15, the predicted best inbred line yielded higher than the predicted to be best Syn-1(4). Cross validation data confirmed our results since, (1) in most cases the best inbred line and the best synthetic could be well enough predicted and since (2) it is more likely that the best inbred line outyields the best synthetic than the opposite and (3) in 10 cases out of 15 , the predicted best inbred line yielded higher than the predicted to be best Syn-1(4).

\section{Selection based on farmers criteria}

The visual estimation of yield in the field by each partner (farmer or scientist) was highly correlated to the realized grain yield after harvesting. The correlation between visually estimated yield and realized yield ranked from $0.44^{\star *}$ to $0.70^{* *}$ in the five single locations and amounted on average to $0.60^{* *}$. Farmers were more or less successful in identifying the highest yielding genotypes.

All partners based the appreciation of the genotypes to a large extent on the score of visual estimation of yield (Table 6). Yield constituted for all partners an important trait for the evaluation of the genotypes; high yielding genotypes were those most appreciated. The correlation of personal appreciation and visual 
estimation of yield reflects the weight of yield that each partner attributed intentionally to his personal appreciation. For instance, the farmer in Tröndel has given a high weight to estimate yield to his personal appreciation $\left(r=0.84^{\star *}\right)$. However, the correlation between personal appreciation and yield did not fully reflect the weight the farmer wanted to attribute to yield; since in spite of been significant $\left(r=0.42^{\star *}\right)$, the correlation between personal appreciation and combine harvest yield was lower than the correlation to his yield estimation.

The other criteria used to evaluate the genotypes were different depending on the location. Personal appreciation was strongly influenced by biotic and abiotic constraints faced by the crop in each location. As diseases were more frequent in Deppoldshausen, Ramsthal and Willmering (Table 2), higher appreciation scores were given to genotypes free from diseases. On average of all locations, grain status was correlated with disease infestation $\left(r=0.41^{* *}\right)$ and favoured genotypes showed rather healthy seeds in Deppoldshausen, Ramsthal and Willmering. In Tröndel, the correlation between personal appreciation and grain status was due to the fact that the farmer has favored genotypes that suffered less from the severe drought stress which happened in the year 2006 in this location. In the conventional location Reinshof, short genotypes were favored due to the susceptibility of genotypes to lodging in this location. Tall genotypes were favored by all partners in organic locations. The farmer in Ramsthal in his evaluation made a compromise between tall and less lodging genotypes. Early flowering and maturing material was favored in Reinshof and Deppoldshausen and at the opposite late flowering and maturing material was favored in Tröndel and Ramsthal. In the organic locations Deppoldshausen, Ramsthal and Willmering, genotypes with high biomass were most appreciated because they out competed weeds. The incidence of weeds was very low in Tröndel and absent in Reinshof due to the weed management (herbicides or manual weeding). Farmers favored small seeded genotypes and in Deppoldshausen and Reinshof, big seeded genotypes were the most appreciated. Big seeded types were high yielding only in Reinshof and Deppoldshausen. The selection criteria used by farmers were neither unusual nor unexpected. They are translating 
mainly the requirements of the agroecological conditions of their field. This result corroborated the findings of other participatory researches (Ceccarelli et al., 2000). Correlations of the scores of personal appreciation in each location (Table 7) showed that the scores in both Deppoldshausen and Reinshof were significantly and positively correlated. This apparently is due to the fact the same partner scored at these locations. The scores of personal appreciation in Reinshof were significantly and negatively correlated to the ones in Tröndel. In the other cases, the scores of personal appreciation were independent. The significant negative correlation and the absence of correlations between the personal appreciations of different locations reflect the large extent of the genotype location interaction and confirm the prospects of local breeding in organic farms.

The 18 best genotypes out of $\mathrm{N}=49$ were identified in each location according to yield performance in a first instance and to the personal appreciation scores in a second instance. The contribution of the different genotypic structure to the best genotypes was assessed (Figure 5 and 6). In all locations, the 18 best genotypes according to yield performance and to personal appreciation scores included the hybrids blend entry. Inbred lines blend and the polycross progenies blend did never rank among these best genotypes. Checks contributed similarly to the highest yielding (23\%) and to the most appreciated genotypes (28\%). A high discrepancy between the selection based on yield performance or personal appreciation was mainly occurring for the contribution of the inbred lines and the polycross progenies.

On average, the total contribution of the inbred lines and their polycross progenies amounted to $71 \%$ of the highest yielding genotypes and to $66 \%$ to the best appreciated genotypes. On average of the locations, the inbred lines contributed with $18 \%$ to the high yielding genotypes whereas the polycross progenies contributed with 53\%. The contribution of the inbred lines and the polycross progenies varied between the locations. The maximum contribution of the inbred lines was achieved in Ramsthal (28\%) and the minimum in Reinshof $(11 \%)$. The contribution of the inbred lines increased markedly when considering 
the personal appreciation (Figure 6). In each single location as well as on average, inbred lines were more frequently present among the best appreciated genotypes than among the highest yielding genotypes. In each location, the highest yielding inbred line ranked among the best appreciated genotypes. Organic farmers apparently did not disfavored homogeneity. Compared to the yield selection, farmers did increase the contribution of the homogeneous inbred lines and decrease the contribution of the heterogeneous polycross progenies to the best appreciated genotypes. Uniformity was apparently appreciated by organic farmers and it seems that heterozygous and heterogeneous material was appreciated not due to its genotypic structure but due to its visible high yield performance. However, it is worthwhile to stress that the difference in yield performance between the best inbred line and the best synthetic was not marked and that the yield of a synthetic is expected to increase with further generations of propagation (Busbice, 1969; Link, 1990). This increase of yield in the synthetics may override the small advantage of the inbred lines over the synthetic. Besides, although it is not visible in the short term, in the long term the synthetics have a great advantage through their heterogeneity and heterozygosity which is their genetic adaptability.

Results of this study have been obtained on farmer's field under organic and local conditions. Large genetic differences were detected that will be of immediate benefit to farmers at no additional costs. On request of the farmers, we gave them the mixture of the components of the predicted best performing Syn-1(4) according to their personal appreciation to continue the synthetic propagation and use it for their own purposes. This material is able to evolve by natural and local selection. The outcome of this study has illustrated that the combined efforts of farmers and breeders in a local breeding approach might lead to very suitable cultivars for organic farming.

\section{Acknowledgements}


Our thanks are addressed to the farmers A. Hausladen (Willmering), G. Neder (Ramsthal) and H. Untiedt (Tröndel) for their very valuable contributions. Sowing and harvesting was achieved faultlessly by Agrostat Company. Finally, we thank BMELV (Bundesministeriums für Ernährung, Landwirtschaft und Verbraucherschutz) for financing this research.

\section{References}

Busbice, T. H., 1969. Inbreeding in synthetic varieties. Crop Sci. 9: 601-604

Becker, H. C., and J. Léon, 1988. Stability analysis in plant breeding. Plant Breeding. 101: 1 -23.

Becker, H., 1988. Breeding synthetic varieties of crop plants. Plant Genet. Breeding Rev. 1: 31-54.

Bond, D. A., 1982. The Development and Performance of Synthetic Varieties of Vicia faba L. In: Faba Bean Improvement, G. Hawtin and C. Webb (eds.), pp. 41-51.

Bond, D. A. and M. H. Poulsen, 1983. Pollination. In: The Faba Bean (Vicia faba L.), P. D. Hebblethwaite (ed.), pp. 77-101. Butterworths, London.

Ceccarelli, S., S.Grando, R. Tutliwer, J. Baha, A. M. Martini, H. Salahieh, A. Goodchild, and M. Michael, 2000. A methodological study on participatory barley breeding. I. Selection phase. Euphytica. 111: 91-104.

Ceccarelli, S., S.Grando, M. Singh, R. M. Michael, A. Shikho, M. Al Issa, A. Al Saleh, G. Kaleonjy, S. M. Al Ghanem, A. L. Al Hassan, H. Dalla, S. Basha, and T. Basha, 2003. A methodological study on participatory barley breeding. I. Response to selection. Euphytica. 133: 185-200.

Cochran, W. G., and G. M. Cox, 1992. Experimental Designs. Second edition. John Wiley and Sons (eds.), Inc. New York.

Courtois, B., B. Bartholome, D. Chaudhary, G. McLaren, C. H. Misra, N. P. Mandal, S. Pandey, T. Paris, C. Piggin, K. Prasad, A. T.Roy, R. K. Sahu, V. 
N. Sahu, S. Sarkarung, S. K. Sharma, A. Singh, H. N. Singh, O. N. Singh, N. K. Singh, R. K. Singh, R. K. Singh, S. Singh, P. K. Sinha, B. V. S. Sisodia, and R. Takhur, 2001. Comparing farmers and breeders rankings in varietal selection for low-input environments: A case study of rainfed rice in eastern India. Euphytica. 122: 537-550.

DWD (Deutscher Wetterdienst), 2006. http://www.dwd.de

Ebmeyer, E., 1987. Zur Bedeutung der Ertragsicherheit in der züchtung von Ackerbohnen. Vortr. Pflanzenzüchtg. 12: 168-179

Ederer, E., and W. Link, 1992 . The polycross-test as a step in breeding partially allogamous crops. Theoretical considerations. Proc. XIIIth EUCARPIA Congress, 6-11 July, Angers, France, Book of Poster Abstracts, pp. 543544.

Einfeldt, C. H. P., S. Ceccarelli, S. Grando, A. Gland-Zwerger and H. H. Geiger, 2005. Heterosis and mixing effect in barley under drought stress. Plant Breeding. 124: 350- 355.

Eurostat (Statistical Office of the European Communities), 2002. http://epp.eurostat.ec.europa.eu/portal/page? pageid=1090,30070682,1090 30298591\& dad=portal\& schema=PORTAL

FAO (Food and Agriculture Organization), 2005. http://faostat.fao.org

Fleck, A., and P. Ruckenbauer, 1989. Der Polycrosstest als methodischer Schritt in der Fababohnenzüchtung (experimentelle Ergebnisse). Die Bodenkultur. 40: 61-72.

Gallais, A., 1992. Pourquoi faire des variétés synthétiques ? Agronomie.12: 601609.

Hebblethwaite, P. D., 1983. Background, Physiology and Breeding. In: The Faba Bean (Vicia faba L.), P. D. Hebblethwaite (ed.), pp. 3-22. Butterworths, London. 
Kaul, H. P.; W. Aufhammer and W. Wägner, 1996. Dry matter and nitrogen accumulation and residues of oil and crop protein crops. European $\mathrm{J}$. Agrono. 5: 137-147.

Link, W., 1990. Autofertility and rate of cross-fertilization: crucial characters for breeding synthetic varieties in faba bean (Vicia faba L.). Theor. Appl. Genet. 79: 713-717.

Link, W., D. Stelling, and E. Ebmeyer, 1994a. Yield stability in faba bean, Vicia faba L. 1. Variation among inbred lines. Plant Breeding. 112: 24-29.

Link, W., D. Stelling, and E. Ebmeyer, 1994b. Factors determining the performance of synthetics in Vicia faba L. 1. Heterogeneity, heterozygosity, and degree of cross fertilization. Euphytica. 75: 77-84.

Schnell, F. W., and H. C. Becker, 1986. Yield and yield stability in a balanced system of widely differing population structures in Zea mays L. Plant Breeding. 97: 30-38.

Stelling, D., W. Link., and E. Ebmeyer, 1994a. Yield stability in faba bean, Vicia faba L.2. Effect of heterozygosity and heterogeneity. Plant Breeding. 112: 30-39.

Stelling, D., W. Link, and E. Ebmeyer, 1994b. Factors determining the performance of synthetics in Vicia faba L. 1. Syn-generation. Euphytica. 75: 85-93.

Tigerstedt, P. M. A., 1994. Adaptation, variation and selection in marginal areas. Euphytica. 77: 171-174.

Utz, H.F., 1991. A computer program for statistical analysis of plant breeding experiments. Institute of Plant Breeding, Seed Science and Population Genetics. University of Hohenheim.

ZMP (Zentrale Markt- und Preisberichtstelle GmbH), 2004. http://www.zmp.de/ 
Table 1. Mean, maximal ( $\max$ ), minimal (min) and amplitude of daily temperatures across the three years during spring bean growing season for each location (DWD, 2006).

\begin{tabular}{lrrrr}
\hline \multirow{2}{*}{ Locations } & \multicolumn{4}{c}{ Temperature } \\
\cline { 2 - 5 } & mean $\mathrm{C}^{\circ}$ & $\max \mathrm{C}^{\circ}$ & $\min ^{\circ}$ & amplitude $^{\circ}$ \\
\hline Trö. & 12.37 & 16.33 & 8.42 & 7.91 \\
Dep. & 11.51 & 17.00 & 6.01 & 10.99 \\
Rei. & 12.51 & 18.00 & 7.01 & 10.99 \\
Ram. & 13.05 & 18.64 & 7.45 & 11.19 \\
Willm. & 11.82 & 18.13 & 5.50 & 12.63 \\
\hline
\end{tabular}

Temp amplitude $\mathrm{C}^{\circ}=$ Temp $\max \mathrm{C}^{\circ}$ - Temp $\min \mathrm{C}^{\circ}$

Table 2. Mean values across three years of the relevant agronomic traits.

\begin{tabular}{lcrrrrrrrr}
\hline Locations & $\begin{array}{l}\text { FLW } \\
\text { days }\end{array}$ & \multicolumn{1}{l}{$\begin{array}{l}\text { HEI } \\
\text { cm }\end{array}$} & $\begin{array}{l}\text { LOD } \\
\text { score }\end{array}$ & $\begin{array}{l}\text { MAT } \\
\text { days }\end{array}$ & $\begin{array}{l}\text { DI } \\
\text { score }\end{array}$ & $\begin{array}{l}\text { GS } \\
\text { score }\end{array}$ & $\begin{array}{l}\text { TGW } \\
\text { g }\end{array}$ & $\begin{array}{l}\text { Y } \\
\text { t/ha }\end{array}$ & $\begin{array}{l}\text { PC } \\
\%\end{array}$ \\
\hline Trö. & 167 & 115.76 & 1.50 & 223 & 2.10 & 3.69 & 495.06 & 3.54 & 25.81 \\
Dep. & 164 & 104.20 & 2.31 & 238 & 3.39 & 3.34 & 516.72 & 3.40 & 25.87 \\
Rei. & 161 & 122.48 & 3.07 & 228 & 1.63 & 2.23 & 469.09 & 4.62 & 26.45 \\
Ram. & 158 & 89.35 & 2.90 & 223 & 5.71 & 5.08 & 454.78 & 2.39 & 27.29 \\
Wil. & 178 & 101.07 & 3.82 & 216 & 4.24 & 5.45 & 540.20 & 2.96 & 28.95 \\
\hline Average & 165 & 107.37 & 2.72 & 226 & 3.61 & 3.76 & 495.17 & 3.38 & 26.88 \\
\hline LSD 5\% & $9.41^{*}$ & $41.54^{*}$ & $1.10^{*}$ & $18.61^{*}$ & $3.51^{*}$ & $2.28^{*}$ & $76.74^{*}$ & $1.61^{*}$ & $0.24^{*}$ \\
\hline
\end{tabular}

Disease infestation (DI, score 1-9; 1: healthy and 9: totally infested), lodging (LOD, score 1-9; 1: fully upright, $9=$ totally lodging) and grains status (GS, score 1-9; 1 : healthy, 9 : fully infested).

Table 3. Combined analysis of variance including variance components $\left(\sigma^{2}\right)$ of grain yield and flowering time across genotypes, years and locations.

\begin{tabular}{|c|c|c|c|c|c|c|c|c|}
\hline \multirow{2}{*}{$\begin{array}{l}\text { Sources of } \\
\text { variations }\end{array}$} & \multicolumn{4}{|c|}{ Grain yield } & \multicolumn{4}{|c|}{ Flowering time } \\
\hline & DF & $\sigma^{2} t^{2} / h^{2}$ & F value & LSD 5\% & DF & $\sigma^{2}$ days ${ }^{2}$ & F value & LSD 5\% \\
\hline Location L & 4 & 1.09 & $5.48^{*}$ & 1.61 & 4 & 42.44 & $6.36^{*}$ & 9.41 \\
\hline Year Y & 2 & 0.60 & $732.86^{\star *}$ & 0.08 & 2 & 13.15 & $994.19^{* *}$ & 0.32 \\
\hline Genotype G & 48 & 0.22 & $8.37^{\star *}$ & 0.49 & 48 & 6.73 & $16.34^{\star *}$ & 1.86 \\
\hline YL & 8 & 0.73 & $178.65^{\star \star}$ & 0.18 & 7 & 23.71 & $358.99^{* *}$ & 0.72 \\
\hline GL & 192 & 0.15 & $3.21^{\star *}$ & 0.72 & 191 & 2.28 & $3.11^{* *}$ & 2.89 \\
\hline GY & 94 & 0.05 & $2.28^{* *}$ & 0.56 & 94 & 0.67 & $2.03^{* *}$ & 2.24 \\
\hline GYL & 373 & 0.09 & $1.90^{* *}$ & 0.90 & 310 & 1.80 & $2.25^{\star *}$ & 3.34 \\
\hline Error & 517 & 0.11 & & & 441 & 1.44 & & \\
\hline
\end{tabular}

Table 4. Mean values and phenotypic variances of the inbred lines and their polycross progenies; and their correlations.

\begin{tabular}{|c|c|c|c|c|c|}
\hline \multirow[b]{2}{*}{ Locations } & \multicolumn{2}{|c|}{ Inbred lines } & \multicolumn{2}{|c|}{ Polycross progenies } & \multirow[b]{2}{*}{$r(I L, P P)$} \\
\hline & $\begin{array}{l}\text { Mean } \\
\text { t/ha }\end{array}$ & $\begin{array}{l}\text { Phenotypic } \sigma^{2} \\
\mathrm{t}^{2} / \mathrm{ha}^{2}\end{array}$ & $\begin{array}{l}\text { Mean } \\
\text { t/ha }\end{array}$ & $\begin{array}{l}\text { Phenotypic } \sigma^{2} \\
\mathrm{t}^{2} / \mathrm{ha}^{2}\end{array}$ & \\
\hline Trö. & 3.15 & 0.53 & 3.90 & 0.29 & $0.55^{\star}$ \\
\hline Dep. & 2.92 & 0.49 & 3.75 & 0.24 & $0.57^{*}$ \\
\hline Rei. & 4.08 & 0.32 & 4.97 & 0.21 & $0.73^{\star *}$ \\
\hline Ram. & 2.22 & 0.39 & 2.48 & 0.32 & $0.57^{\star}$ \\
\hline Wil. & 2.58 & 0.46 & 3.21 & 0.22 & $0.71^{\star *}$ \\
\hline Average & 2.99 & 0.44 & 3.66 & 0.26 & $0.63^{* *}$ \\
\hline
\end{tabular}


Table 5. Average yield performance of the inbred lines and the synthetics Syn-1(4), and yield performance and identity of the best inbred line and the best Syn-1(4) in each location .

\begin{tabular}{lcccrrr}
\hline Locations & $\begin{array}{l}\text { Average } \mathrm{Y}(\mathrm{t} / \mathrm{ha}) \\
\text { of } 18 \mathrm{IL}\end{array}$ & $\begin{array}{l}\text { Average } \mathrm{Y}(\mathrm{t} / \mathrm{ha}) \\
\text { of } 3060 \text { Syn-1(4) }\end{array}$ & $\begin{array}{l}\mathrm{Y}(\mathrm{t} / \mathrm{ha}) \text { of the } \\
\text { best IL }\end{array}$ & Best IL & $\begin{array}{l}\mathrm{Y}(\mathrm{t} / \mathrm{ha}) \text { of the } \\
\text { best Syn-1(4) }\end{array}$ & $\begin{array}{l}\text { Best Syn-1(4) } \\
\text { components }\end{array}$ \\
\hline Trö. & 3.15 & 3.74 & 4.78 & 1 & 4.47 & $1 ; 18 ; 15 ; 17$ \\
Dep. & 2.92 & 3.58 & 4.27 & 4 & 4.19 & $18 ; 4 ; 10 ; 6$ \\
Rei. & 4.08 & 4.79 & 5.42 & 10 & 5.39 & $10 ; 11 ; 3 ; 4$ \\
Ram. & 2.22 & 2.43 & 3.50 & 1 & 3.07 & $1 ; 6 ; 5 ; 10$ \\
Wil. & 2.58 & 3.08 & 3.91 & 14 & 3.73 & $14 ; 1 ; 3 ; 7$ \\
\hline
\end{tabular}

Table 6. Coefficients of correlation between the personal appreciation and the agronomic traits.

\begin{tabular}{|c|c|c|c|c|c|c|c|c|c|c|}
\hline & FLW & $\mathrm{HEI}$ & LOD & MAT & DI & BM & YE & Y & GS & TGW \\
\hline Trö. & $0.44^{\star \star}$ & $0.67^{\star \star}$ & - & $0.43^{\star \star}$ & - & - & $0.84^{\star \star}$ & $0.42^{\star \star}$ & $-0.29^{\star}$ & $-0.37^{\star *}$ \\
\hline Dep. & $-0.55^{\star \star}$ & $0.38^{* *}$ & - & - & $-0.32^{*}$ & $0.61^{* *}$ & $0.59^{\star \star}$ & $0.52^{* *}$ & $-0.44^{* *}$ & $0.47^{\star *}$ \\
\hline Rei. & $-0.51^{\star *}$ & $-0.49^{* *}$ & $-0.54^{\star *}$ & - & & & $0.60^{\star \star}$ & $0.48^{* *}$ & - & $0.38^{\star \star}$ \\
\hline Ram. & $0.42^{\star \star}$ & $0.79^{\star \star}$ & $-0.30^{*}$ & $0.32^{*}$ & $-0.35^{\star}$ & $0.71^{\star *}$ & $0.68^{\star \star}$ & $0.49^{\star *}$ & $-0.53^{\star *}$ & $-0.29^{*}$ \\
\hline Wil. & - & $0.39^{* *}$ & - & - & $-0.34^{*}$ & $0.34^{*}$ & $0.66^{* *}$ & $0.36^{*}$ & $-0.42^{* *}$ & $-0.37^{* *}$ \\
\hline
\end{tabular}

- non significant coefficient of correlation

Table 7. Correlations between personal appreciation scores attributed in each location to the 49 genotypes tested.

\begin{tabular}{lcccc}
\hline Locations & Trö. & Dep. & Rei. & Ram. \\
\hline Dep. & - & & & \\
Rei. & $-0.48^{* *}$ & $0.46^{* *}$ & & \\
Ram. & - & - & - & - \\
Wil. & - & - & - & - \\
\hline
\end{tabular}

- non significant coefficient of correlation 


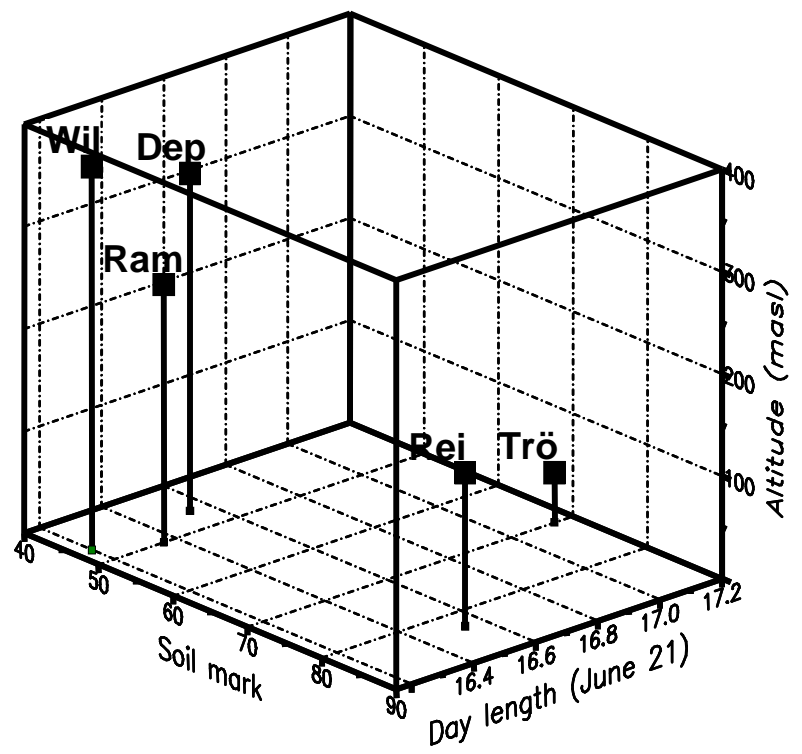

Figure 1. Day length at $21^{\text {st }}$ June (hours), altitude (m.a.s.l) and "Ackerzahl" (German soil quality index; $0=$ minimum soil quality; $100=$ maximum soil quality) of the five studied locations.

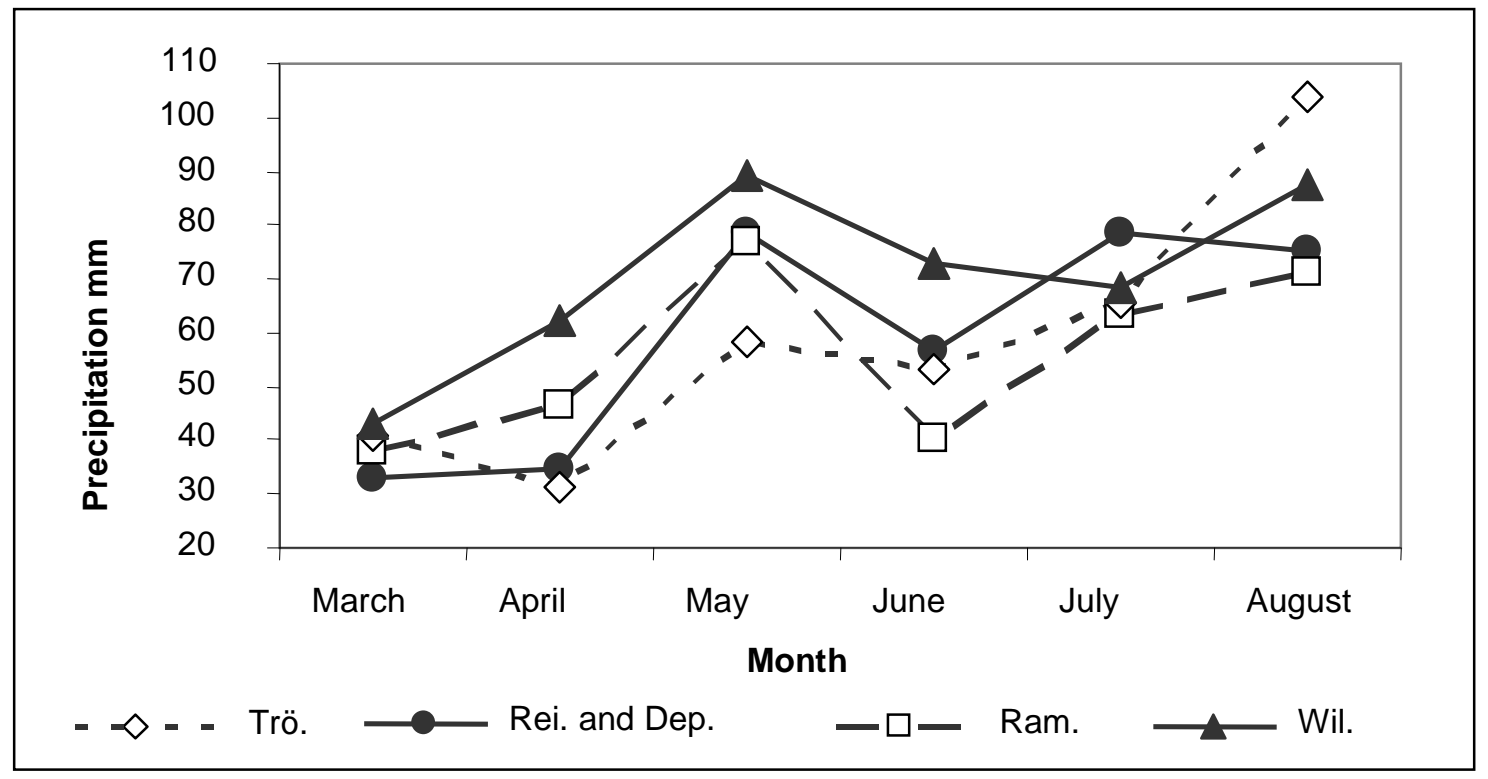

Figure 2. Amount of precipitation in each location for each month of spring bean growing season (data are means across the three years 2004-2006) (DWD, 2006). 


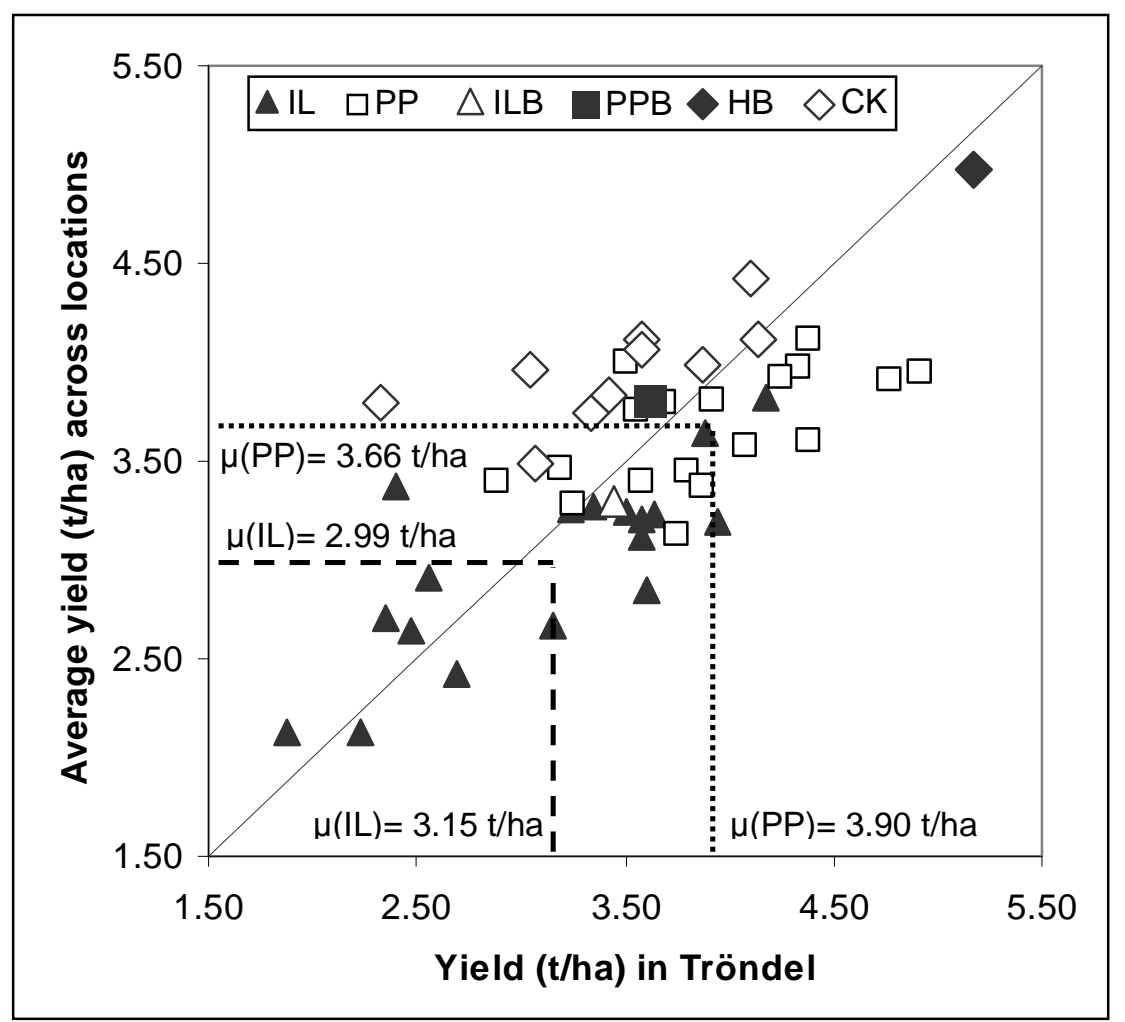

Figure 3. Distribution of the genotypes in Tröndel correlated with the average across all locations according to grain yield (means across three years; t/ha).

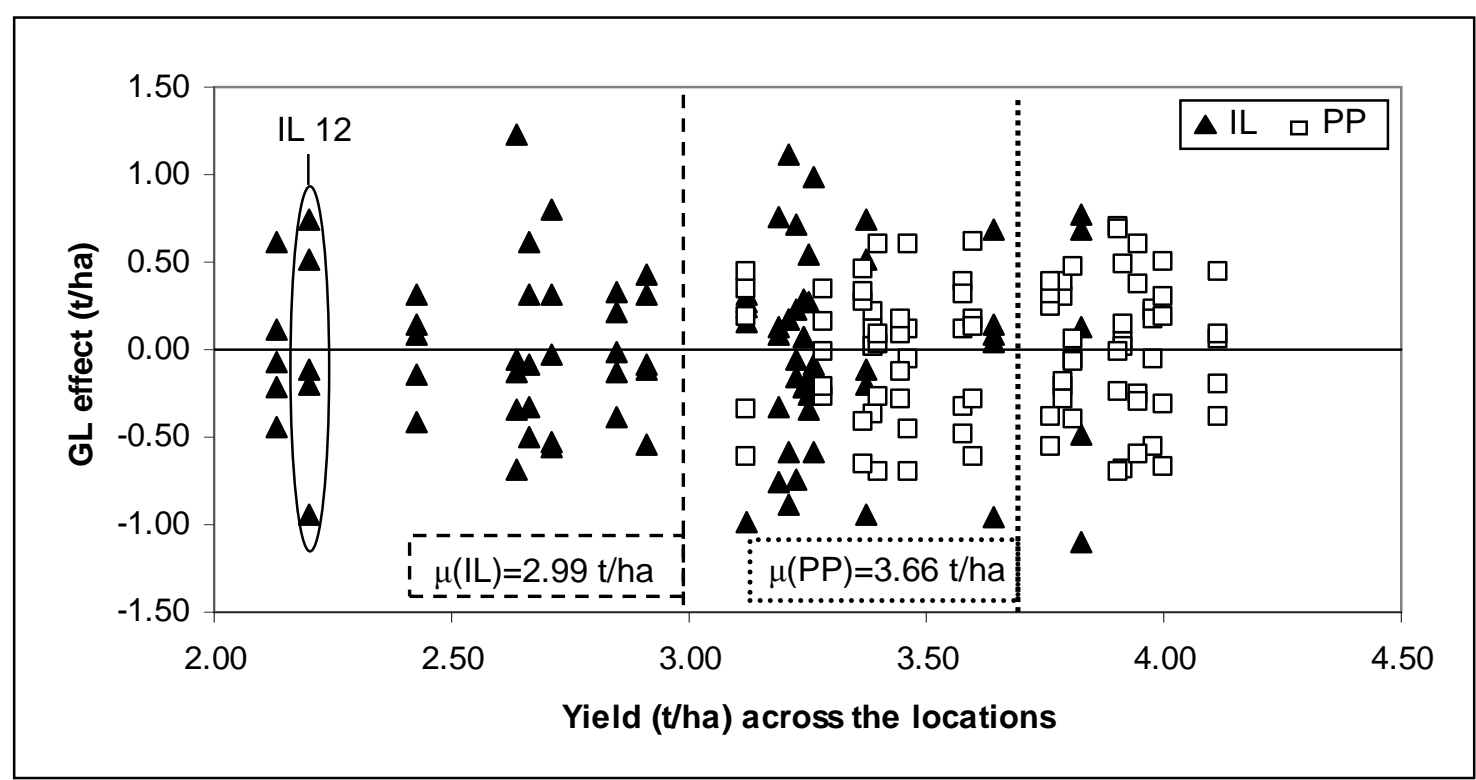

Figure 4. The relationship between the extent of $G \times L$ interaction effects of the inbred lines and the polycross progenies and their yield performance (means across three years). 


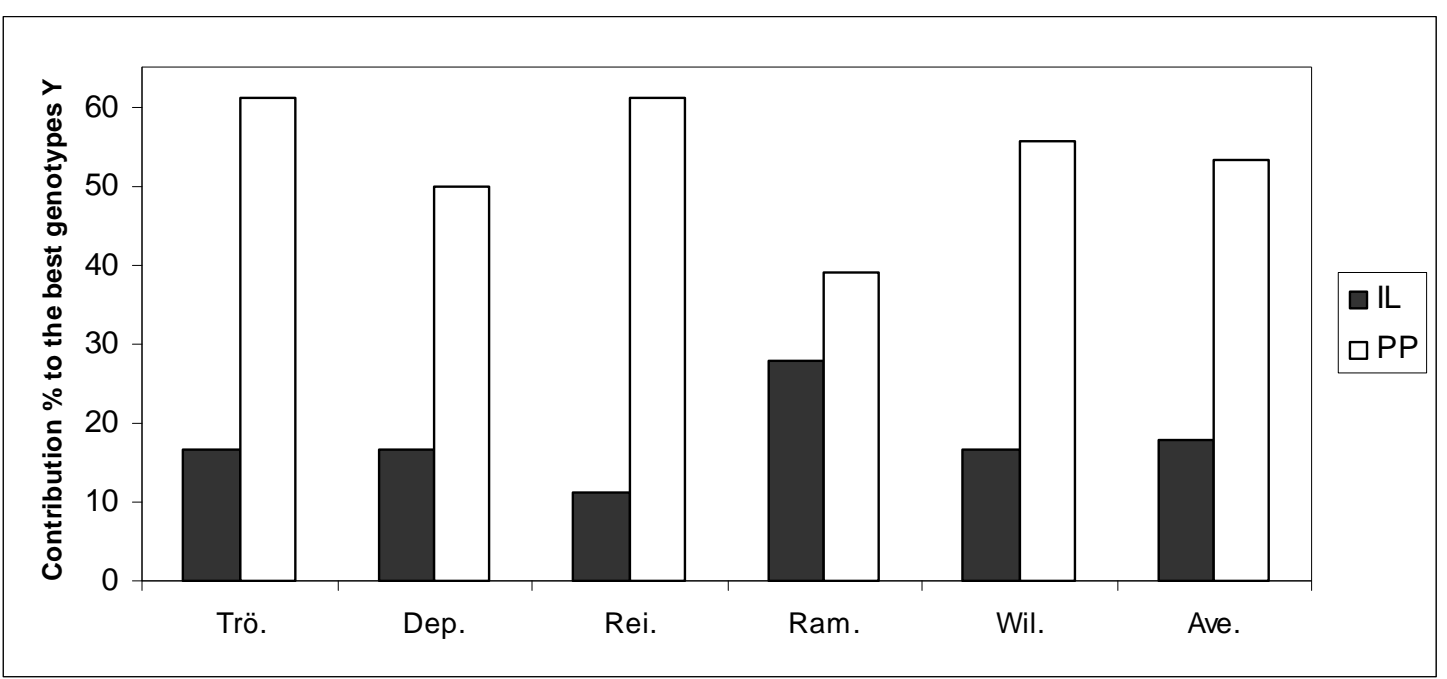

Figure 5. Contribution in \% of the inbred lines and the polycross progenies to the eighteen best genotypes according to the yield performance $(\mathrm{Y})$.

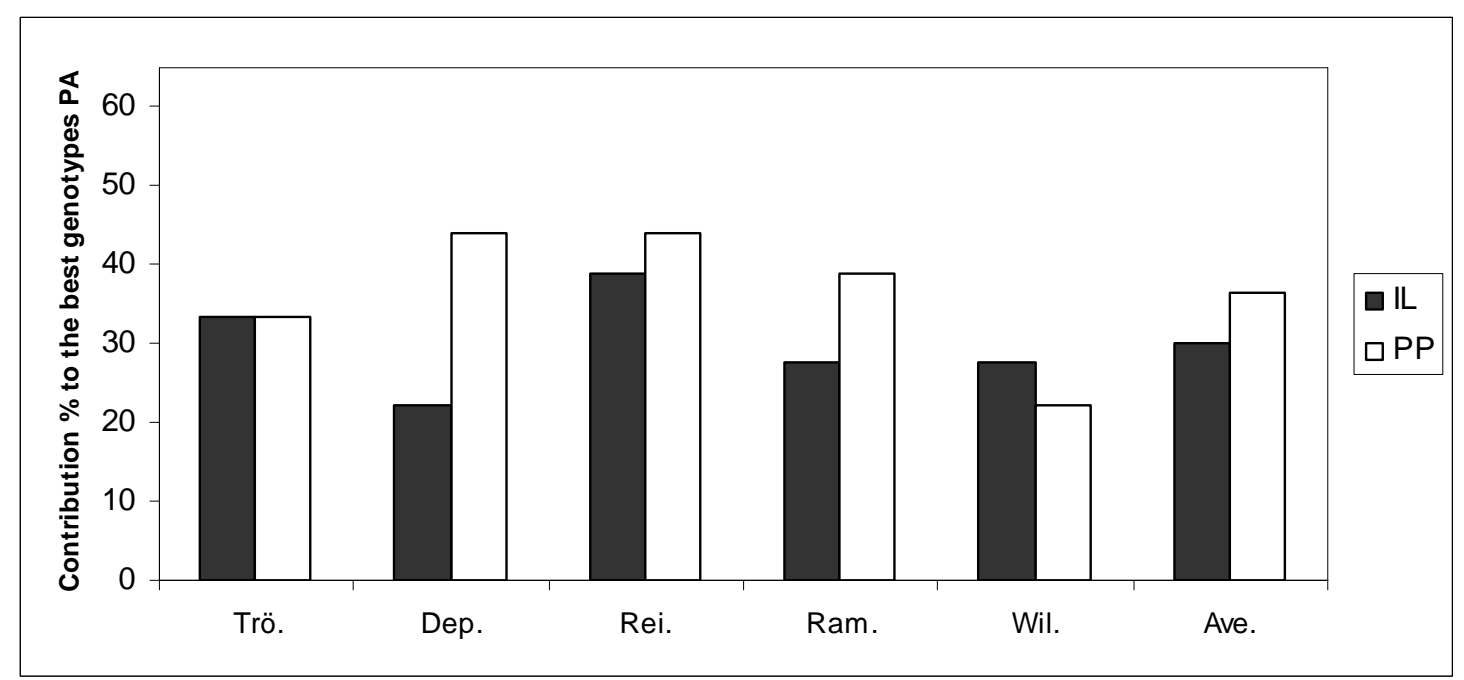

Figure 6. Contribution in \% of the inbred lines and the polycross progenies to the eighteen best genotypes according to the personal appreciation (PA). 


\section{Winter faba bean}

\section{Introduction}

Winter faba bean are early flowering and maturing compared to spring faba bean. They are believed to perform better and to show a more stable grain yield than spring beans (Herzog, 1989; Herzog and Geisler, 1991), unless winters are too harsh. However, winter beans are not yet adopted in the cropping system in Germany. Cultivars from UK were reportedly not sufficiently winter-hardy for the German climate (von Kittlitz, 1974). German cultivars of winter faba bean were developed (Littman, 1979) but were not found to withstand the rigors of German winters (Herzog, 1987). The objective of this experiment was to test a set of winter faba bean genotypes with contrasting genotypic structures, i.e., different for their heterozygosity and heterogeneity level but similar for their allele frequency under organic conditions in Germany and to determine, through a participatory approach, which type of winter faba bean cultivar is adequate for organic farming.

\section{Material and Methods}

\section{Breeding material and experimental design}

Winter bean genotypes with different degree of heterogeneity and heterozygosity (Appendix II) were tested in field trials across four organic locations (Tröndel, Deppoldshausen, Ramsthal and Willmering) and one conventional location (Reinshof) in Germany in 2004, 2005 and 2006. At Reinshof, one replicate was not treated with agro-chemical inputs. The agro-ecological conditions of the locations were described in the spring bean experiment (first part in Chapter I). Eighteen homozygous winter bean inbred lines were used here, per se and to produce four different genotypic structures with orthogonal genetic background: polycross progenies from the inbred lines, three inbred line blends, three polycross progeny blends, and in addition checks were used (Table.1). 
The trials were laid out as lattice design with two replicates involving 56 entries in 2005 and 2006. From these 56 entries, 19 were tested in 2004 in a complete block design with two replicates. The plot size was $2.2 \mathrm{~m}^{2}$ (2004 and 2005) and $4.8 \mathrm{~m}^{2}$ (2006) with an average of 25 seeds/ m2. The trials were altogether sown in the middle of October and harvested in the end of August.

\section{Participatory approach and measurements}

As for the spring bean experiment, each partner (farmer or scientist) was involved in his/her location for the trial management, the scoring of the agromorphological traits of all plots, the visual estimation of yield at maturity and the scoring of personal appreciation of the material. Additionally, overwintering (OW, $\%$ ) was scored at the end of the winter and expressed the number of surviving plants relatively to the initial number before the frost.

\section{Statistical analyses}

The statistical analysis was carried out using PLABSTAT (Utz, 1991). Concerning the data of 2005 , the lattice designs were analyzed separately for each location. According to Cochran and Cox (1992), adjusted entry means were used for the subsequent analysis of variance for each location and finally a combined analysis of variance across locations was performed. A combined analysis across the years 2004 and 2005 was performed for the common 19 genotypes. For each data set, a mixed model was used where the years $(Y)$ were random and the factors genotypes $(G)$ and locations $(L)$ were fixed. The winter in 2006 was extremely harsh and no genotype survived in the trials of the four organic locations. The data of the location Reinshof were presented (see below).

For the year 2005, the prediction of the best synthetic according to yield performance was done as described in material and methods of the spring bean experiment. Correlation coefficients of the trait personal appreciation with the other scored traits were presented for each location. For statistical significance, + 
is used to indicate significances at $10 \%$ level of error probability, * at $5 \%$ level of error probability and ** at $1 \%$ level of error probability.

\section{Results and discussion}

The winter season in the year 2006 was very harsh compared to the previous winters. In the locations studied, 85\% more days with a temperature equal or less than $-6{ }^{\circ} \mathrm{C}$ were recorded in the winter 2006 compare $d$ to the winters in 2004 and 2005 (Figure 1). Faba bean genotypes did not or almost not survive the harsh frost in four locations (Tröndel, Deppoldshausen, Ramsthal and Willmering); only in Reinshof, faba bean genotypes survived to an extent that allowed the assessment of agronomic traits.

The mean values of relevant agronomic traits across the year 2004 and 2005 (Table 2) showed that indeed, the locations were different regarding their agroecological conditions. As in the case of spring beans, the genotypes in the conventional location recorded the highest performance. On average, overwintering of the genotypes was highest in Reinshof and Tröndel and lowest in Ramsthal. Genotypes in Reinshof were on average early flowering and maturing, tall and lodging. As in the case of spring beans, no significant differences were detected between the treated and the untreated replicate in Reisnhof. The agro-ecological conditions in Ramsthal were unfavorable (low overwintering, high disease infestation and low quality of harvested seeds) and led to the lowest yield. Deppoldshausen was the most favorable organic locations with the highest average yield performance.

The combined analysis of variance across locations, years and genotypes showed that all sources of variation were significant for grain yield and overwintering (Table 3). This analysis covered the 19 common entries in 2004 and 2005. Genotype $\times$ Location interaction $(\mathrm{G} \times \mathrm{L})$ contributed $\left(0.58 \mathrm{t}^{2} / \mathrm{ha}^{2}\right)$ more than half as much as the genotypes $\left(0.89 \mathrm{t}^{2} / \mathrm{ha}^{2}\right)$ to the yield variation. For region specific breeding, where the location of selection is the target location, this is a clear advantage since the variance available for the selection is broadened by 
including the $\mathrm{G} \times \mathrm{L}$ interaction variance, thus increasing the expected gain from selection. The analysis of variance in the year 2005 across the 56 genotypes and the five locations (Table 4), showed that the $G \times L$ interaction variance for both grain yield and overwintering was as well highly significant.

The location Deppoldshausen was taken as a representative example to illustrate the pattern of the genotypes' distribution according to the grain yield (Figure 2). As for the spring beans, the distribution of winter faba bean genotypes was reflecting their genotypic structure. On average, inbred lines were less performing than polycross progenies (3.82 t/ha $<5.16 \mathrm{t} / \mathrm{ha}$ ). The inbred line Avrissot/1 was the lowest yielding in Deppoldshausen as well as across all locations. The inbred line L79/79/1 was the highest yielding in Deppoldshausen, whereas across all locations Bulldog/1-4 derived from the cultivar Bulldog (UK) was the highest yielding inbred line. In a recent study, this line was as well found to be among the best performing genotypes when tested across a range of European environments including Germany, Austria, Czech Republic and Estonia (Arbaoui et al., 2007).

It never occurred that, whether on average or in any single location, an inbred line outyielded the best polycross progeny. Checks were distributed across the whole range of all other genotypes.

In the year 2006, data could be collected only at Reinshof. There, average yield in 2006 was about $42 \%$ lower compared to 2005 (Figure 3). In the year 2006, the variance among the inbred lines $\left(2.85 \mathrm{t}^{2} / \mathrm{ha}^{2}\right)$ and among their polycross progenies (1.35 $\left.\mathrm{t}^{2} / \mathrm{ha}^{2}\right)$ were twice as much as their variance in $2005\left(1.31 \mathrm{t}^{2} / \mathrm{ha}^{2}\right.$, $0.62 \mathrm{t} 2 / \mathrm{ha}^{2}$, resp.; cf. Table 5). Apparently the harsh winter conditions uncovered additional differences among the winter bean genotypes. The inbred lines Avrissot/1, Webo/1-1-1 and S5-45 were the least winter-hardy inbred lines since they did not survive the winter (Figure 3). The inbred line Webo/1-1-1 is derived from the German cultivar Webo which empirically did not prove to be to sufficiently winter-hardy for continental climate in Germany (Herzog, 1987). The inbred line Côte d'Or/2-4 derived from the French cultivar Côte d'Or was the most 
stable inbred line; it yielded in the harsh winter as much as in the mild winter. The inbred line Hiverna/1-1-2 derived from the German cultivar Hiverna was the best yielding inbred line under high frost stress and is obviously the most winter-hardy inbred line.

To compare between the inbred lines and their polycross progenies, mean values and variances of inbred lines and their polycross progenies for grain yield were assessed in each location and in all combined locations (Table 5). From the ANOVA, the least significant difference and the significance level of the differences between inbred lines and between polycross progenies were estimated (Table 5).

Results showed that across all locations, the differences between the polycross progenies as well as the differences between the inbred lines were highly significant. Among locations, yield performance of the inbred lines was more or less correlated with the performance of their polycross progenies (in Reinshof $r=$ $0.80^{\star *}$; and in Ramsthal $r=0.17$ ). In the combined analysis, the correlation between the inbred lines and their polycross progenies was highly significant $(r=$ $\left.0.76^{* *}\right)$.

The polycross progenies yielded on average higher than the inbred lines due to the heterosis effect; whereas the variance among inbred lines was higher than the polycross progenies variance.

In a local breeding approach, exploitable variances are realized from the performance in a specific location where the interaction between genotypes and this location is included. The average value of the variances of specific locations displays the average genotype variance plus the average of $G \times L$ interaction variance for a typical single location. In local breeding, the variances estimated in each location as well as the average of the variances across locations were markedly higher than the variance that can be used in formal plant breeding (Combined analysis, cf. Table 5), estimated from the mean values of yield over locations. 
The variance used in the formal plant breeding is narrow compared to the variances at single locations (Table 5). The higher the genotype $\times$ location interaction effect is, the more efficient is local breeding compared to formal plant breeding.

The performance of synthetics at the first generation Syn-1, selected and created from 18 potential components (inbred lines) was predicted on the basis of the inbred lines performance and their polycross progenies performance in 2005 (see material and methods of spring beans). For all locations, the optimum size of synthetics was found to be $\mathrm{N}=4$ components, corroborating the results found in spring beans.

The analysis of the best inbred line in each location showed (Table 6) that the inbred line IL 6 (Hiverna/1-1-2) was specifically adapted to both Willmering and Reinshof. The three other locations had each a different specifically adapted inbred line; IL 11 (Wibo/1) in Tröndel, IL 7 (L79/79/1) in Deppoldshausen, and IL 9 (L979/S1/1/1/1sn) in Ramsthal. In each location, the best inbred line was one of the four components of the best Syn-1(4). As for the spring beans, the best inbred lines contributed to the components of the best synthetic. The best synthetics among the locations were established from eight different components out of the 18 available. Similarly to the case of the spring beans, among locations, the Syn-1(4) yielded on average higher than the inbred lines which is in concordance with the theoretical expectations established by Gallais (1992). Unlike to the spring bean experiment, in winter beans the comparison between the highest yielding inbred line and the highest yielding Syn-1(4) revealed that apart from Ramsthal, in the other four locations the highest yielding Syn-1(4) outyielded the highest inbred line.

Personal appreciation was significantly correlated with overwintering and with yield estimation (Table 7). Yield is among the most important traits in farmers criteria of appreciation. The other criteria were location-specific and depended partly on the given biotic and abiotic conditions. For instance, diseases were more frequent in Deppoldshausen and Ramsthal. Therefore the selection was 
oriented toward resistant genotypes. In Reinshof, where diseases and lodging were a major concern, selection was against infested, infected and lodging genotypes. Tall genotypes were favored by all partners through a compromise between tall and stiff genotypes. As in the case of spring beans, the farmers' criteria of appreciation reflected the agro-ecological features of each location. The 18 best genotypes out of $\mathrm{N}=56$ according to yield and according to the personal appreciation were identified. The inbred lines blends were neither among the best yielding genotypes nor among the best appreciated genotypes. Checks contributed similarly to the best yielding genotypes (26\%) and to the best appreciated genotypes (24\%). As for the spring bean trial, the marked difference between the composition of the highest yielding and the best appreciated genotypes was due to the difference in the contribution of the inbred lines and the polycross progenies (Figure 4 and 5). The contribution of the inbred lines to the highest yielding genotypes amounted $11 \%$ and increased to $38 \%$ in the best appreciated genotypes; whereas the polycross progenies contributed with $52 \%$ to the highest yielding genotypes and their contribution decreased to $32 \%$ in the best appreciated genotypes. The highest yielding inbred line ranked among the best appreciated genotypes. Compared to the selection based on yield performance, farmers appreciated the homogeneous inbred lines more and the heterogeneous polycross progenies less. Besides yield performance, homogeneity was apparently markedly appreciated by organic farmers.

The outcome of this experiment on winter faba bean was corroborating the findings and the conclusions drawn from the spring faba bean experiment. Heterozygosity was found to be the factor enhancing most markedly yield in faba bean (Stelling et al., 1994). To satisfy the apparent criteria of the farmers, it is essential to breed for heterozygous and homogeneous cultivars. Such characteristics are only available in hybrid cultivars which unfortunately are not possible to be produced at commercial level in faba bean, as no existing system for cytoplasmic male sterility proved to be stable in faba bean (Bond, 1987). The alternative type of cultivars are synthetic cultivars which are partly heterozygous and are bred generally with a certain level of homogeneity for morphological and 
developmental traits such as flowering time, maturity time, height and seed shape and color. It is important to stress that the best appreciated checks in all locations were essentially synthetic cultivars such as Target and Punch originating from United Kingdom.

A prediction of synthetic cultivars with the objective to compare locally the best inbred line with the best synthetic cultivar in winter beans was only possible for one year (2005), reducing the reliability of the present results.

\section{References}

Arbaoui, M., C. Balko, and W. Link, 2007. Study of faba bean (Vicia faba L.) winter-hardiness and development of screening methods for frost tolerance. Under submission to Crop Science.

Bond, D. A., 1987. Recent developments in breeding faba beans (Vicia faba L.). Plant Breeding. 99: 1-26.

Cochran, W. G. and G. M. Cox, 1992. Experimental Designs. Second edition. John Wiley and Sons (eds.), Inc. New York.

Gallais, A., 1992. Pourquoi faire des variétés synthétiques ? Agronomie.12: 601609.

Herzog, H., 1987. Freezing resistance and development of faba beans as affected by ambient temperature, soil moisture and variety. J. Agron. Crop Sci. 159: 90-100.

Herzog, H., 1989. Freezing resistance and performance of faba bean populations during winter seasons in Northern Germany. J. Agron. Crop Sci. 162: 225235.

Herzog, H., and G. Geisler, 1991. Yield structure of winter beans grown in Northern Germany in dependence of different environments, seed rates, sowing rates and genotypes. J. Agron. Crop Sci. 167: 145-154. 
Littman, H., 1979. Winterbohnen. Veröffentlichung des RationalisierungsKuratoriums für Landwirtschaft, August 1979, 167-170.

Stelling, D., W. Link, and E. Ebmeyer, 1994. Factors determining the performance of synthetics in Vicia faba L. 1. Syn-generation. Euphytica. 75: $85-93$

Utz, H. F. 1991. A computer program for statistical analysis of plant breeding experiments. Institute of Plant Breeding, Seed Science and Population Genetics. University of Hohenheim.

von Kittlitz, E., 1974. Ergebnisse mehrjähriger Feldversuche mit Winterackerbohnen und einige Konsequenzen für die Züchtung. Referat, Tagung Pflanzenbauwissenschaften, Hohenheim (unveröffentlicht). 
Table 1.Genotypic structure and frequency of the genotypes involved in the winter bean trials.

\begin{tabular}{lcccccc}
\hline Years & IL & PP & ILB & PPB & CK & Total \\
\hline Winter bean (2004) & 11 & 0 & 0 & 0 & 8 & $\mathbf{1 9}$ \\
Winter bean (2005) & 18 & 18 & 3 & 3 & 14 & $\mathbf{5 6}$ \\
Winter bean (2006) & 18 & 18 & 3 & 3 & 14 & $\mathbf{5 6}$ \\
\hline
\end{tabular}

IL: inbred lines PP: polycross progenies ILB: inbred lines blend PPB: polycross progenies blend CK: check

Table 2. Mean values of relevant agronomic traits in each location across two years (2004 and 2005).

\begin{tabular}{lccccccccc}
\hline Locations & $\begin{array}{c}\text { OW } \\
\%\end{array}$ & $\begin{array}{c}\text { FLW } \\
\text { days }\end{array}$ & $\begin{array}{c}\mathrm{HEl} \\
\mathrm{cm}\end{array}$ & $\begin{array}{c}\text { LOD } \\
\text { score }\end{array}$ & $\begin{array}{c}\text { MAT } \\
\text { days }\end{array}$ & $\begin{array}{c}\text { DI } \\
\text { score }\end{array}$ & $\begin{array}{c}\text { GS } \\
\text { score }\end{array}$ & $\begin{array}{c}\text { TGW } \\
\text { g }\end{array}$ & $\begin{array}{c}\mathrm{Y} \\
\text { t/HA }\end{array}$ \\
\hline Trö. & 70.66 & 144 & 119.57 & 2.00 & 220 & 2.00 & 1.56 & 609.09 & 3.51 \\
Dep. & 64.82 & 147 & 110.39 & 3.50 & 230 & 4.27 & 2.53 & 594.13 & 4.29 \\
Rei. & 77.67 & 135 & 130.24 & 4.63 & 223 & 2.23 & 2.45 & 567.42 & 5.68 \\
Ram. & 52.95 & 139 & 87.63 & 2.75 & 216 & 6.65 & 3.31 & 590.18 & 1.57 \\
Wil. & 59.46 & - & 105.99 & 2.20 & 210 & - & 2.95 & 633.32 & 2.84 \\
\hline Average & 65.11 & 141 & 110.37 & 3.33 & 220 & 3.54 & 2.60 & 598.83 & 3.58 \\
\hline Disease infestation (DI, score 1-9; 1: healthy and 9: totally infested), lodging (LOD, score 1-9; 1: fully upright, \\
9= totally lodging) and grains status (GS, score 1-9; 1: healthy, 9: fully infested).
\end{tabular}

Table 3. Combined analysis of variance including variance components $\left(\sigma^{2}\right)$ of grain yield and overwintering across genotypes, years (2004 and 2005) and locations.

\begin{tabular}{|c|c|c|c|c|c|c|c|c|}
\hline \multirow{2}{*}{ Source of variation } & \multicolumn{4}{|c|}{ Yield t/ha } & \multicolumn{4}{|c|}{ Overwintering \% } \\
\hline & DF & $\sigma^{2} t^{2} / h^{2}$ & F value & LSD 5\% & DF & $\sigma^{2} \%{ }^{2}$ & F value & LSD $5 \%$ \\
\hline Years (Y) & 1 & 0.407 & $26.06^{\star \star}$ & 0.400 & 1 & 15.95 & $8.06^{*}$ & 4.74 \\
\hline Locations (L) & 4 & 2.245 & $4.34+$ & 3.090 & 4 & 61.26 & $4.45+$ & 23.90 \\
\hline Genotypes (G) & 18 & 0.894 & $3.07^{*}$ & 1.960 & 18 & 114.78 & $2.41^{*}$ & 26.92 \\
\hline$R: L Y$ & 10 & 0.113 & $3.27^{* *}$ & 0.620 & 10 & 14.24 & $2.70^{* *}$ & 8.05 \\
\hline$L \times Y$ & 4 & 1.238 & $50.94^{\star *}$ & 0.440 & 4 & 72.31 & $18.31^{* *}$ & 5.70 \\
\hline$G \times Y$ & 17 & 0.771 & $9.19^{\star \star}$ & 0.860 & 17 & 146.88 & $10.25^{\star *}$ & 11.10 \\
\hline$G \times L$ & 72 & 0.576 & $3.44^{* *}$ & 1.350 & 72 & 23.73 & $1.60^{\star *}$ & 17.56 \\
\hline GxR:LY & 225 & 0.942 & & & 226 & 158.74 & & \\
\hline Total & 351 & & & & 352 & & & \\
\hline
\end{tabular}

Table 4. Combined analysis of variance including variance components $\left(\sigma^{2}\right)$ of grain yield and overwintering across genotypes and locations in the year 2005.

\begin{tabular}{l|rlrl|rrrr}
\hline \multirow{2}{*}{ Source of variation } & \multicolumn{4}{|c|}{ Yield t/ha } & \multicolumn{4}{c}{ Overwintering \% } \\
\cline { 2 - 8 } & DF & $\sigma^{2} \mathrm{t}^{2} / \mathrm{ha}^{2}$ & $\mathrm{~F}$ Value & LSD 5\% & DF & $\sigma^{2} \%^{2}$ & F value & LSD 5\% \\
\hline Locations $(\mathrm{L})$ & 3 & 2.828 & $504.88^{* *}$ & 0.21 & 3 & 255.07 & $200.94^{* *}$ & 3.15 \\
Genotypes $(\mathrm{G})$ & 55 & 0.698 & $9.88^{* *}$ & 0.78 & 55 & 112.09 & $7.28^{* *}$ & 11.80 \\
G×L & 162 & 0.108 & $1.52^{\star *}$ & 1.27 & 163 & 32.21 & $1.82^{* *}$ & 17.49 \\
Error & 158 & 0.206 & & & 159 & 39.23 & & \\
\hline
\end{tabular}


Table 5. Mean values, phenotypic variances with their significances and least significant differences for yield ( $t / h a$ ) of both, inbred lines and polycross progenies; and their correlation ( $r$ ).

\begin{tabular}{|c|c|c|c|c|c|c|c|}
\hline Locations & $\begin{array}{l}\text { Inbred li } \\
\mu(\mathrm{t} / \mathrm{ha})\end{array}$ & $\begin{array}{l}\sigma^{2}\left(t^{2} / h^{2}\right) \\
\text { les }\end{array}$ & LSD 5\% & $\begin{array}{l}\text { Polycros } \\
\mu(t / h a)\end{array}$ & $\begin{array}{l}\text { s progenies } \\
\sigma^{2}\left(\mathrm{t}^{2} / \mathrm{ha}^{2}\right)\end{array}$ & LSD $5 \%$ & $r(I L, P P)$ \\
\hline \multicolumn{8}{|c|}{ Local breeding approach } \\
\hline Trö. & 3.49 & $1.59^{* *}$ & 1.45 & 4.20 & 1.07 & 3.31 & 0.25 \\
\hline Dep. & 3.82 & $1.91^{* *}$ & 1.24 & 5.16 & $0.42^{\star}$ & 1.48 & $0.66^{* *}$ \\
\hline Rei. & 4.40 & $1.45^{\star *}$ & 1.54 & 6.18 & $0.73^{\star}$ & 1.48 & $0.80^{* *}$ \\
\hline Ram. & 1.76 & $0.59^{\star *}$ & 1.16 & 2.49 & 0.42 & 2.13 & 0.17 \\
\hline Wil. & 1.62 & $1.01^{* *}$ & 1.09 & 2.53 & $0.46^{\star}$ & 1.61 & $0.53^{*}$ \\
\hline Average & 3.02 & 1.31 & - & 4.14 & 0.62 & - & - \\
\hline \multicolumn{8}{|c|}{ Formal breeding approach } \\
\hline Combined analysis & 3.02 & $0.71^{* *}$ & $0.55^{\star \star}$ & 4.14 & $0.51^{* *}$ & 0.89 & $0.76^{\star *}$ \\
\hline
\end{tabular}

Table 6. Average yield performance of the inbred lines and the synthetics Syn-1(4), and yield performance and identity of the best inbred line and the best Syn-1(4) in each location.

\begin{tabular}{lcccccc}
\hline Locations & $\begin{array}{c}\text { Average } \mathrm{Y}(\mathrm{t} / \mathrm{ha}) \\
\text { of } 18 \mathrm{IL}\end{array}$ & $\begin{array}{c}\text { Average } \mathrm{Y}(\mathrm{t} / \mathrm{ha}) \\
\text { of } 3060 \mathrm{Syn}-1(4)\end{array}$ & $\begin{array}{c}\mathrm{Y}(\mathrm{t} / \mathrm{ha}) \text { of the } \\
\text { best IL }\end{array}$ & Best IL & $\begin{array}{c}\mathrm{Y}(\mathrm{t} / \mathrm{ha}) \text { of the } \\
\text { best Syn-1(4) }\end{array}$ & $\begin{array}{c}\text { Best Syn-1(4) } \\
\text { components }\end{array}$ \\
\hline Trö. & 3.35 & 4.96 & 5.76 & 11 & 6.66 & $6 ; 11 ; 18 ; 7$ \\
Dep. & 3.82 & 4.88 & 5.44 & 7 & 5.75 & $6 ; 7 ; 4 ; 3$ \\
Rei. & 4.39 & 5.81 & 5.91 & 6 & 6.93 & $6 ; 3 ; 4 ; 8$ \\
Ram. & 1.97 & 2.15 & 3.40 & 9 & 3.16 & $9 ; 7 ; 18 ; 12$ \\
Wil. & 1.58 & 1.75 & 2.52 & 6 & 3.06 & $6 ; 3 ; 4 ; 8$ \\
\hline
\end{tabular}

Table 7. Coefficients of correlation between the personal evaluation and the agronomic traits.

\begin{tabular}{|c|c|c|c|c|c|c|c|c|}
\hline Locations & OW & FLW & $\mathrm{HEI}$ & LOD & MAT & $\mathrm{DI}$ & $Y$ & YE \\
\hline Trö. & $0.34^{*}$ & - & $0.29^{*}$ & - & $0.30^{*}$ & - & $0.31^{*}$ & $0.64^{* \star}$ \\
\hline Dep. & $0.39^{* *}$ & - & $0.52^{\star *}$ & $-0.36^{\star \star}$ & - & $-0.32^{*}$ & $0.64^{* *}$ & $0.44^{\star \star}$ \\
\hline Rei. & $0.30^{*}$ & - & $0.34^{*}$ & $-0.66^{\star *}$ & $0.37^{* *}$ & $-0.23^{*}$ & $0.45^{\star *}$ & $0.48^{* *}$ \\
\hline Ram. & $0.75^{\star \star}$ & - & $0.71^{* *}$ & $-0.48^{* *}$ & - & $-0.31^{*}$ & $0.79^{* *}$ & $0.78^{\star \star}$ \\
\hline
\end{tabular}

- non significant coefficient of correlation 


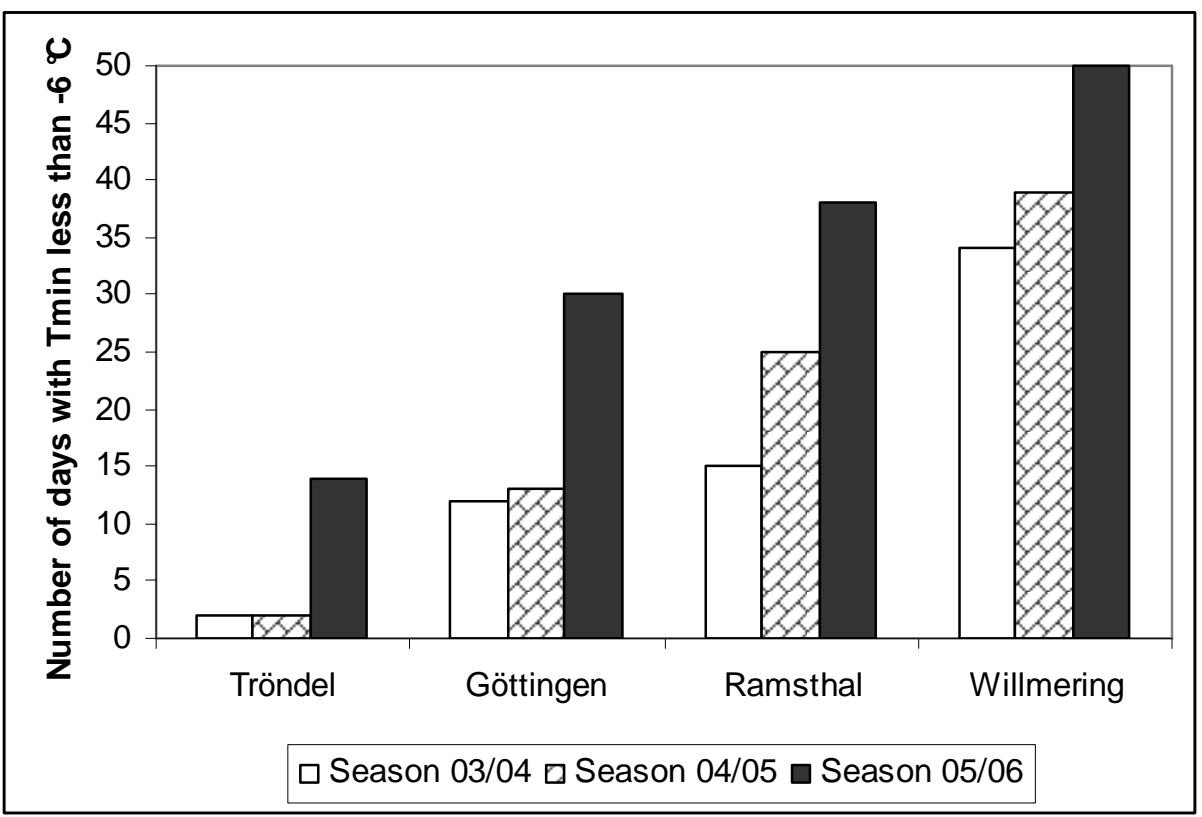

Figure 1. Number of days with minimum temperature equal or less than $-6^{\circ} C$ in the three season and the five locations studied. (Göttingen data are the data of Deppoldshausen and Reinshof).

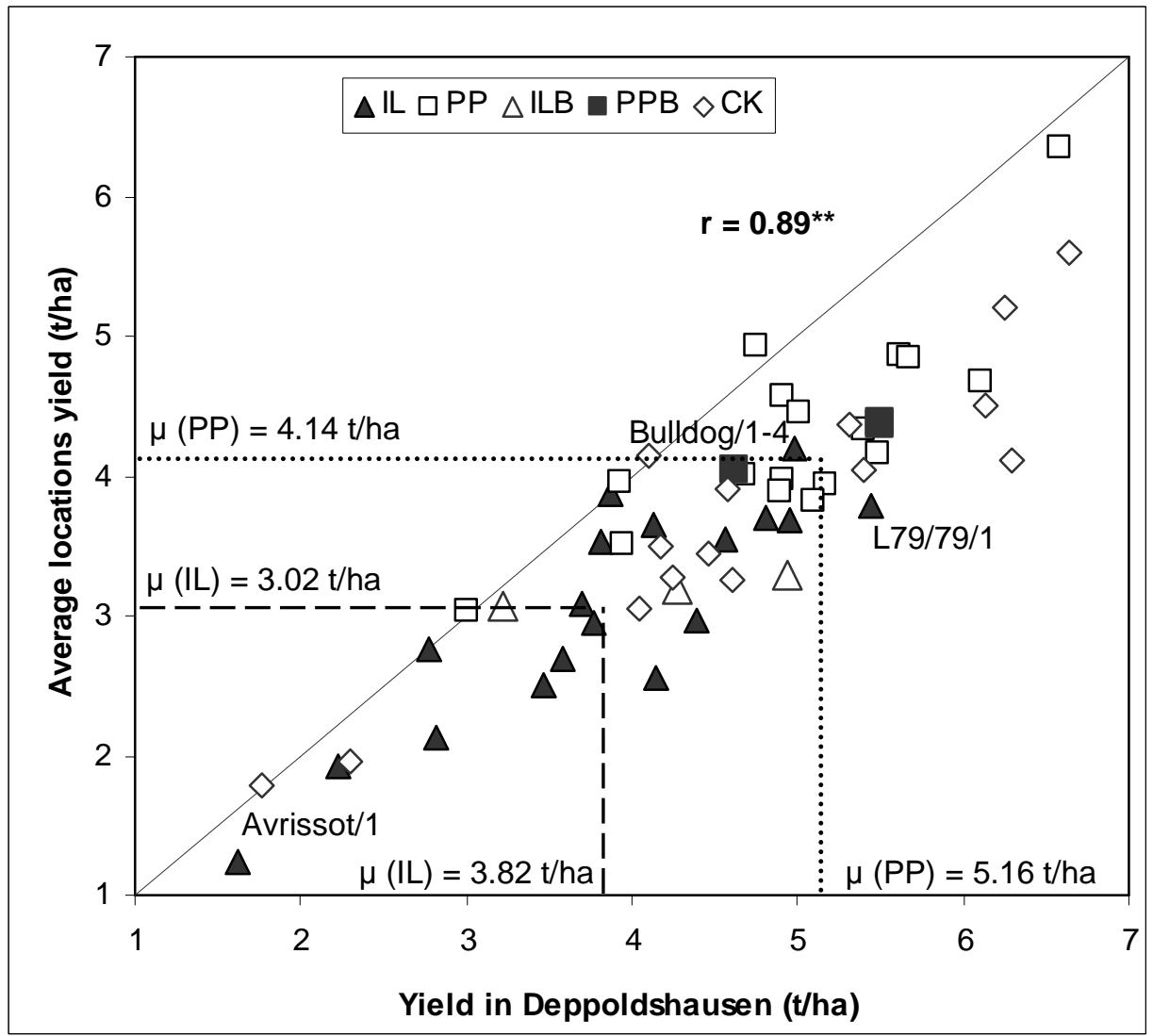

Figure 2. Distribution of the genotypes in Deppoldshausen compared with their averages across all locations according to grain yield ( $\mathrm{t} / \mathrm{ha}$ ) in the year 2005 . 


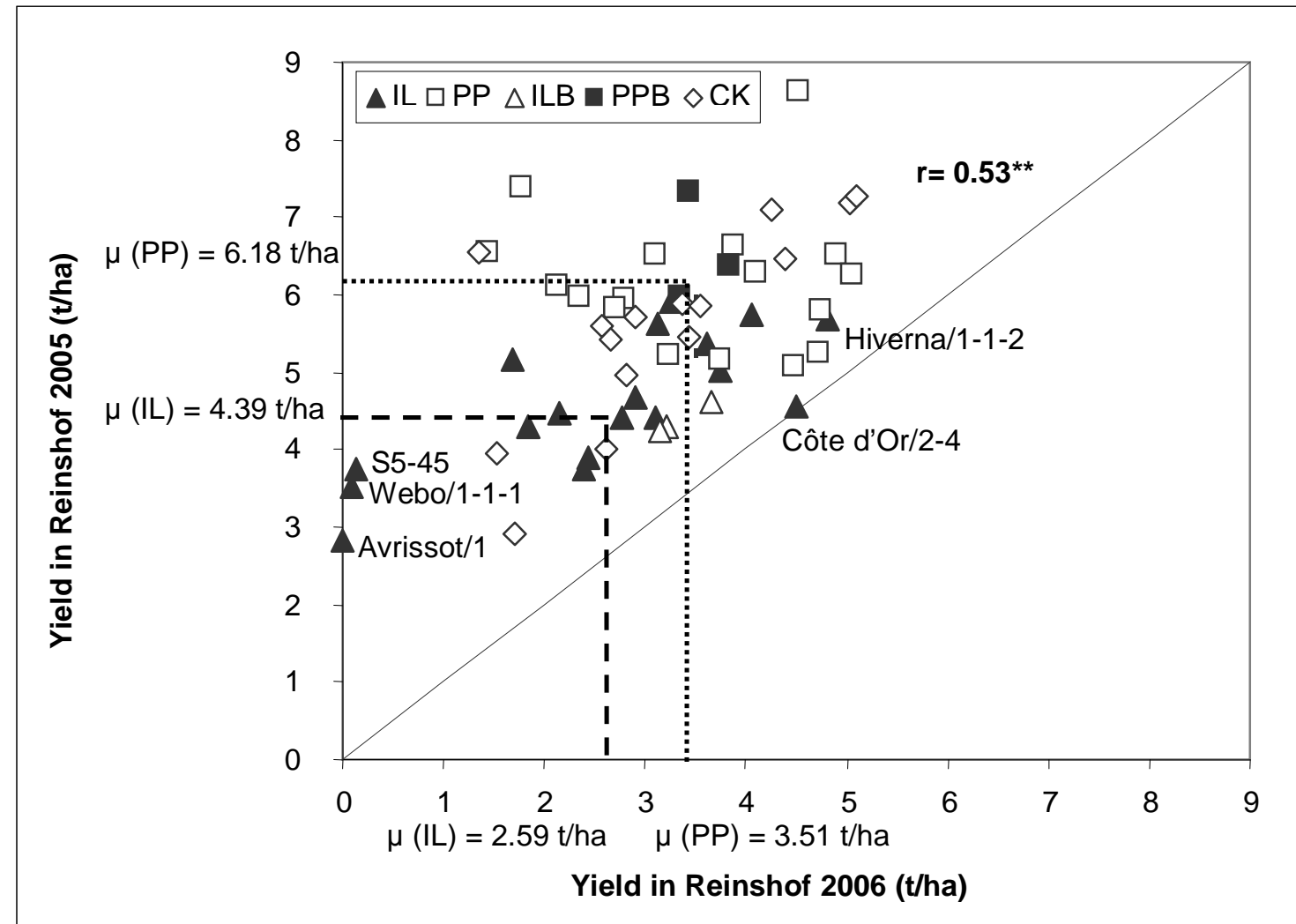

Figure 3. Relationship between the performance of the genotypes in Reinshof for the year 2005 and the year 2006 according to grain yield (t/ha).

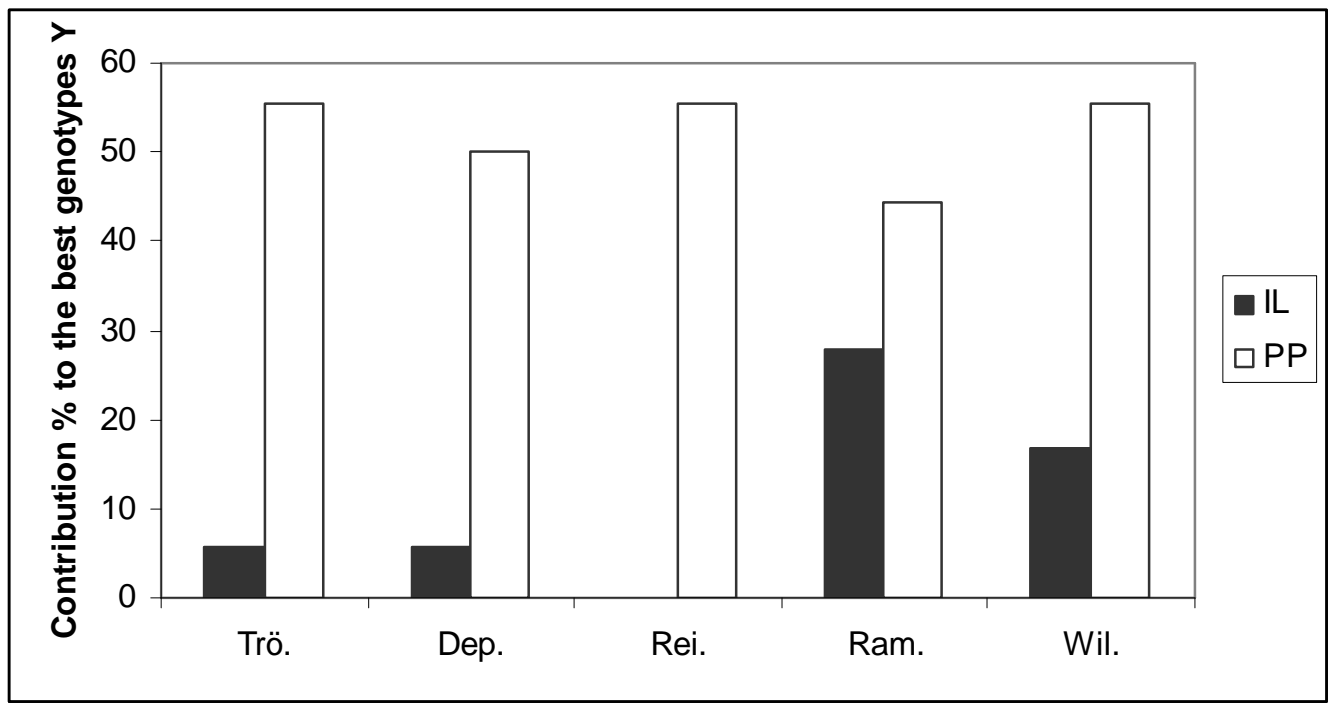

Figure 4. Contribution in \% of the inbred lines and the polycross progenies to the eighteen best genotypes according to the yield performance $(\mathrm{Y})$ in 2005. 


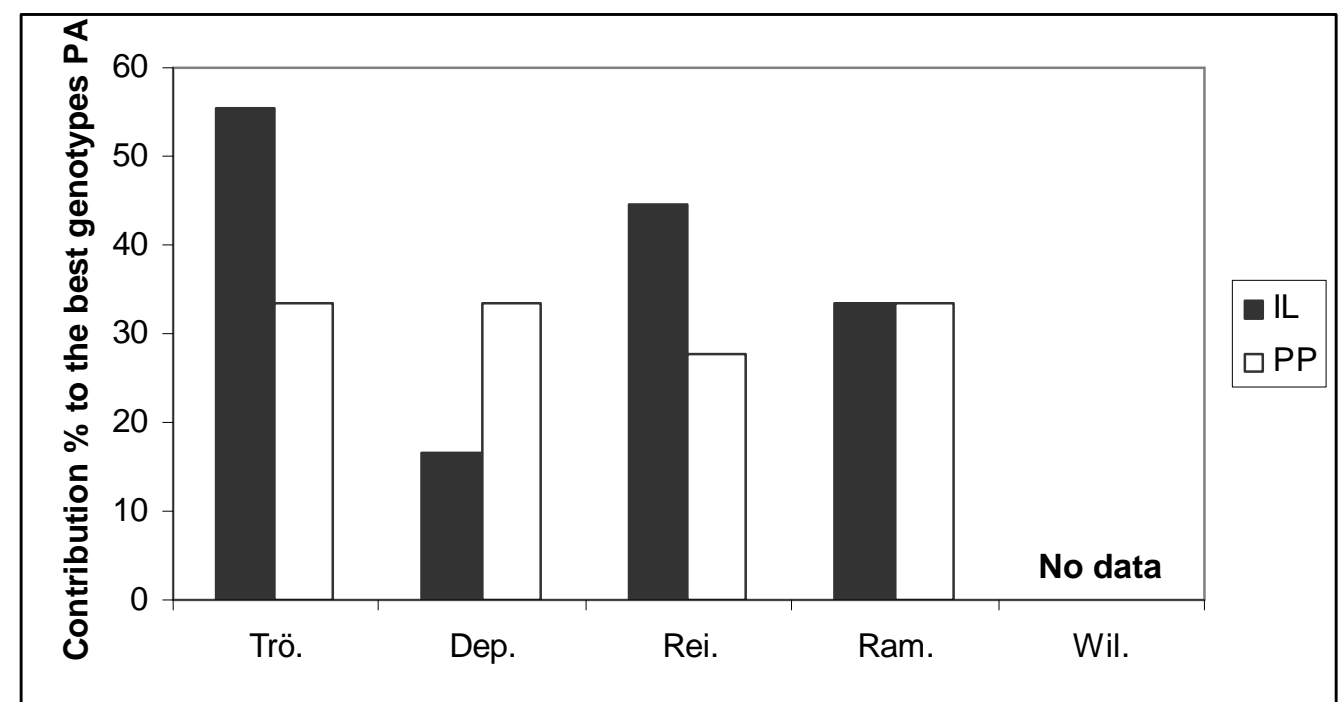

Figure 5. Contribution in \% of the inbred lines and the polycross progenies to the eighteen best genotypes according to the personal appreciation (PA) in 2005. 


\title{
Chapter II. Comparison between local vs. formal breeding and inbred line vs. synthetic cultivars for organic farming. Case of Vicia faba L.
}

L. Ghaouti and W. Link

Key words: Faba bean, genotype $\times$ location interaction, local breeding, formal breeding, inbred lines, synthetics.

\begin{abstract}
As organic farming is characterized by a large environmental heterogeneity, genotype $\times$ location interaction is expected to be larger across organic cropping areas than in conventional ones.

A strong asset of local breeding is the possibility to select in the target environment and to exploit genotype $\times$ location interactions, being repeatable over time. The objective of this study was to study for faba bean the effectiveness of local breeding versus formal breeding for grain yield in organic farming and to compare the performance of inbred lines and corresponding synthetics using a local breeding approach and a formal breeding approach. A set of 18 inbred lines, their polycross progenies and 13 checks was tested in four organic locations and one conventional station in Germany in 2004, 2005 and 2006. Due to the large genotype $\times$ location interaction, local breeding proved to generate higher gains from selection and was obviously more efficient than formal breeding. The optimum size of synthetics for all locations was four parental components. Based on the genotypic performance and variance of inbred lines and synthetics at the first generation Syn-1, and on intensity of selection, the best Syn-1(4) and the best inbred lines were predicted. Despite the large variance of inbred lines available in local breeding, due to the partial realization of heterosis in the synthetics, these were the best performing in both breeding strategies. Unlike pure lines, they are providing the option of further local evolution and adaptation over time.
\end{abstract}




\section{Introduction}

Formal plant breeding generally has concentrated on increasing yield and quality in environments that were modified by application of agro-chemicals. The importance of adaptation to variable and even risky low-input conditions often found in organic farming received little or no attention (Almekinders and Elings, 2001). Organic farmers normally use cultivars derived from formal breeding, typically being input responsive and broadly adapted, just because there is very little 'organic breeding'. Formally bred cultivars are unlikely to succeed optimizing the organic cropping system. The obvious reason is that such cultivars, although often defined as 'widely adapted', are actually specifically adapted to rather optimum conditions as far as agrochemical inputs are used to control weeds, pests and diseases and to provide nutrients when breeding them. Therefore, their superiority in these environments was often not expressed in sub-optimal environments (Ceccarelli, 1994). Organic production in developed countries shares common features with marginal area production in developing countries such as heterogeneous environments, large diversity of farmer's needs and lack of specifically adapted cultivars (Desclaux, 2005). Therefore, genotypeenvironment interaction is expected to be large in organic cropping. Genotypeenvironment interaction results when the differences in performance between genotypes change from one environment to another one. Plant breeders can deal with genotype-environment interaction in three ways: to ignore, to avoid or to exploit them (Eisemann et al., 1990). The formal plant breeder decides to avoid them by selecting cultivars that are broadly adapted to the entire range of their target environments (Ceccarelli et al., 2000). The efficiency of formal plant breeding is likely to be limited in organic cropping systems where the genotypeenvironment interactions are supposed to be large. Local breeding is an alternative approach which aims to exploit the genotype-environment interactions by selecting for specific adaptation. The assumption is that specific adaptation is the result of exploiting an over-time repeatable genotype-environment interaction in a specific location (genotype-location interaction; Bänziger and Cooper, 2001). 
Effectiveness of local breeding vs. formal breeding for yield in organic farming

Local breeding can be compared with formal breeding on the basis of the predicted response in the target location from selection in other locations. Falconer and Mackay (1989) suggested that when genotype-environments interactions are high, yield in each environment is to be regarded as a separate trait. In this case, yield performance is not necessarily maximized by identical sets of alleles. In local breeding, the environment represents a location. The choice of the appropriate breeding approach to select genotypes for an organic location is very much depending on the comparison between direct and correlated response to selection in a given location. The outcome of this comparison is predicted using the ratio of correlated to direct selection (Falconer and Mackay, 1989): $\frac{C_{L(D)}}{R_{L}}=r_{G} \frac{h_{D}}{h_{L}} \quad$ [Eq.1]; where $C R_{L(D)}$ is the correlated response in the target location $(L)$ to selection in the data set $(D), R_{L}$ is the response to direct selection in the target location $(L), r_{G}$ is the genetic correlation between yield in $L$ and $D, h_{L}$ is the square root of heritability in the target location and $h_{D}$ is the square root of heritability in the data set of selection. Correlated response may exceed direct response only if heritability is higher in the selection data set than in the target location and if the value of $r_{G}$ is high.

Comparison of inbred line vs. synthetic cultivar in local breeding and in formal breeding for organic conditions

One of the critical issues in breeding for organic conditions is to identify the appropriate category of cultivar fitting the requirements of organic conditions and principles. In faba bean, a partially allogamous crop, inbred lines and synthetics are the main bred types of cultivars. Synthetic cultivars are a specific type of population cultivars. They are produced by open pollination of selected components during a limited number of generations. The number of components in a synthetic is restricted, and they are usually selected based on their per se performance and their combining ability (Becker, 1988). The mixture of the 
components is called collectively Syn-0, and the first offspring from Syn-0 is called collectively Syn-1.

Both genetic diversity and specific local adaptation are sought in organic farming principles. However a contradiction opposes high diversity and high specific adaptation in a cultivar as an increase of diversity brings a decrease in specificity of adaptation. Synthetics express a part of the heterosis; they are heterozygous and heterogeneous and give the option to be diverse and adaptable (Tigerstedt, 1994) since they could locally evolve and become steadily better adapted over time. Inbred lines are homogeneous and homozygous thus giving far more options to be specifically and locally adapted (as well as mis-adapted) than population cultivars. Due to the absence of heterosis in inbred lines, on average, inbred lines are expected to be less performing than corresponding synthetics. Nevertheless, our hypothesis is that, due to the higher genetic variance among inbred lines than among the synthetics, the locally best adapted inbred line may outyield the locally best adapted synthetic.

The major objectives of our research were:

(1) To study the effectiveness of local breeding versus formal breeding for yield in organic locations.

(2) To compare the yield performance of inbred lines and corresponding synthetics in organic conditions using a local breeding approach and a formal breeding approach.

\section{Material and Methods}

\section{Breeding material and experimental design}

The material consisted on a set of eighteen inbred lines (IL) derived from eighteen old and new European cultivars. They were developed via single seed descent for at least six generations. Through open pollination among these eighteen inbred lines, eighteen polycross progenies (PP) were produced as described by Fleck and Ruckenbauer (1989). Thirteen checks (CK) composed 
mainly from new European cultivars were used. Altogether, the material consisted of 49 genotypes which were tested in five locations in Germany during three years (2004, 2005 and 2006). The testing sites involved four organic locations and a conventional one in Germany. Three organic locations were organic farms, located at Tröndel, Ramsthal and Willmering. The remaining two locations belong to our Department's experimental stations: Deppoldshausen (organic nursery) and Reinshof (conventional nursery). At Reinshof, one replicate was not treated with agrochemical inputs. The variation in the geographical position of the locations from North to South and from coast to continental area was meant to cover a wide diversity of agro-ecological conditions. The trials were laid out as a lattice design with two replicates. The plot size was $7.2 \mathrm{~m}^{2}$ with an average of 40 seeds $/ \mathrm{m}^{2}$. Grain yield ( $\mathrm{Y}$; $\mathrm{t} / \mathrm{ha}$ ) was determined for each plot.

\section{Statistical analyses}

The lattice designs were analyzed separately for each location in each year using PLABSTAT (Utz, 1991). According to Cochran and Cox (1992), adjusted entry means were taken for the subsequent analysis of variance for each location and finally a combined analysis of variance across locations and years was performed to assess the genotype environment interaction $(\mathrm{G} \times \mathrm{E})$. Analyses of variance were conducted with all factors considered random. Sums of square of genotypes $(G)$, genotype $\times$ location $(G \times L)$, genotype $\times$ year $(G \times Y)$ and genotype $\times$ location $\times$ year $(G \times L \times Y)$ were partitioned into variation attributable to inbred lines, polycross progenies and checks. The contrast analysis allowed testing the inbred lines versus their polycross progenies and to test for differences in their interaction with location, with years and with year $\times$ location. For statistical significance, + indicated significances at $10 \%$ level of error probability, * indicated significances at $5 \%$ and ${ }^{* *}$ indicated significances at $1 \%$ level of error probability.

In order to compare local and formal breeding approaches in this study, statistical parameters were established for each approach (Table 1). Formal breeding approach is exploiting genotypes' means across years and locations; whereas 
local breeding approach is based on genotypes' means across years in a single location; this single location is termed 'typical organic location'. Taking the averages of the five available locations, the parameters of this 'typical single organic location' were established. Variances and heritabilities of the typical organic location as well as the combined data were finally derived from the combined analysis of variance across genotypes, years and locations. The genotypic variance available for selection in the typical organic location is the average of the genotypic variances in each of the five locations, which is identical to the sum of the genetic variance plus the genotype $\times$ location interaction variance as taken from the combined analysis of variance.

Effectiveness of local breeding versus formal breeding for yield in organic locations

The target locations were either (1) the five single locations or (2) the typical organic location. Three categories of data sets were used for selection (data across the three years):

Data set (L'): Each of the five locations served as selection location and as target location. The correlated response in a target location $(L)$ to selection in a different location ( $\left.\mathrm{L}^{\prime}\right)$ was compared to the direct selection in the target location (L).

Data set (com-L): From the single locations' data, a combined data set across locations was established by omitting the data of one location (L); altogether five such combined data sets were thus established. The correlated response in a location $(\mathrm{L})$ to selection in the combined data of the four residual locations' (com$\mathrm{L})$ data was compared to the direct selection in the location (L).

Data set (com): The combined data set from the five locations served for selection and the typical organic location (TL) was the target location.

\section{Heritabilities}

Heritabilities were estimated as the ratio of genotypic to the phenotypic variance. Heritabilities of the five locations were derived from the analyses of variance 
across three years in each single location. Heritabilities of the data sets (com-L) were derived from the combined analysis across three years and across each four-locations-combination. Heritability of the data set (com) was derived from the combined analysis of variance across three years and the five locations. The heritability of the typical organic location was estimated as presented in Table 1.

\section{Genetic correlations}

The estimate of $r_{G}$ is expressed as following (Falconer and Mackay, 1989):

$r_{G}=\frac{\operatorname{Cov}_{G}(x y)}{\sigma_{G}(x) \cdot \sigma_{G}(y)}$ [Eq.2]; where $r_{G}$ is defined as for equation [Eq.1], $\operatorname{Cov}_{G}(x y)$ is the covariance of genotype means in the target location $x$ and in the selection data set $\mathrm{y}$, and $\sigma_{\mathrm{G}}(\mathrm{x})$ is the genetic standard deviation within the target location $\mathrm{x}$ and $\sigma_{G}(y)$ is the genetic standard deviation within the selection data set $y$. The genetic covariances were estimated by PLABCOV (Utz, 1991).

Genetic correlation coefficients of each of the five locations with the combined data set across years and locations were estimated. The average of these five genetic correlations represented the genetic correlation between the typical organic location and the combined data set across years and locations.

Additionally, to detect whether the ranking of genotypes changed from one location to another one, Spearman correlation coefficients between the yield performance in the different locations were calculated through PLABSTAT (Utz, 1991).

\section{Prediction of the ratio of response to indirect selection vs. direct selection}

\section{for yield in organic locations.}

The extent to which gains from selection in data sets (1L') or in (com-L) were likely to be expressed in a target location (L); and the extent to which gain from selection in the data set (com) were likely to be expressed in a typical organic location (TL) were predicted according to equation [Eq.1]. 
Comparison of inbred line vs. synthetic cultivar in local breeding and in formal breeding

\section{Prediction of the yield performance of synthetics in the first generation}

In our case the parental components for the prospected synthetic cultivars are inbred lines. The performance of a synthetic cultivar can be predicted using the performance of the polycross progenies of its parents (Ederer and Link, 1992). From eighteen inbred lines, $2.6 \times 10^{5}$ synthetic cultivars are possible to generate, with synthetics based on two to eighteen parents. It is crucial to determine the optimum size (i.e. optimum number of components) of the synthetics and to predict their performance. The performance of a synthetic with $\mathrm{k}$ components in the first generation Syn-1(k) is predicted as follows (Ederer and Link, 1992):

$\operatorname{Syn}_{1}(k) \approx \frac{1}{k} \sum_{i=1}^{k}\left[S_{i}+\frac{k-1}{k} \frac{m}{m-1}\left(P_{i}-S_{i}\right)\right] \quad[$ Eq.3]; where $k$ is the number of components in a synthetic cultivar, $\mathrm{m}$ is the number of components in the polycross ( $N=18$ in our case), $S_{i}$ is the performance of the inbred line $i$ and $P_{i}$ is the performance of the polycross-progeny of the inbred line i. This prediction is based on the assumption that (a) the relationship between panmictic index and yield performance is linear and (b) the paternally transmitted general combining ability effects are neglected as well as specific combining ability effects.

The genotypic performance of synthetics in the first generation Syn-1 was predicted for each single location and for the combined case across all locations. The prediction was based on genotypic (see below) yield performances of the inbred lines and their polycross progenies. These genotypic performances were estimated in each location and in the combined data across all locations based on the phenotypic values of the inbred lines and the polycross progenies and their corresponding heritabilities [Eq.4]. The genotypic values were estimated using $\mathrm{h}$ instead of, as usual, $\mathrm{h}^{2}$. For the inbred lines and the polycross progenies, since they were field tested, genotypic variance components are available from ANOVA. For the synthetic cultivars, since they are only predicted, no ANOVA 
and thus no genotypic variance components are available. This was resolved by estimating the genotypic variances from genotypic values of all possible synthetics.

The reason behind using $h$ instead of $h^{2}$ is the following. On the one hand, the variance among genotypic values, the values being estimated using $h^{2}$, is different from the genotypic variance component arising by ANOVA, as explained in (McLean et al., 1991). On the other hand, the variance among genotypic values estimated by equation [4] is identical to the variance component arising by ANOVA. Thus equation [4] was applied to estimate genotypic values of the lines and the polycross progenies, which then allowed the prediction of genotypic values of all synthetics. These values were consequently used to estimate a genotypic variance among the synthetics that was adequate to be compared with the ANOVA-derived genotypic variance among the inbred lines.

$g_{x}=\mu+h\left(p_{x}-\mu\right)$ [Eq.4]; where in a given location, $g_{x}$ is the genotypic value of a genotype $x$ and $p_{x}$ is its phenotypic value; $\mu$ is the mean performance of all genotypes and $h$ is the square root of heritability in the location or data set. Heritabilities of inbred lines and polycross progenies were derived from separate analyses of variance of inbred lines and polycross progenies in each single location and in the combined case. The statistical parameters of inbred lines and polycross progenies for a typical location were derived based on the formula in Table (1). For the determined optimum size of synthetics (see below), the performances of all possible synthetics were predicted through the program SynVo 3.1 (Doust, 2007) following Ederer and Link (1992); and their mean performance and genetic variance were estimated in each single location and in the combined data sets (com-L) across locations.

\section{Comparison between the best inbred line and the best synthetic}

Based on different intensities of selection (i), and on the mean performance $(\mu)$ and genetic standard deviation $\left(\sigma_{G}\right)$ among inbred lines and synthetics, the performance of the selected inbred lines and synthetics were predicted [Eq.5] 
and compared in each single location, in the typical organic location (local breeding) and in the combined data set across all locations (formal breeding).

Performance of selected genotypes $=\mu+\left(i \times \sigma_{G}\right)$ [Eq.5]

The intensities of selection depended on the proportions of selection (alpha) and on the initial population size and were derived from Falconer and Mackay (1989; pp 379-380).

\section{Results and discussion}

Analysis of variance revealed that yield differed significantly among genotypes, locations, years and their interaction effects (Table 2). The variance of the genotype $\times$ environment $(G L+G Y+G Y L)$ interactions $\left(0.30 \mathrm{t}^{2} / \mathrm{ha}^{2}\right)$ was larger than the genotypic variance $\left(0.20 \mathrm{t}^{2} / \mathrm{ha}^{2}\right)$. Genotype $\times$ location interactions $\left(0.15 \mathrm{t}^{2} / \mathrm{ha}^{2}\right)$ were the strongest component of the genotype $\times$ environment interactions and contributed more than three quarter as much as the genotypes to the yield variation. The large extent of genotype $\times$ location interactions compared to genotype $\times$ year interactions is crucial for local breeding since the specific adaptation in local breeding is the result of exploiting this over-time repeatable genotype $\times$ environment interaction.

Effectiveness of local breeding versus formal breeding for yield in organic locations

The location Ramsthal was the lowest yielding (2.96 t/ha) and Reinshof was the highest yielding location (4.62 t/ha). In Reinshof, the conventional location, the untreated replicate did not yield significantly different from the treated replicate. Apparently, the high performance in Reinshof was mainly due to very favorable climatic conditions and the high quality of the soil. Therefore, this location was considered with the other four organic locations to estimate the parameters of a typical single location.

Two types of genotypes $\times$ location interactions are usually distinguished: cross over interactions and non cross over interactions. Cross over interactions result 
in a change in the rank of genotypes between locations whereas non cross over interactions do not (Ceccarelli et al., 1992; Evans, 1993).

Spearman's rank correlations between the performance of genotypes in each location (Table 3) were relatively low and in some cases even not significantly different from zero what proved that the ranking of genotypes from one location to another one was changing, i.e. cross over interactions happened. Cross over interactions reflect the presence of specific adaptation of genotypes to specific locations. Therefore, they have the potential to influence whether a local breeding program is more adequate than a formal breeding program. The genetic correlation between the locations was more or less high (Table 4). Maximum genetic correlation existed between Tröndel and Willmering $(r=0.81)$ whereas there was a minimum genetic correlation between Deppoldshausen and Ramsthal $(r=0.15)$. The yield performance in the location Ramsthal was generally very weakly correlated with the yield performance in other locations. Low genetic correlations indicate that performances between the locations were controlled by substantially different sets of genes (Falconer, 1989).

All predicted ratios of correlated response in a given location to selection in the other location vs. a direct selection in the given location were lower than 1 (Table 5 ), with a variation from 0.14 (correlated response in Deppoldshausen to selection in Ramsthal vs. direct selection in Deppoldshausen) to 0.85 (correlated response in Tröndel to selection in Willmering vs. direct selection in Tröndel). Hence, indirect selection did not result in greater predicted yield in target locations than direct selection. The predicted gain from selection in any target location when selection was applied in a combined data set across locations (excluding the target location) was not as high as the gain from selection achieved through direct selection in the target locations (Table 6).

To increase gain from selection in a typical organic location, direct selection proved to be markedly more efficient than the indirect selection conducted in the combined data set (Table 7). Thus, local breeding in organic conditions proved to be more efficient than formal breeding. The fact that a direct selection is more 
effective than indirect selection in this case is mainly due to the high heritability in the target locations and consequently in the typical organic location as well.

The factors behind the high heritability in the typical organic location are recognized through the inspection of its expression in terms of variance components (Table 1). The genetic variance in a typical location, sum of both the "true" genetic variance and the genotype $\times$ location interactions variance, was markedly inflated by the large genotype $\times$ location interactions variance and thus increased the heritability. Besides, although the contribution of the variance of genotype $\times$ location interactions variance and genotype $\times$ location $\times$ year interaction were as well inflated in the phenotypic variance of the typical organic location, the phenotypic variance did not increase in the same proportion as the genetic variance. Therefore heritability in the typical organic location was higher than the heritability of the combined data across years and locations.

Another aspect which is related to the increase of heritability in the target location is the level of replication. Increasing replication in both target and selection locations reduces the predicted advantage of indirect selection (Atlin and Frey, 1990) and whenever $r_{G}$ is less than one, some level of replication will exist at which the predicted ratio of correlated response in the typical organic location caused by selection in a combined data set is lower than direct response to selection in the typical organic location. In a study conducted on oats in low productivity environments, Atlin and Frey (1990) found that direct selection in a low productivity environment was superior to indirect selection when selection was based on a total of eight replicates. In the present research, testing was done on the basis of three years and two replicates (six replicates) in the target locations and this replication level seemed to be high enough to observe an advantage of direct selection over indirect selection. Through the analysis of direct selection vs. indirect selection in this study, local breeding of faba bean in organic conditions is predicted to generate higher gains from selection and is apparently more efficient than formal breeding. 
Comparison of inbred line vs. synthetic cultivar in local breeding and in formal $\underline{\text { breeding for organic conditions }}$

The differences among the inbred lines, the polycross progenies and the checks were highly significant for grain yield (Table 2). Inbred lines yielded significantly different from the polycross progenies. The genotypes in the three groups (IL, PP and CK) interacted significantly with locations and with years. The interaction of inbred lines and checks with locations $\times$ years was significant whereas the polycross progenies did barely and not significantly interact with locations $x$ years. The interaction of inbred lines and polycross progenies with locations constituted the largest component of their interaction with the environments. For both, inbred lines and polycross progenies, their interaction with the locations contributed more than their genetic variance to the yield variation. The polycross progenies were significantly more stable than the inbred lines across locations, years and across year $\times$ location (Table 2 ). It is to be expected that heterozygous genotypes are less susceptible to environmental influences than homozygous ones (Becker and Léon, 1988). Indeed, it was shown that yield stability increased with the increase of heterozygosity and heterogeneity in several crops such as faba bean (Stelling et al.,1994a), rape seed (Léon, 1991) and barley (Einfeldt et al., 2005). The lower stability of inbred lines across locations reflects their option to be specifically adapted to specific local conditions, when compared to the polycross progenies.

In each single location and across all locations, due to the partial heterosis expressed in the polycross progenies, they yielded on average higher than the inbred lines (Table 8), whereas the inbred lines had a larger variance than their polycross progenies. The genotypic performance of synthetics at the first generation Syn-1 was predicted on the basis of the genotypic performance of the inbred lines and their polycross progenies (see material and methods). Through a compromise between the reduction of inbreeding depression by increasing the number of components and increasing gain from selection by decreasing the number of selected components (Becker, 1988; Gallais, 1992), the optimum size 
of synthetics for all locations and across all locations was found to be $\mathrm{N}=4$ components. A set of 3060 synthetics Syn-1(4) was possible to be generated from 18 inbred lines as potential components. Among locations and in the combined data across all locations, the expected Syn-1(4) yielded on average higher than the inbred lines (Table 8) but the variance among Syn-1(4) was very markedly lower than the inbred line variance. These results are corroborating the theoretical findings of Gallais (1992). For inbred lines as well as for the Syn-1(4), the variance used in formal breeding is narrow compared to the variance of a typical organic location used in local breeding which is broadened by the inclusion of genotype $\times$ location interaction variance. The variance of inbred lines available for a typical location $\left(0.34 \mathrm{t}^{2} / \mathrm{ha}^{2}\right)$ is more than twice the variance available in the combined data across all locations $\left(0.155 \mathrm{t}^{2} / \mathrm{ha}^{2}\right)$. The extent of the increase of the variance of Syn-1(4) in a typical organic location compared to the combined case across locations was less marked than in the case of the inbred lines. The comparison between the yield performance of the best inbred lines and the best synthetics in local breeding (typical organic location) and in formal breeding (combined data across the locations) is crucial, since the synthetics have the advantage of a higher average performance whereas the inbred lines, especially in the typical organic location, have the advantage of a higher expected gain of selection.

Equation [Eq.5] (see material and methods) shows that the performance of the selected genotypes depends on the mean performance and standard deviation of the initial population and on the intensity of selection i.

Intensity of selection, i, depends mainly on the proportion of the population (a) included in the selected group and to a lower extent on the initial population size $(\mathrm{N})$. As the selected proportion of the population, ( $\alpha$ ), decreases or as the initial population size, $(\mathrm{N})$, increases, the selection intensity increases and the gain from selection increases as well. In this study case, the intensity of selection ( $\mathrm{i}=$ 3.687) derived from ( $\alpha=1 / 3060$ and $N=3060)$ is set as the strictest intensity of selection. Higher intensities of selection are theoretically possible but are disregarded in this study case. Two reasons are behind this setting, first is the 
restrictions in identifying lines that fit together when creating a cultivar (distinctness- uniformity -stability), and second is to not overly rely on the fine tuned shape of the normal distribution.

For the population of the 18 inbred lines and the population of 3060 Syn-1(4), selection was applied with the same proportion $\alpha=1 / 18$ (the strictest for $N=18$ inbred lines) and the performance of the best inbred line and the best synthetics was predicted in each location, in the typical organic location and in the combined data across locations (Figure 1). In the typical organic location, as the same selection proportion $(\alpha=1 / 18)$ was applied for both inbred lines and synthetics, through the large variance of inbred lines, their gain from selection allowed the best inbred line to outyield the mean of the best group ( $N=170)$ of Syn-1(4), but this advantage was not maintained as the maximum intensity of selection was applied for synthetics through a proportion of selection of $\alpha=$ 1/3060. In a typical location, the best Syn-1(4) was expected to yield $4.38 \mathrm{t} / \mathrm{ha}$ and the best inbred line was expected to yield 4.04; whereas in the combined data across locations, the expected yield of the best Syn-1(4) was $4.19 \mathrm{t} / \mathrm{ha}$ and the expected yield of the best inbred line was $3.71 \mathrm{t} / \mathrm{ha}$. In local breeding, the best inbred line was expected to yield only $8 \%$ less than the best Syn-1(4) whereas it was expected to yield $13 \%$ less than the best Syn-1(4) in formal breeding.

Considering a theoretical case where the selected proportion is fixed to $(\alpha=1 / 18)$, and where the initial population size of inbred lines and corresponding Syn-1(4) varies from $\mathrm{N}=18$ to $\mathrm{N}=3060$, the predicted performance of selected inbred lines and selected synthetics were compared. In both formal breeding context (Figure 2) and local breeding context (Figure 3), the gain of selection of both, inbred lines and Syn-1(4), increased with the increase of selection intensity caused by the increase of the initial population size ( $\alpha$ was constant). Because of the large variance among inbred lines, their gain of selection was markedly larger than the gain of selection of Syn-1(4). However, in formal breeding context, even the large genetic variance among inbred lines did not allow the best inbred lines to yield higher than the group of the best Syn-1(4). In local breeding, the gain of selection 
among inbred lines was larger than in formal breeding (Figure 3). The inbred line $\times$ location interaction variance was as large as the genotypic variance and its additional contribution in the variance exploited in local breeding provided this advantage to the inbred lines. With a proportion of selection of $1 / 18$ and whatever the initial population size is, in formal breeding, the best Syn-1(4) is expected to yield higher than the best inbred; whereas in local breeding, the tendency was inversed, the best inbred lines were performing higher than the selected group of Syn-1(4). However, it is important to stress that the initial population size of inbred lines and initial population size of predicted synthetics will not be identical in reasonable situations. The initial population size of synthetics will be always markedly superior, and will allow a much stricter intensity of selection among synthetics than among inbred lines, counterbalancing the small variance among synthetics. Therefore, the superiority of inbred lines and synthetics in local and formal breeding context was discussed again, considering a case of an unlimited initial population size for the inbred lines and thus anyway for the synthetics, and varying size of the selected fraction. Thus, local and formal breeding programs with many inbred lines to select from are considered here.

In both formal (Figure 4) and local breeding (Figure 5) context and for both inbred lines and Syn-1(4), as the selected proportion increases, thus as the intensity of selection decreases, the gain of selection decreases as well.

The advantage of the synthetics is their superior average performance and the advantage of the inbred lines is their superior variance. Therefore, the selected inbred lines will outperform the synthetics in case of high intensity of selection; whereas synthetics will outperform the inbred lines in case of weak selection. In formal breeding context, with a strict selection fraction of $(\alpha=0.005)$, the best inbred lines yielded higher than the best Syn-1(4). As the selection was weaker, best inbred lines were not anymore competitive and already at $(\alpha=0.016)$ the best synthetics yielded as much as the best inbred lines and their superiority increased with further weakened intensity of selection (Figure 4). In local breeding, the threshold where the best synthetics yielded as much as the best inbred lines was at $(\alpha=0.16)$, i.e., about ten fold higher than in the case of formal 
breeding (Figure 5). Inbred lines due to their high interaction with the locations are more likely to be selected as best cultivar in local breeding than in formal breeding.

In a real situation, the selected fraction as well as the population size, are different for synthetics and inbred lines.

Considering local breeding, in order to find a best inbred line that yields as much as or better than the best synthetic Syn-1(4) $(1 / 3060 ; 4.38 \mathrm{t} / \mathrm{ha})$, a population of 75 inbred lines is required. In formal breeding, even with a population of 400 inbred lines, the best inbred line was not expected to outperform the best Syn1(4). An inbred line is much more likely to outyield the best synthetic in local breeding than in formal breeding. However, a local breeding program with 75 inbred lines seems unrealistically large for faba bean.

Besides, the predicted performance of synthetics in this study is based on the first generation, Syn-1, and their yield is expected to increase with successive Syn-generations until the equilibrium (Busbice, 1969; Wright, 1977: Link, 1990). On the basis of the average performance of the inbred lines (2.99 t/ha) and the average performance of Syn-1(4) (3.52 t/ha), and assuming 50\% cross pollination (a verified figure in faba bean; Bond and Poulsen, 1983; Link, 1990), it is possible to estimate the average yield performance of synthetics at the equilibrium Syn- $\infty$ (4). In the first generation, the panmictic index $(P)$ is 0.5 meaning that $50 \%$ of the individuals are hybrids $\left(F_{1}\right)$ and $50 \%$ are inbred. Thus the average yield of Syn-1(4) (3.52 t/ha) can be decomposed as follows:

$\mu($ Syn- $1(4))=0.5 \mu(\mathrm{IL})+0.5 \mu\left(\mathrm{F}_{1}\right)$

The term $(\mu(\mathrm{IL})=2.99 \mathrm{t} / \mathrm{ha})$ is the average performance of all inbred lines and $\mu\left(F_{1}\right)$ is the average performance of all possible $F_{1}$ hybrid crosses. Thus, the average performance of $F_{1}$ is $\mu\left(F_{1}\right)=4.05 t / h a$.

In a partially cross pollinated crop, the average panmictic index in a population at the equilibrium is expressed depending on $x$ the degree of cross fertilization:

$\mathrm{Pe}=2 \mathrm{x} /(1+\mathrm{x})$ 
Assuming $50 \%$ cross fertilization, the panmictic index at the equilibrium is $\mathrm{Pe}=$ 0.667. The average performance of Syn (4) at the equilibrium is expected to be:

$\mu(\operatorname{Syn}-\infty(4))=0.33 \mu(\mathrm{IL})+0.67 \mu\left(\mathrm{F}_{1}\right)=3.70 \mathrm{t} / \mathrm{ha}$

Yield is expected on average to increase from Syn-1(4) to Syn- $\infty$ (4) by about 5\%, i.e. from $3.52 \mathrm{t} / \mathrm{ha}$ to $3.70 \mathrm{t} / \mathrm{ha}$. Comparable experimental results have been reported by Stelling et al. (1994b) in faba bean. It is worthwhile to note that the

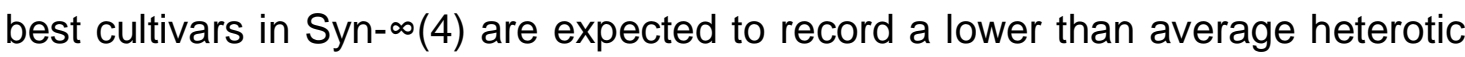
increase of yield. Indeed, as the components of synthetics are selected for their per se performance as well as for their combining ability, the components of the best synthetics are among the best performing inbred lines. The heterotic increment is expected to be negatively correlated with the performance of the inbred lines (Fleck and Ruckenbauer, 1989) and hence the heterosis in the best synthetics is expected to be lower than the average heterosis across all synthetics.

The greater the genotype $\times$ location interaction, the more effective is local breeding compared to formal breeding. Genotype $\times$ location interaction contributed to a large extent to the yield variation of faba bean in organic locations. Local breeding apparently is an option to breed faba bean cultivars for organic locations since it is expected to achieve a higher gain of selection than formal breeding. The large genotype $\times$ location interactions contributed to the development of several regional breeding programs such the development of regional breeding programs for wheat in Australia (Bänziger and Cooper, 2001). The question of how to acquire the necessary budget for local breeding is not treated here.

The superiority of the best inbred line over the best synthetic is also depending on the degree of cross fertilization. A low degree of cross fertilization would be disadvantageous for the synthetics since their mean performance will decrease and the best inbred line may easier outperform the best synthetic. Although synthetics were less specifically adapted than inbred lines to local conditions, due to their partial expression of heterosis they showed the best genotypic 
performance in the typical organic location and the best synthetic was expected to yield higher than any inbred line. The prediction of synthetics based on the inbred line and the polycross progenies performance is not the most comprehensive approach. The most comprehensive prediction of synthetics is based on the general varietal ability and specific varietal ability (Link and Ederer, 1993). The prediction approach used in this study is neglecting the paternally transmitted gca effects and sca effects. Due to this, the genetic variance among synthetics as used here is somewhat too small. Removing this bias would improve the perspectives of the synthetic cultivars when compared to pure line cultivars. Moreover, the prediction is based on the assumption that the relationship between the panmictic index and performance is linear. The latter assumption is the most questionable, since it excludes epistasis and effects of heterogeneity. In a Syn-1 generation, a specific type of heterogeneity occurs: individuals with extremely different heterozygosity levels are produced (hybrids and inbred lines). A recent study on the effect of mixtures between hybrids and inbred lines showed a marked and positive effect of heterogeneity of $3 \%$ on yield performance in faba bean (Ghaouti and Link, 2007). The genotype $\times$ year interaction was found to be smaller for the polycross progenies than for the inbred lines. The synthetics are even expected to be less interacting with the years than polycross progenies, indicating a better reliability of the performance of synthetics across the years compared to the inbred lines. A further aspect favoring synthetics is their option to locally evolve and become better adapted over time which constitutes a very valuable aspect in organic farming.

Lineal breeding would achieve more gain in local breeding than in formal breeding for organic locations. The yield of the best expected inbred line although lower than the yield of the best expected synthetic is still high. Growing an inbred line cultivar in organic conditions is also a reasonable alternative when uniformity in certain characters is important, as for example in vegetable beans or when quality aspects are important such as zero tannins or low vicine convicine. 


\section{Acknowledgement}

Our thanks are addressed to the farmers A. Hausladen (Willmering), G. Neder (Ramsthal) and H. Untiedt (Tröndel) and to Werner Vogt-Kaute from NaturlandVerband für naturgemäßen Landbau for their valuable contributions. Finally, we thank BMELV (Bundesministerium für Ernährung, Landwirtschaft und Verbraucherschutz, Mrs. Minister Künast) for financing this research.

\section{References}

Almekinders, C. J. M., and A. Elings, 2001. Collaboration of farmers and breeders: Participatory crop improvement in perspective. Euphytica 122: 425-438

Atlin, G. N., and K. J. Frey, 1990. Selecting oat lines for yield in low-productivity environments. Crop Sci. 30: 556-561.

Bänziger, M., and M. Cooper, 2001. Breeding for low input conditions and consequences for participatory plant breeding: Examples from tropical maize and wheat. Euphytica. 122: 503-519.

Becker, H., 1988. Breeding synthetic varieties of crop plants. Plant Genetics and Breeding Review. 1: 31-54.

Becker, H. C., and J. Léon, 1988. Stability analysis in plant breeding. Plant Breeding. 101: 1-23.

Bond, D. A., and M. H. Poulsen, 1983: Pollination In: The Faba Bean (Vicia faba L.), P.D. Hebblethwaite (ed.), pp. 77-101. Butterworths, London.

Busbice, T. H., 1969. Inbreeding in synthetic varieties. Crop Sci. 9: 601-604.

Ceccarelli, S., 1994. Specific adaptation and breeding for marginal conditions. Euphytica. 77: 205-219. 
Ceccarelli S., S. Grando, and J. Hamblin, 1992. Relationship between barley grain yield measured in low - and high-yielding environments. Euphytica. 64: 49-58.

Ceccarelli, S., S. Grando, R. Tutliwer, J. Baha, A. M. Martini, H. Salahieh, A. Goodchild, and M. Michael, 2000. A methodological study on participatory barley breeding. I. Selection phase. Euphytica. 111: 91-104.

Cochran, W. G., and G. M. Cox, 1992. Experimental Designs. Second edition. John Wiley and Sons (eds.), Inc. New York.

Desclaux, D., 2005. Participatory Plant breeding Methods for Organic Cereals. In: Proceedings of the COST SUSVAR/ECO-PB Workshop on Organic Plant Breeding Strategies and the Use of Molecular Markers, Lammerts Van Bueren, E. T., and H. Ostergard, (eds.), pp. 17-23.

Doust, E., 2007. http://www.uni-goettingen.de/en/sh/48273.html

Ederer, E., and W. Link, 1992 . The polycross-test as a step in breeding partially allogamous crops. Theoretical considerations. Proc. XIIIth EUCARPIA Congress, 6-11 July, Angers, France, Book of Poster Abstracts, pp . 543544.

Einfeldt, C. H. P., S. Ceccarelli, S. Grando, A. Gland-Zwerger, and H. H. Geiger, 2005. Heterosis and mixing effect in barley under drought stress. Plant Breeding. 124: 350- 355.

Eisemann, R. L., M. Cooper, and D. R. Woodruff, 1990. Beyond the Analytical Methodology: Better Interpretation and Exploitation of Genotype-byEnvironment Interaction in Breeding. In: Genotype by Environment Interaction and Plant Breeding, M.S. Kang (ed.), pp. 108-117. Dept. of Agron. Louisiana State Agric. Experiment Stn., Baton Rouge, USA.

Evans, L. T., 1993. Crop evolution, adaptation and yield. Cambridge University Press, $500 \mathrm{pp}$.

Falconer, D. S., and T. F. C. Mackay, 1989. Introduction to quantitative genetics. 4th ed. Longmann, Malaysia. 
Fleck, A., and P. Ruckenbauer, 1989 . Der Polycrosstest als methodischer Schritt in der Fababohnenzuchtung (experimentelle Ergebnisse). Die Bodenkultur 40: 61-72.

Gallais, A., 1992. Pourquoi faire des variétés synthétiques ? Agronomie.12: 601609.

Ghaouti, L., and W. Link, 2007. Relevance of competition effects among genotypes in breeding faba bean (Vicia faba L.). prepared for submission.

Hanson, W.D., 1964. Genotype-Environment Interaction Concepts for Field Experimentation. Biometrics.20: 540-552.

Léon, J., 1991. Heterosis and mixing effects in winter oilseed rape. Crop Sci. 31: 281-284.

Link, W., 1990: Autofertility and rate of cross-fertilization: crucial characters for breeding synthetic varieties in faba bean (Vicia faba L.). Theor. Appl. Genet. 79: $713-717$.

Link, W., and W. Ederer, 1993. The Concept of Varietal Ability for Partially Allogamous Crops. Plant Breeding. 110: 1-8.

McLean, R.A., W. L. Sanders and W.W. Stroup, 1991. A unified approach to mixed linear models. The American Statisticien. 45: 54-64.

Stelling, D., W. Link., and E. Ebmeyer, 1994a. Yield stability in faba bean, Vicia faba L.2. Effect of heterozygosity and heterogeneity. Plant Breeding. 112: 30-39.

Stelling, D., W. Link, and E. Ebmeyer, 1994b. Factors determining the performance of synthetics in Vicia faba L. 1. Syn-generation. Euphytica. 75, 85-93.

Tigerstedt, P. M. A., 1994. Adaptation, variation and selection in marginal areas. Euphytica. 77: 171-174. 
Utz, H. F. 1991. A computer program for statistical analysis of plant breeding experiments. Institute of Plant Breeding, Seed Science and Population Genetics. University of Hohenheim.

Wright, A. J., 1977. Inbreeding in synthetic varieties of field beans (Vicia faba L.). J. Agric. Sci. Camb. 75: 495-501. 
Table 1. Statistical parameters exploited in formal breeding and in local breeding adapted from Hanson, 1964.

\begin{tabular}{lccc}
\hline Breeding approach & Mean (t/ha) & Variance $\left(\mathrm{t}^{2} / \mathrm{ha}^{2}\right)$ & $\mathrm{h}^{2} \S$ \\
\hline $\begin{array}{l}\text { Formal breeding } \\
\text { Combined data across } Y \text { and } L\end{array}$ & $\mu$ & $\sigma^{2}{ }_{\mathrm{G}}$ & $\frac{\sigma_{\mathrm{G}}^{2}}{\sigma_{\mathrm{G}}^{2}+\frac{\sigma_{\mathrm{GL}}^{2}}{\mathrm{~L}}+\frac{\sigma_{\mathrm{GY}}^{2}}{\mathrm{Y}}+\frac{\sigma_{\mathrm{GYL}}^{2}}{\mathrm{LY}}+\frac{\sigma_{\mathrm{e}}^{2}}{\mathrm{LY}}}$ \\
\hline $\begin{array}{l}\text { Local breeding } \\
\text { Typical location }\end{array}$ & $\mu$ & $\sigma_{\mathrm{G}}^{2}+\sigma_{\mathrm{GL}}^{2}$ & $\frac{\sigma_{\mathrm{G}}^{2}+\sigma_{\mathrm{GL}}^{2}}{\sigma_{\mathrm{G}}^{2}+\sigma_{\mathrm{GL}}^{2}+\frac{\sigma_{\mathrm{GY}}^{2}}{\mathrm{Y}}+\frac{\sigma_{\mathrm{GYL}}^{2}}{\mathrm{Y}}+\frac{\sigma_{\mathrm{e}}^{2}}{\mathrm{Y}}}$ \\
\hline
\end{tabular}

$\S L$ (number of locations) $=5 ; Y$ (number of years $)=3 ; L Y=15$.

Table 2. Combined analysis of variance across genotypes, locations and years for grain yield.

\begin{tabular}{|c|c|c|c|c|}
\hline Source of variation & DF & $M S\left(t^{2} / h^{2}\right)$ & $\sigma^{2}\left(t^{2} / h^{2}\right)$ & $F$ value \\
\hline Locations L & 4 & 176.84 & 1.019 & $6.63^{\star}$ \\
\hline Years Y & 2 & 77.39 & 0.206 & $385.65^{\star \star}$ \\
\hline Genotypes G & 48 & 3.83 & 0.195 & $8.37^{\star \star}$ \\
\hline $\mathrm{IL}$ & 17 & 3.32 & 0.155 & $7.18^{\star \star}$ \\
\hline PP & 17 & 1.21 & 0.092 & $4.84^{\star \star}$ \\
\hline CK & 12 & 2.58 & 0.141 & $9.06^{\star \star}$ \\
\hline IL vs PP & 1 & 63.45 & - & $7.66^{\star}$ \\
\hline CK vs IL,PP & 1 & 12.50 & - & 3.26 \\
\hline$Y \times L$ & 8 & 26.67 & 0.540 & $132.91^{\star \star}$ \\
\hline$G \times L$ & 192 & 0.64 & 0.148 & $3.21^{\star \star}$ \\
\hline $\mathrm{IL} \times \mathrm{L}$ & 68 & 0.80 & 0.179 & $3.03^{\star *}$ \\
\hline$P P \times L$ & 68 & 0.40 & 0.095 & $3.46^{\star \star}$ \\
\hline $\mathrm{CK} \times \mathrm{L}$ & 48 & 0.37 & 0.062 & $1.97^{\star \star}$ \\
\hline $\mathrm{IL} \times \mathrm{L} v s \mathrm{PP} \times \mathrm{L}$ & 4 & 5.37 & - & $7.40^{\star \star}$ \\
\hline$C K \times L v s I L, P P \times L$ & 4 & 0.60 & - & $3.75+$ \\
\hline$G \times Y$ & 94 & 0.46 & 0.052 & $2.28^{\star \star}$ \\
\hline $\mathrm{IL} \times \mathrm{Y}$ & 34 & 0.46 & 0.040 & $1.75^{\star}$ \\
\hline$P P \times Y$ & 34 & 0.25 & 0.027 & $2.14^{\star \star}$ \\
\hline$C K \times Y$ & 22 & 0.29 & 0.019 & $1.50+$ \\
\hline $\mathrm{IL} \times \mathrm{Y} v s \mathrm{PP} \times \mathrm{Y}$ & 2 & 3.01 & - & $4.14+$ \\
\hline $\mathrm{CK} \times \mathrm{Y} v s \mathrm{IL}, \mathrm{PP} \times \mathrm{Y}$ & 2 & 3.28 & - & $20.35^{\star \star}$ \\
\hline$G \times Y \times L$ & 373 & 0.20 & 0.095 & $1.90^{\star *}$ \\
\hline $\mathrm{IL} \times \mathrm{Y} \times \mathrm{L}$ & 133 & 0.26 & 0.158 & $2.50^{* \star}$ \\
\hline$P P \times Y \times L$ & 136 & 0.12 & 0.011 & 1.11 \\
\hline$C K \times Y \times L$ & 88 & 0.19 & 0.084 & $1.79^{\star}$ \\
\hline ILXLXY vs PPxYxL & 8 & 0.73 & - & $6.86^{\star \star}$ \\
\hline CKxLxY vs IL, $\mathrm{PP} \times \mathrm{YL}$ & 8 & 0.16 & - & $1.52^{\star \star}$ \\
\hline Pooled error & 517 & 0.11 & 0.106 & 1.00 \\
\hline
\end{tabular}


Table 3. Spearman correlations between the locations for grain yield (t/ha).

\begin{tabular}{lllll}
\hline r Spearman (L, L) & Trö. & Dep. & Rei. & Ram. \\
\hline Dep. & $0.583^{\star \star}$ & 1.000 & & \\
Rei. & $0.436^{\star *}$ & $0.665^{\star *}$ & 1.000 & \\
Ram. & 0.242 & 0.107 & $0.289^{\star}$ & 1.000 \\
Wil. & $0.609^{\star *}$ & $0.357^{\star}$ & $0.400^{\star *}$ & $0.544^{\star \star}$ \\
\hline
\end{tabular}

Table 4. Genetic correlations between the locations for grain yield (t/ha).

\begin{tabular}{lllll}
\hline$r_{G}(L ; L)$ & Trö. & Dep. & Rei. & Ram. \\
\hline Dep. & $0.736++$ & 1.000 & & \\
Rei. & $0.529++$ & $0.793++$ & 1.000 & \\
Ram. & $0.397++$ & 0.146 & $0.336++$ & 1.000 \\
Wil. & $0.805++$ & $0.494+$ & $0.561++$ & $0.560++$ \\
\hline
\end{tabular}

,+++ means that the coefficient is larger than one and two times its standard error, respectively.

Table 5. Predicted ratios of correlated response in a location $L$ to selection in an other location $v s$. direct response to selection in the location L.

\begin{tabular}{l|c|lllll}
\hline \multicolumn{2}{c}{$\mathrm{CR}_{L\left(\mathrm{~L}^{\prime}\right)} / \mathrm{R}_{\mathrm{L}}$} & \multicolumn{3}{l}{ Target location $(\mathrm{L})$} \\
\cline { 3 - 7 } & & Trö. & Dep. & Rei. & Ram. & Wil. \\
\hline Selection location $\left(\mathrm{L}^{\prime}\right)$ & $\mathrm{h}^{2}$ & 0.756 & 0.807 & 0.853 & 0.767 & 0.833 \\
\hline Trö. & 0.756 & 1.000 & 0.712 & 0.498 & 0.394 & 0.767 \\
Dep. & 0.807 & 0.761 & 1.000 & 0.771 & 0.150 & 0.486 \\
Rei. & 0.853 & 0.562 & 0.815 & 1.000 & 0.354 & 0.568 \\
Ram. & 0.767 & 0.400 & 0.142 & 0.319 & 1.000 & 0.537 \\
Wil. & 0.833 & 0.845 & 0.502 & 0.554 & 0.584 & 1.000 \\
\hline
\end{tabular}

Table 6. Predicted ratio of correlated response in a location $(L)$ to selection in the four residual location (com-L) vs. direct response to selection in the location $(L)$.

\begin{tabular}{lllccc}
\hline $\mathrm{L}$ & $\mathrm{h}^{2} \mathrm{~L}$ & Com $-\mathrm{L}$ & $\mathrm{h}^{2}$ Com- & $\mathrm{r}_{\mathrm{G}}(\mathrm{L} ;$ Com- $\mathrm{L})$ & $\mathrm{CR}_{\mathrm{L}(\text { Com- } \mathrm{L})} / \mathrm{R}_{\mathrm{L}}$ \\
\hline Trö & 0.756 & Com -Trö. & 0.704 & 0.798 & 0.770 \\
Dep. & 0.807 & Com -Dep. & 0.733 & 0.717 & 0.683 \\
Rei. & 0.853 & Com -Rei. & 0.722 & 0.710 & 0.653 \\
Ram. & 0.767 & Com -Ram. & 0.778 & 0.608 & 0.612 \\
Wil. & 0.833 & Com -Wil. & 0.717 & 0.738 & 0.685 \\
\hline
\end{tabular}

Table 7. Predicted ratios of correlated response in the typical organic location (TL) to selection in the combined set across all locations (Com) vs. direct response to selection in the typical organic location (TL).

\begin{tabular}{llllll}
\hline $\mathrm{TL}$ & $\mathrm{h}^{2} \mathrm{TL}$ & Com & $\mathrm{h}^{2} \mathrm{com}$ & $\mathrm{r}_{\mathrm{G}}(\mathrm{TL} ;$ Com) & $\mathrm{CR}_{\mathrm{TL}(\mathrm{Com})} / \mathrm{R}_{\mathrm{TL}}$ \\
$\begin{array}{l}\text { Typical organic } \\
\text { location }\end{array}$ & 0.803 & $\begin{array}{l}\text { Combined across } \\
\text { five locations }\end{array}$ & 0.765 & 0.773 & 0.755 \\
\hline
\end{tabular}


Table 8. Mean values, genetic variances inbred lines, polycross progenies and predicted Syn-1(4) and heritabilities of inbred lines and polycross progenies.

\begin{tabular}{lllllllll}
\hline \multirow{2}{*}{ Locations } & \multicolumn{3}{l}{ Inbred lines } & \multicolumn{3}{c}{ Polycross progenies } & \multicolumn{2}{c}{ Syn-1(4) } \\
\cline { 2 - 9 } & $\begin{array}{l}\mu \\
(\mathrm{t} / \mathrm{ha})\end{array}$ & $\begin{array}{l}\sigma^{2} \mathrm{~g} \\
\left(\mathrm{t}^{2} / \mathrm{ha}^{2}\right)\end{array}$ & $\mathrm{h}^{2}$ & $\begin{array}{l}\mu \\
(\mathrm{t} / \mathrm{ha})\end{array}$ & $\begin{array}{l}\sigma^{2} \mathrm{~g} \\
\left(\mathrm{t}^{2} / \mathrm{ha}^{2}\right)\end{array}$ & & $\begin{array}{l}\mu \\
(\mathrm{t} / \mathrm{ha})\end{array}$ & $\begin{array}{l}\sigma^{2} \mathrm{~g} \\
\left(\mathrm{t}^{2} / \mathrm{ha}^{2}\right)\end{array}$ \\
\hline Trö & 3.15 & 0.410 & 0.775 & 3.90 & 0.236 & 0.806 & 3.74 & 0.0483 \\
Dep & 2.92 & 0.297 & 0.612 & 3.75 & 0.192 & 0.808 & 3.58 & 0.0406 \\
Rei & 4.08 & 0.266 & 0.845 & 4.97 & 0.188 & 0.878 & 4.79 & 0.0357 \\
Ram & 2.22 & 0.330 & 0.851 & 2.48 & 0.150 & 0.692 & 2.43 & 0.0925 \\
Wil & 2.58 & 0.370 & 0.800 & 3.21 & 0.173 & 0.803 & 3.08 & 0.0486 \\
\hline $\begin{array}{l}\text { Typical organic } \\
\text { location }\end{array}$ & 2.99 & 0.335 & 0.768 & 3.66 & 0.188 & 0.796 & 3.52 & 0.0531 \\
\hline Combined & 2.99 & 0.155 & 0.699 & 3.66 & 0.092 & 0.720 & 3.52 & 0.0328 \\
\hline
\end{tabular}

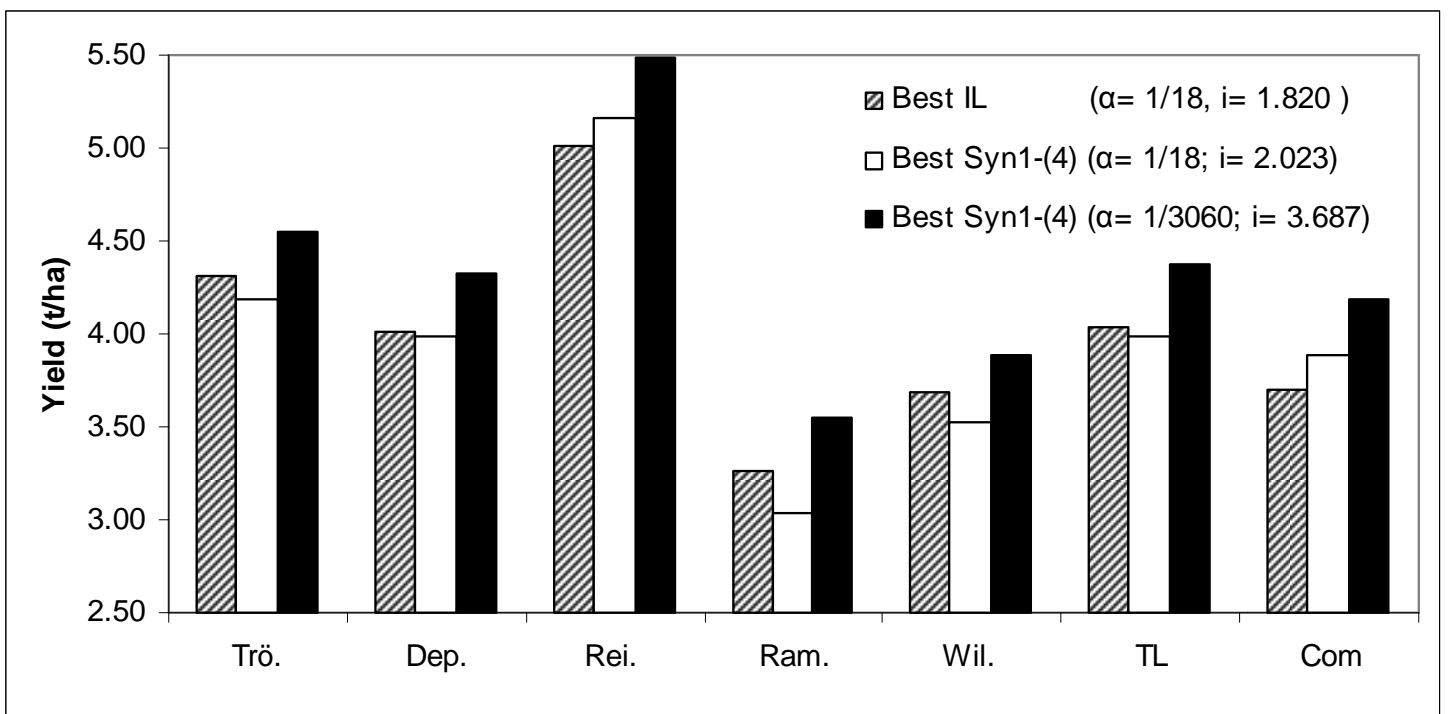

Figure 1. Comparison between the yield performance of the best inbred line (1/18), the best group of synthetics (1/18) and the best synthetic (1/3060) in each location, in the typical location and in the combined analysis across locations. 


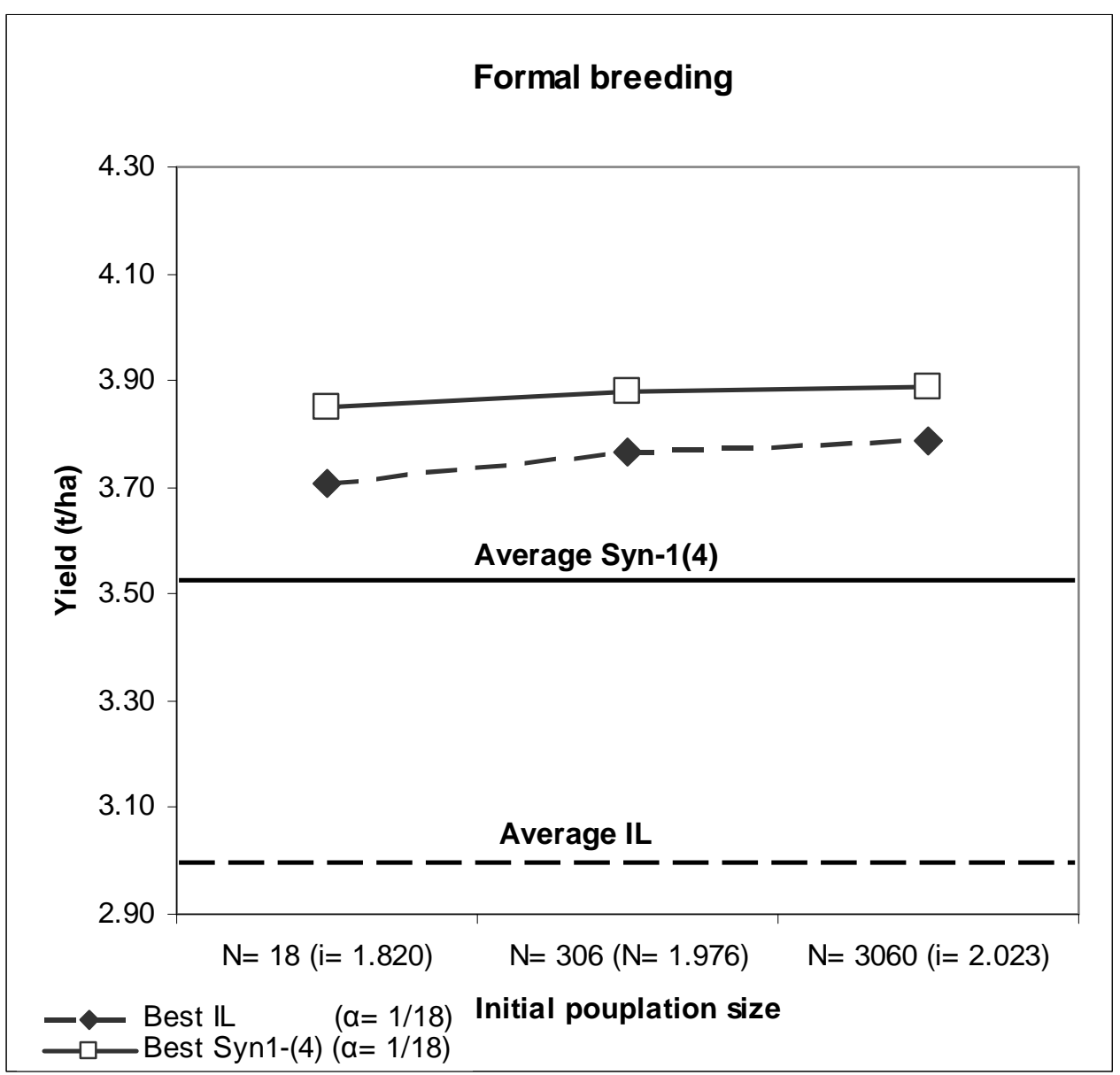

Figure 2. Formal breeding; performance of the best inbred lines and the best Syn-1(4) selected from the combined data across locations assuming different initial population sizes $(\mathrm{N})$ and the same selection proportion $(\alpha=1 / 18)$. 


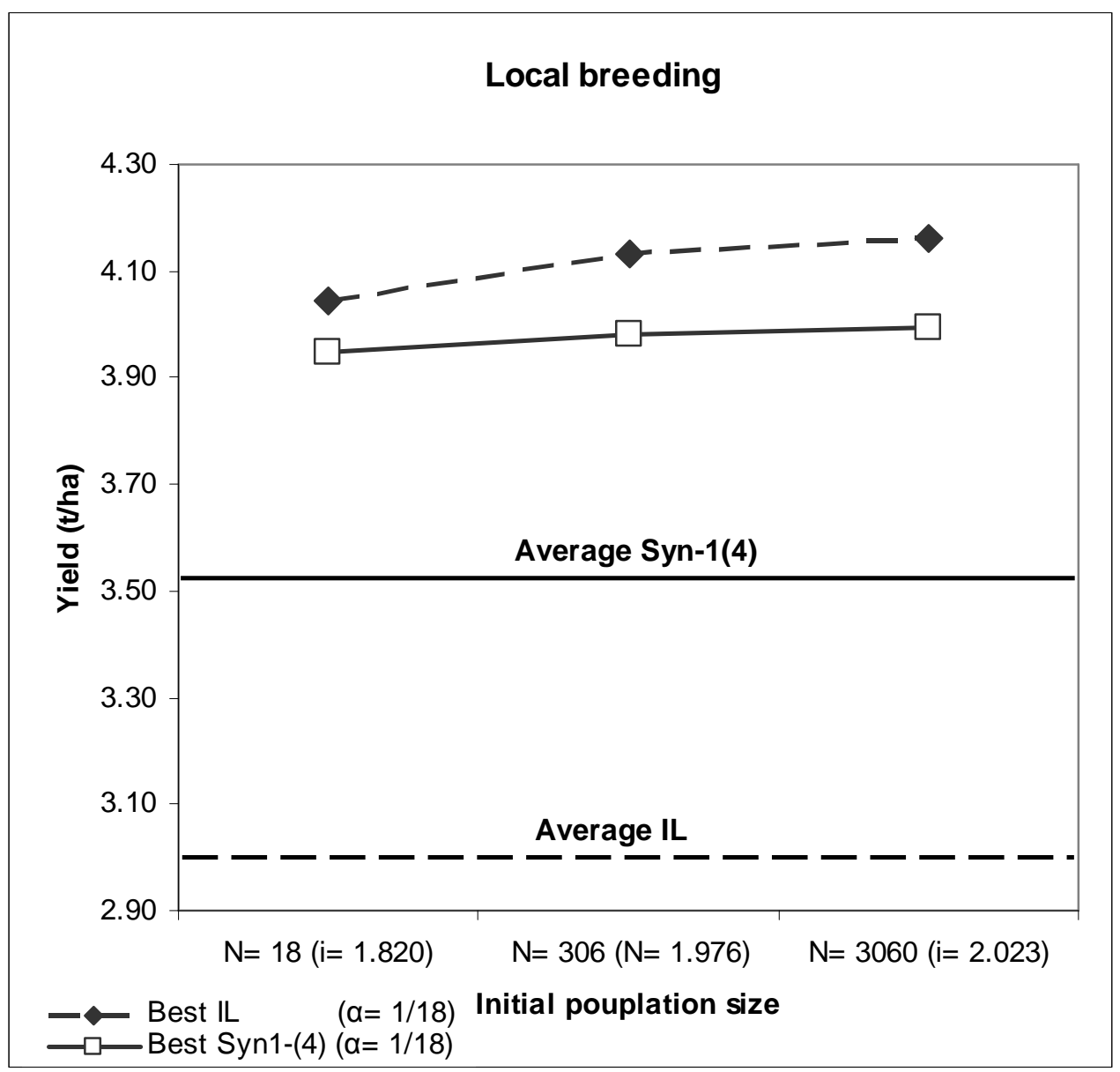

Figure 3. Local breeding; performance of the best inbred lines and the best Syn-1(4) selected from the typical organic location assuming different initial population sizes $(\mathrm{N})$ and the same selection proportion $(\alpha=1 / 18)$. 


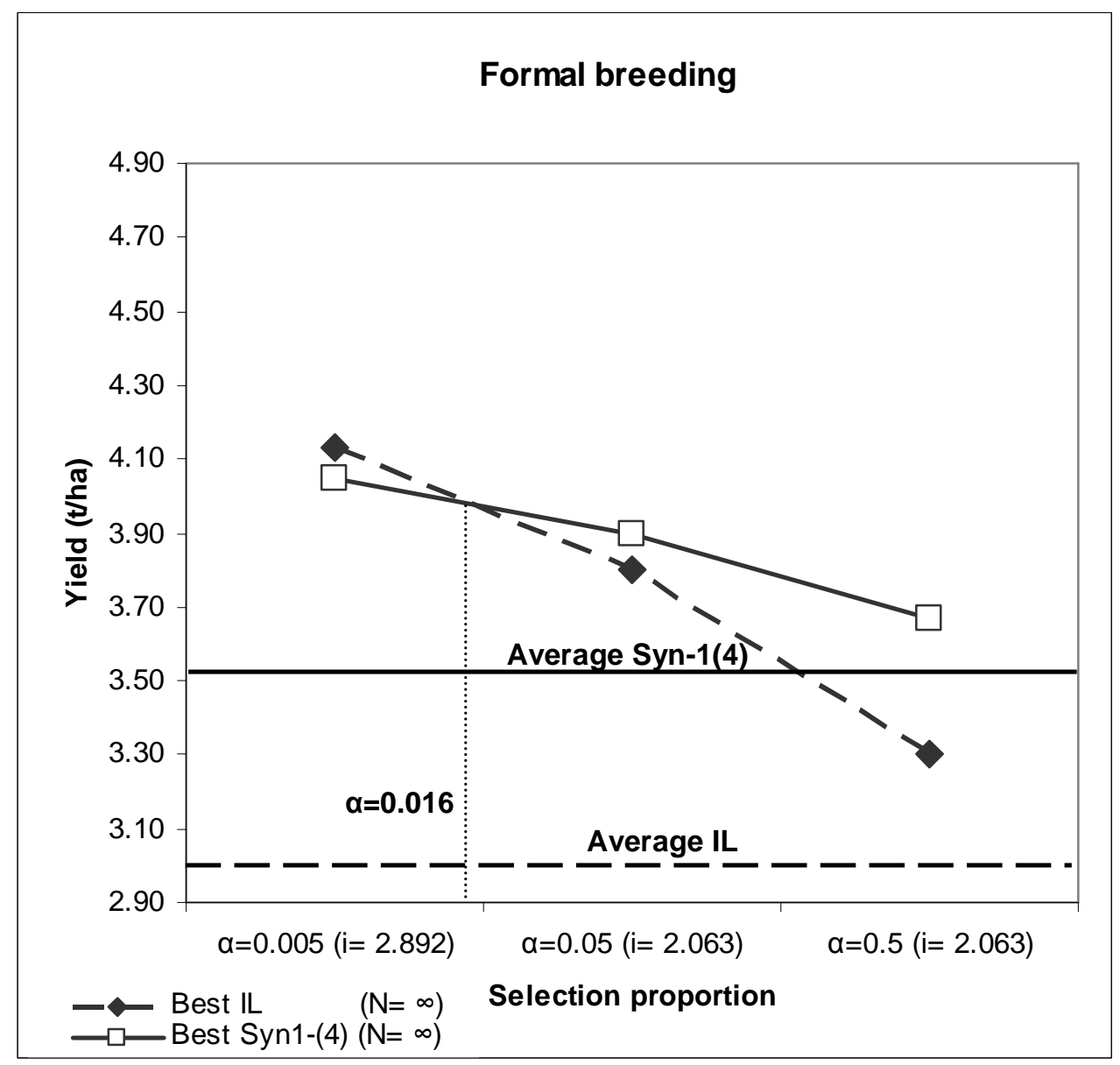

Figure 4. Formal breeding; performance of the best inbred lines and the best Syn-1(4) selected from the combined data across locations assuming the same initial population size $(N=\infty)$ and different selection proportion (a). 


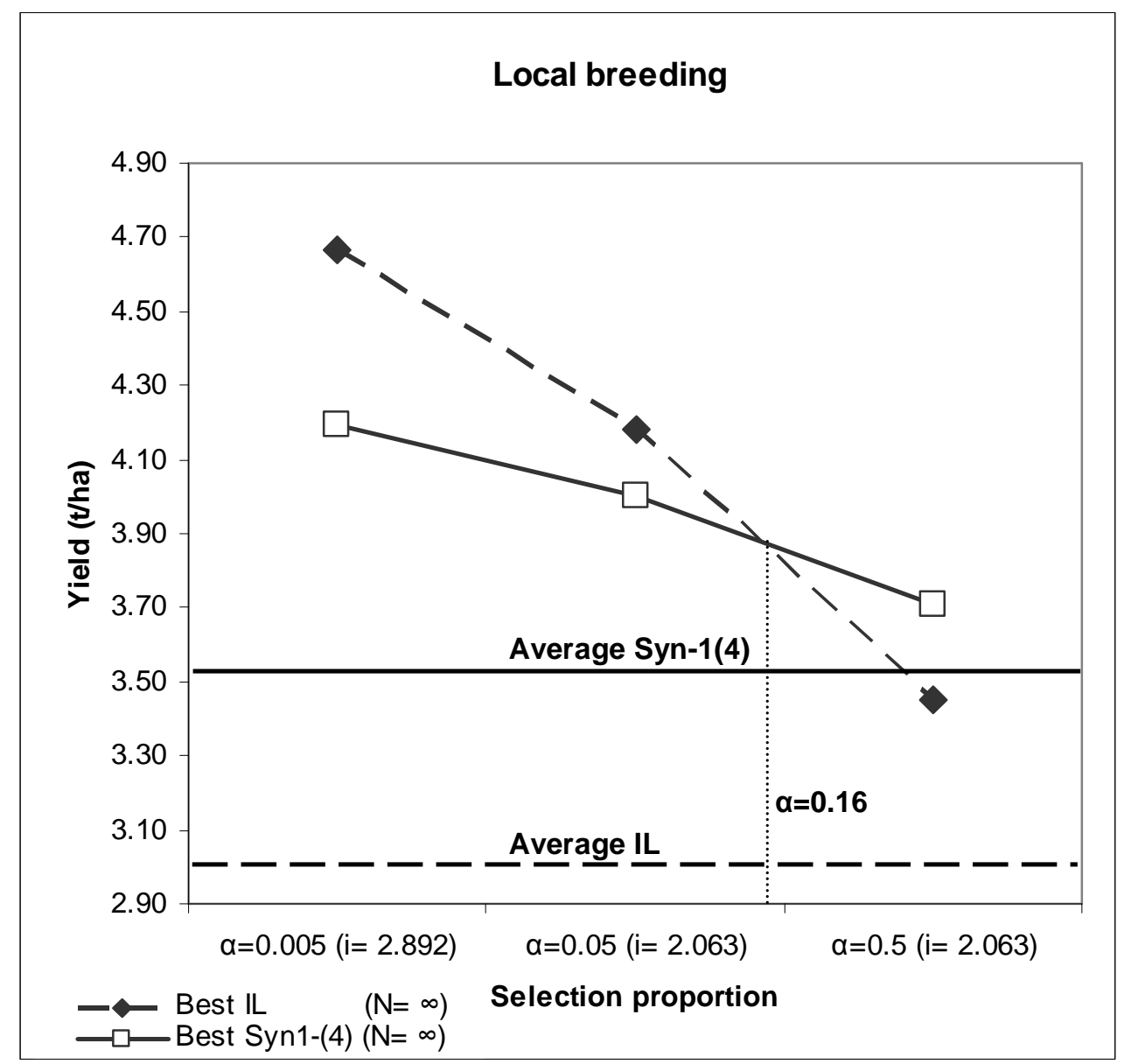

Figure 5. Local breeding; performance of the best inbred lines and the best Syn-1(4) selected from the typical organic location assuming the same initial population size $(\mathrm{N}=\infty)$ and different selection proportion $(\alpha)$. 


\title{
Chapter III. Relevance of competition effects among genotypes in breeding faba bean (Vicia faba L.)
}

L. Ghaouti and W. Link

Keywords: Faba bean, competition effect, inbreeding coefficient, plant height

\begin{abstract}
Variation among plants for their inbreeding coefficients is known to influence the agronomic performance of a faba bean crop stand. Here, effects of heterogeneity for inbreeding status and in addition for plant height were investigated using two component mixtures. In three years trial, a tall hybrid, a tall hybrid blend, a short hybrid blend, a tall and a short inbred line were tested in all possible two components "line plus hybrid" and "line plus line" combinations. A sequence of five proportions of the two components was established per combination. As the hybrids' proportion increased, hybrid and inbred line plants in these mixtures became significantly taller, slimmer and less yielding. Hybrid plants performed better when surrounded by inbred line plants and over compensated the loss in performance of the inbred line plants at the plot level. Even among the two inbred lines, the taller line was a stronger competitor than the shorter line, albeit less markedly so. Heterogeneity in plant height per se was not found to be favorable, whereas heterogeneity for inbreeding status was favorable for performance, in spite of being an obstacle in breeding.
\end{abstract}

\section{Introduction}

In faba bean, a partially allogamous crop, the extent of natural cross-fertilization can vary considerably and is reported to amount on average to $30 \%$ to $60 \%$ (Bond and Poulsen, 1983; Link, 1990). Because of this intermediate natural reproductive system, population cultivars in faba bean differ considerably for their levels of heterozygosity and heterogeneity (Stelling et al., 1994), depending in particular on their average degree of cross-fertilization, and the genetic distances and the genetic constitution of their parental components (Stelling et al., 1994). 
In the early generation Syn-1 of a synthetic cultivar derived from open pollination of unrelated inbred lines, a maximum variation between individuals occurs with respect to their individual inbreeding coefficient $F$ (Link et al., 1994). This generation Syn-1 is a mixture of two kinds of genotypes with either $F=1$ (fully inbred plants) or $\mathrm{F}=0$ (hybrid plants). In Syn-2, additional individuals with $\mathrm{F}=0.5$ (F2 plants and BC1 plants) are occurring. Considering 50\% cross-fertilization, the standard deviation of the individual inbreeding coefficient in Syn-1 would amount to $\sigma_{\mathrm{F}}\left(\right.$ Syn-1) $=0.50$ and would decrease gradually at the generation Syn- $\infty$ to $\sigma_{\mathrm{F}}$ $($ Syn $-\infty)=0.36$. Obviously, open pollinated cultivars in faba bean are in general constituted from a mixture of individuals with contrasting inbreeding coefficient levels, and thus with contrasting heterosis-related vigour. The competition between those individuals for biotic and abitioc resources, and their mutual influence on their agronomic phenotypes are hindrances usually ignored in faba bean breeding. In ecology, competition is defined as the interaction between two or more groups of organisms that use a common resource in short supply. The competitive ability of an individual has two aspects: (1) the competitive effect being the ability to suppress neighbor individuals and (2) the competitive response being the ability to avoid being suppressed by neighbor individuals (Goldberg and Landa, 1991).

As the genetic resemblance between two individuals increases, their requirements become more similar. It follows that the most intensive competition is intra-specific and inter-varietal (Sammeta and Levins, 1970).

Competition for light constitutes an important component of total competition (Donald, 1958) and plant height is an obvious component of the struggle for light. In population cultivars in faba bean, plant height is likely to be different among genotypes and is expected to lead to competition.

So far, no study was found to focus on competition among faba bean genotypes at the single plant level. Moreover, few experimental data have been reported on the joint effect of heterozygosity and heterogeneity on yield and other agromorphological traits in faba bean. In an early study (Bond et al., 1966), effects of 
mixing inbred lines and hybrids on faba bean grain yield have been reported, focusing on the use of a CMS system for hybrid seed production for commercial use. Mixing effects were reported at the plot level, not at the level of individual components of mixtures.

Hence, in the present study the inbreeding coefficient and plant height were used as causal features of competition among faba bean genotypes and the objective was (1) to investigate their effects on yield and other agronomic traits in faba bean at the plot level and at the individual genotype level and (2) to compare the competitive ability of genotypes with different inbreeding coefficient and plant height.

\section{Material and Methods}

\section{Breeding material and experimental design}

The experiment was conducted across three years (2004, 2005 and 2006) in one location (Göttingen) and one replicate per location and involved five spring bean genotypes with the most contrasting inbreeding coefficient and with contrasting plant height: tall and short inbred lines $(F=1)$ and tall and short hybrids $(F=0)$. The two inbred lines were a tall inbred line "Merkur/2" (MER) and a short inbred line "Troy/1" (TRO). They were derived from the Czechian variety "Merkur" and the German variety "Troy" by selfing for at least six generations. Three hybrid entries were used: "tall hybrid" (TH), "tall hybrids blend" (THB), and "short hybrids blend" (SHB). The entry THB was composed from a blend of 13 tall hybrids and the entry SHB was composed from a blend of 13 short hybrids. The parental lines of the hybrids were adapted European lines and included "Merkur/2" and "Troy/1".

The two inbred lines constituted two different so-called units (U1= MER and U2= TRO) of the experiment layout and were both tested (i.e., grown as mixture) with the three hybrid entries (TH, THB and SHB) called hybrid combiners in three combinations (C1, C2 and C3) (Figure 1). Additionally, in the U1, MER was tested with TRO as combiner in the combination C4. Similarly, in the U2, TRO 
was tested with MER as combiner in the combination C5. Thus, two-component mixtures were realized, with the proportion of the components varying in five steps between 0 and 1 . Consequently, competition effects were investigated with various mixtures (M1 to M5) encompassing homogeneous and heterogeneous plots: (M1) pure inbred line stands, (M2) 1/2 inbred line and 1/2 combiner, (M3) 1/3 inbred line and 2/3 combiner, (M4) 1/6 inbred line and 5/6 combiner and the last mixture was (M5) the pure combiner stands. The design of the mixture used is "replacement design" (Snaydon, 1991), where the plant density of the pure plots was the same as to the density of mixed plot.

The experiment disposed on four factors: years $(Y=3)$, units $(U=2)$, mixtures $(M=$ 5) and combinations ( $\mathrm{C}=3$, i.e $\mathrm{C} 1, \mathrm{C} 2$ and $\mathrm{C} 3)$ (Figure 1). The two combinations with only inbred line components, C4 and C5, were analysed separately (see below). The factor year was considered as a block factor. The factors $U$ and $M$ were laid out as a split block (Steel and Torrie, 1981; Piepho et al., 2003). Hence, $\mathrm{U}$ and $\mathrm{M}$ were tested as for a randomized block design (Cochran and Cox, 1992) in which UY and MY served as errors. The interaction MU was tested with the error term MUY. Due to the increasing proportion of hybrids from the mixtures M1 $(0 \%)$ to M5 (100\%), and due to heterosis for plant height, the average plant height of the plot was expected to increase from M1 to M5. To avoid a pertinent effect of the plot height on the neighbor plots, the mixtures (M1 to M5) were not randomized within the years but laid out as indicated in Figure 1.

Factor $U$ was serving as a main plot to accommodate the factor $C(C 1, C 2$ and $\mathrm{C} 3)$. Each of the two levels of (U) was split into three sub-plots and assigned the three levels of the factors $C$. The sub-plots $C$ constituted a split plot design, with $U$ as main plot. The main effect $C$ and its interaction with $U$ were both tested with the pooled error $(C Y+C U Y)$. The relation between the factor $C$ an $M$ was the same as that between the factor $\mathrm{U}$ and $\mathrm{M}$ : a split block design. Both interactions MC and MCU were tested with the pooled error (MCY + MCUY).

The plot size was $7.2 \mathrm{~m}^{2}$ with an average of 26 seeds $/ \mathrm{m}^{2}$. Five plants were sampled within each pure plot (units or combiners plots). In plots containing 
mixtures, five plants were sampled for both components (unit and combiner): sampled plants were identified by unambiguous morphological features and harvested accordingly at maturity.

\section{Measurements and statistical analysis}

Plant height $(\mathrm{HEl} ; \mathrm{cm})$, main stem cross section area at the second lowest inflorescence (SSA; $\left.\mathrm{cm}^{2}\right)$, number of secondary stems, plant grain yield (Ypl) and plant grain yield components were recorded for each sampled plant. Grain yield, number of pods, number of seeds per pod and thousand grain weight (TGW) were recorded for each sampled plant in main stem as well as in secondary stems.

First the combinations ( $\mathrm{C} 1, \mathrm{C} 2$ and $\mathrm{C} 3)$ involving hybrid combiners are considered. Based on the yield data of single components (inbred line and hybrid combiners) in the mixtures and on their proportion in these mixtures $(0,1 / 6,1 / 3$, $1 / 2,2 / 3,5 / 6$ or 1 ), an expected yield performance of each plot was calculated and averaged across years, units and hybrid combiners. This expected plot yield was named "Yield Expected on basis of components' data in the Mixtures", YEM. Furthermore, on the basis of yield of the pure plots (M1 and M5) and the proportion of the components in the mixtures, the "Yield Expected on basis of Pure plots", (YEP) was calculated for M2, M3 and M4 and averaged across years, units and hybrid combiners. It represented a linear relation between plot yield and the components' proportion in the mixtures and implied absence of competition between the components. The combine harvest of the plot (including the yield of single plants sampled within plots before combine harvest) provided yield data of each plot. These data were then averaged across years, units and hybrid combiners as "Yield of the Combine Harvest", (YCH).

The number of plants was counted in pure plots (M1 and M5) at maturity stage. Across the three years the number of plants per plot averaged 145 plants in 2004, 151 plants in 2005 and 154 plants in 2004. On average of the three years the number of plants per pure plots averaged 150 plants $(83 \%$ of the sowing 
density). For each year, this plant density was used to estimate the plot performance as YEM and YEP.

For the nine agronomic traits recorded, separate analyses of variance were performed for the inbred line components and the hybrid components across $\mathrm{C} 1$, $\mathrm{C} 2$ and C3. In the same manner, separate analyses of variance were performed for the combinations involving the two inbred lines as combiners (C4) and (C5).

At the plot level, similarly an analysis of variance of the combine harvest yield was performed for the combinations involving the hybrid combiners $(C 1, C 2$ and C3), while two separate analyses of variance were performed for the combinations C4 and C5. Analyses of variances involving the hybrid combiners followed the statistical model described above. Analyses of variance for the combinations $\mathrm{C} 4$ and $\mathrm{C} 5$ had only the two factors year $(Y)$ and mixture $(M)$. Three mixtures were common between the combinations C4 and C5: pure MER stands (M1and M5), the mixture M2 and the pure TRO stands (M5 and M1). Only the results of main effects and their two level interactions were presented (the three level interactions were not significant).

\section{Results and discussion}

The analysis of the agronomic performance of the five genotypes studied in pure plots (Table 1) showed that the difference in grain yield was neither significant among the inbred lines nor among the hybrids. The inbred line MER was as expected significantly taller than the inbred line TRO. The hybrids $\mathrm{TH}$ and THB were significantly taller than the SHB. The tall inbred line MER and SHB were rather similar for their plant height.

The analysis of variance of the combine harvest yield $(\mathrm{YCH})$ at the plot level showed significant differences between the five mixtures (M) and a significant interaction $(\mathrm{CU})$ between the two inbred lines and the three hybrid combiners involved (Table 2). The increase of the hybrid proportion in the mixtures had a significant positive effect on the combine harvest yield, and in pure stands, hybrids yielded $39 \%$ more than the inbred lines (Table 3 ). In a similar study on 
faba bean, Bond (1966) found that the superiority of hybrids varied from $17 \%$ to $71 \%$. It varied e.g in forage yield of pearl millet from 63\% (Andrews et al., 1993) to $160 \%$ (Burton, 1989). In grain yield of winter oilseed, Becker and Engqvist (1999) found it to vary from $33 \%$ to $44 \%$.

To throw light on the mutual phenotypic interaction between the inbred lines and the hybrids in the mixed stands, data of combiners and units as single components were analyzed. The analysis of variance of the inbred line components across the units, the combinations and the mixtures revealed that the inbred lines' plant yield, plant height and main stem cross section area differed significantly among mixtures (Table 4). Main stem yield reflected by the number of pods per main stem (PMS) constituted the only yield component which generated the significant variation of inbred lines' plant yield among the mixtures. The units established from the tall and the short inbred line were on average not significantly different for any trait, even not for their plant height, although in pure stands, MER was significantly taller than TRO (Table 1). The difference of plant height between the two inbred lines obviously did not modulate their competitive response to the hybrids. On the other hand, the three combinations (hybrid combiners) had significantly different effects on the inbred lines PMS and consequently significantly different effects on their plant yield. In combination with the short hybrids blend (C3), the inbred line plants showed a higher grain yield and more pods (Table 5 ) than when combined with the tall hybrid $(\mathrm{C} 1)$ or with the tall hybrids blend (C2). In mixed stands with inbred lines, the two taller hybrids were stronger competitors than the short hybrids blend. The three hybrid combiners did not differ significantly for their grain yield in pure stands but for plant height (Table 1). It is likely that plant height influenced the competitive effect of hybrid plants, but plant height of the inbred lines did not influence their competitive response to the hybrids' competition. The relationship of plant height with competitive ability as reflected in literature is equivocal. Plant height was found to be correlated with competitive ability in soybean (Mumaw and Weber, 1957); whereas no association between plant height and the competitive ability was established in barley (Sakai, 1961). 
The corresponding analysis of variance of the three hybrid components (Table 6) displayed the same pattern of results as for the two inbred line components. Plant yield, number of pods per main stem, plant height and main stem cross section of the hybrid combiners differed significantly among mixtures, i.e, different proportions of inbred lines as neighbor plants in mixed stands $(M)$ had significantly different competitive effect on the Ypl, PMS, HEI and SSA of the hybrid components. However, these competitive effects were not significantly different between the two units $(U)$.

Across the mixtures, the three hybrid combiners ( $\mathrm{C} 1, \mathrm{C} 2$ and $\mathrm{C} 3$ ) were significantly different for their plant height and their yield components PMS and TGW (details not shown). The competitive response of the three hybrid combiners to both inbred lines in mixed stands was apparently depending on the plant height of the hybrid combiner (Table 6). On average across all mixtures and units, the short hybrid combiner was significantly shorter by $14 \mathrm{~cm}$ than the two other tall hybrid combiners (details not shown). The three hybrid combiners had about the same grain yield performance.

Taking into account results on inbred line and hybrid components, competition in mixed stands obviously existed between individuals with contrasting inbreeding coefficient (inbred lines and hybrids) and contrasting plant height, and had marked and significant effects on plant yield, number of pods per main stem, plant height, and main stem cross section area of both inbred lines and hybrid plants.

From the pure inbred line stands (M1) across the mixtures to the pure hybrid stands (M5), as the proportion of hybrids was increasing and the inbred lines proportion was decreasing, competition became stronger (Table 7). Plants under increased competition were significantly taller, slimmer and less yielding. On average, from the pure inbred line stands (M1) to the mixture M2 (1/2 inbred line and $1 / 2$ hybrid), inbred lines genotypes recorded a decrease of yield by $47 \%$ and a decrease of stem cross section area by $31 \%$; whereas their height increased by $5 \%$. This result corroborated the findings of Burton (1989) in pearl millet where 
the forage yield of inbred line culms decreased as the proportions of hybrids increased in the mixtures. Relatively to the pure stands, the forage yield of inbred line culms decreased by $30 \%$ in the mixture with $20 \%$ of hybrids and it decreased by $56 \%$ as the hybrids proportion was $80 \%$.

The tendency for the hybrids was inversed in the present study. On average, from the pure hybrid stands (M5) to the mixture M2 (1/2 inbred line and 1/2 hybrid), hybrid plants recorded an increase of yield by $40 \%$ and an increase of stem cross section area by $32 \%$; at the opposite, their height decreased by $8 \%$. Obviously, a single hybrid plant in pure hybrid stands was not displaying its maximum performance. When surrounded by inbred line plants, which were weaker competitors than hybrid plants, a hybrid plant was showing a better performance. Sakai (1955) reported as well that a strong competitor suffers more in homogeneous state than in mixture with weak competitor. Considering plant yield as example, with the increase of hybrids proportion, the advantage of the strongly competitive genotype (hybrids) seemed to be directly proportional to the number of weaker surrounding genotypes (inbred lines).

At the plant level, as the hybrids proportion increased (Table 8a), yield gain of the hybrid plants as compared with their pure stands decreased whereas the yield loss of the inbred line plants as compared to their pure inbred line stands increased. The gain in yield achieved by one hybrid plant was increasingly failing to compensate the loss in yield of one inbred line plant as the hybrid proportion increased.

At the plot level (Table 8b) and in each mixed stand, the actual proportions of both inbred lines and hybrids were used to calculate the weighted average gain in yield of hybrid genotypes and the weighted average loss in yield of inbred lines. Unlike to the plant level, at the plot level the weighted gain in performance of hybrids was indeed compensating and even increasingly over-compensating the weighted loss in performance of the inbred lines as the hybrids proportions increased in mixed stands. Mixed stands are therefore expected to yield more than weighted average yield solely based on yield performance of inbred lines in 
pure stands and hybrids in pure stands. This is called active competition; the stronger competitor is the more productive component in the mixture (Sammeta and Levins, 1970).

On the basis of the performance of hybrid components and inbred line components in the mixtures, and on their actual mixture proportions, a weighted average performance of a single plant was estimated for plant yield, number of pods per main stem, plant height and stem cross section area in each mixture (Table 9). As the proportion of hybrids increased and although both inbred line and hybrid plants suffered from competition, the performance of the mixtures increased for all traits.

The relationship of the agronomic performance of the plots with their hybrid proportion is obviously more complex than linear relationship, since it is apparently not based on simple additive performance of inbred lines and hybrids in pure stands.

In order to elucidate this aspect, yield performance at the plot level was studied and for different hybrid proportions the combine harvest yield $(\mathrm{YCH})$ and the expected plot yield from mixtures component (YEM) and finally the expected plot yield from pure plot components (YEP) (cf. Material and Methods) were compared. The expected yield YEP implies either no competitive interaction between inbred lines and hybrids or that the hybrid plants' gain just compensates the inbred line plants' loss in the mixtures.

Although the combine harvest yield $(\mathrm{YCH})$ increased when the hybrids proportion rose, it is particularly interesting to note that in both $\mathrm{YCH}$ and $\mathrm{YEM}$, the relation between hybrids fraction and yield was not linear (Figure 2). The discrepancy between $\mathrm{YCH}$ and YEM at one side, and YEP on the other side increased with the increase of hybrids proportion in the mixtures thus with the strengthening of the competition. In mixture M4 (83\% hybrids) the $\mathrm{YCH}$ and $\mathrm{YEM}$ are even about as high as the yield of the pure hybrid stands. The heterogeneity for the individual inbreeding coefficient (hybrids and inbred lines) was advantageous and led to this increase in grain yield. Previous studies in faba bean ascribed as well 
similar differences in performance between mixed stands (hybrids and inbred lines) and the mean performance of hybrids and inbred lines in pure stands to the heterogeneity in the inbreeding coefficient (Link et al., 1994).

The mixture with the minimum proportion of hybrids in our case (50\%) yielded already $88 \%$ of the pure hybrid stands (Table 3). Bond et al. (1966) found that mixtures with $67 \%$ hybrid proportion did not yield significantly less than the pure hybrid stands. For winter rapeseed, $50 \%$ to $75 \%$ hybrid plants in mixtures yielded nearly the same as the pure hybrid stands (Becker and Engqvist, 1999). In pearl millet, this threshold hybrid proportion was 40 to $50 \%$ (Burton, 1948, 1989).

Combine harvest yield (YEC) and the expected plot yield (YEM) were supposed to give the same results. From M2 to M4, YEM deviated increasingly from $\mathrm{YCH}$ (Figure 2). We take into account that (1) the deviation of $\mathrm{YEM}$ from $\mathrm{YCH}$ happened only in mixed stands where competition took place between inbred lines and hybrids, (2) the deviation of YEM from $\mathrm{YCH}$ increased as the hybrids proportion increased and as the competition increased, (3) the inbred lines were the weaker competitor which suffered increasingly as the hybrids proportion increased (Table 7), (4) the sampling of single inbred line and hybrids plants in each mixture did only include alive plants, (5) when harvesting single plants, indeed several weak inbred lines plants had zero yield what did never happen with hybrid plants. It is therefore probable that several inbred line plants were eliminated (died) in mixed stands and were not found at maturity. This phenomenon was already suggested by several authors. In winter rapeseed, Becker and Engqvist (1999) stated that at usual plant density, hybrids at a fraction of $50 \%$ to $75 \%$ may suppress the inbred line plants completely. In pearl millet, Burton (1989) showed that when inbred lines made up initially $20 \%$ in the mixtures, few inbred line plants were surviving in the next stages.

In the present study as well, apparently some inbred line plants were eliminated prior to harvest time. Inbred line plants eliminated as response to the competition 
with the hybrids may be the cause of the deviation of YEM from $\mathrm{YCH}$. Consequently, YEM was an overestimation of $\mathrm{YCH}$ in mixed stands.

In a second approach, the focus was on the combinations ( $\mathrm{C} 4$ and $\mathrm{C} 5$ ) involving only the two inbred lines. Both inbred lines were not significantly different for their yield and thousand grain weight (Table 1). The assumed source of competition was the plant height. Hence, heterogeneity effects due to the variation in plant height were represented in this case. In both combinations, effect of mixtures on the short inbred line TRO was significant to highly significant for its plant yield, number of pods per main stem, plant height and main stem cross section area; while on the tall inbred line MER, mixtures had only an effect on its plant height (Table 10 and 11). An average of performance for MER and TRO was calculated across both combinations for three common mixtures; the pure stands of MER, the pure stands of TRO and the mixture (1/2 MER and 1/2 TRO). From the pure TRO stands to the mixture (1/2 MER and 1/2 TRO), TRO plants recorded a decrease in yield by $26 \%$ and a decrease in stem cross section area by $9 \%$; whereas their height increased by $7 \%$. The tendency was inversed for MER plants. From the pure MER stands to the mixture (1/2 MER and 1/2 TRO), MER plants decreased their height by $4 \%$.

In mixed stands, the short TRO plants were obviously competing with MER for light thus increasing their height while the tall MER plants became shorter. Hence, there was a significant competitive effect of the tall inbred line on the short inbred line especially for plant yield, albeit the competitive response of the tall inbred line was neither significant for plant yield nor for pod number.

The behavior of the tall inbred line MER as strong competitor differed from the behavior of the hybrids as strong competitor. The competitive response and the competitive effect of hybrid genotypes were marked and significant, whereas the inbred line MER had a significant competitive effect but its competitive response was rather absent. The competitive effect exerted from MER on TRO was not as strong as the one exerted from the hybrids. 
The hybrid SHB and the inbred line MER had a similar height but were maximal different for their inbreeding status (Table 1). From the pure TRO stands to the mixture (1/2 TRO and 1/2 combiner), the plant yield of TRO decreased by $26 \%$ when combined with MER whereas it decreased by $50 \%$ when combined with SHB (details not shown). Hence, heterozygosity level had a considerable effect on the competition between genotypes in mixed stands; competition between inbred lines and hybrids was mutually very marked. To a lower extent than heterozygosity, plant height influenced competition between genotypes with variable plant height in mixed stands. With plant height as source of competition, the competitive effect and response of strong competitors depended on their genetic status. Independently from the plant height, the competitive ability of hybrid genotypes was stronger than the competitive ability of inbred line genotypes.

Contrary to the heterogeneity in mixtures of hybrids and inbred lines, the heterogeneity in mixtures of the tall and the short inbred lines was not advantageous in the present experiment. The effect of heterogeneity was negative for plot yield and averaged $-13 \%$ from the pure stands of both inbred lines to the mixture (1/2 MER and 1/2 TRO). However the differences between all mixtures of MER and TRO for $\mathrm{YCH}$ were not significant (details not shown).

The effect of heterogeneity was described in many studies. At the homozygous level in faba bean, Link et al. (1994) found that the effect of heterogeneity was positive but its significance depended on the environments considered. They found as well that the effect of heterogeneity caused by mixing hybrids and inbred lines was higher than the effect of heterogeneity caused by mixing inbred lines, which corroborated our findings. In winter oilseed rape, line mixtures outyielded lines by 6\% (Léon, 1991). For rapeseed, Schuster and Friedt (1985) as well as Léon and Diepenbrock (1987) found an advantage in mixing lines to increase yield, whereas others (Grabiec and Krzymandki, 1984) have found no advantage. 
The fact that allogamy is partially expressed in faba bean does not hinder the use of heterosis in open fertilizing cultivars to be nearly as efficient as in completely cross fertilizing crops, since a hybrid proportion of $50 \%$ did not yield markedly less than the pure hybrid stands.

As the inbreeding coefficient of individuals was obviously associated with their competitive ability, individuals of open pollinated cultivars would therefore be subjected to competitive stresses of varying degrees and the competitive effects and responses would shape at a large expense the performance of such cultivars. The advantage of the heterogeneity in the inbreeding coefficient resulted from the joint effect of heterosis and competitive ability which gave a convincing advantage to the mixed stands compared to their otherwise expected yield (YEP). Competition among genotypes varying in their inbreeding coefficient should be henceforth taken in consideration while breeding population cultivars. Breeders select based on predictions similar to the prediction of $\mathrm{YCH}$ based on YEP. Phenomena disturbing such predictions are hindrances in breeding. Although at a lower extent than in hybrid-inbred line mixtures, the active competition is supposed to take place as well in an open fertilizing cultivar. Its performance is hence markedly influenced by active competition between its components. The occurrence of active competition among genotypes with contrasting inbreeding coefficient is enforcing the findings that mass selection is less effective in partially allogamous population than in pure self fertilizing or in pure cross fertilizing populations (Wright and Cochran, 1985; Kelly and Williamson, 2000). The individuals with the highest inbreeding coefficient are partly suppressed whereas the performance of the hybrids is, due to active competition, superior to a higher extent than expected. Therefore, they are the most likely individuals to be selected in mass selection. This is not translated into sustainable genetic gain as long as their choice was based on superior heterosis, i.e., heterozygosity (Wright and Cochran, 1985). Heterogeneity in plant height is as well influencing competition among genotypes in mixed stands and should be minimized while selecting the parental components of a population cultivar in faba bean. 


\section{Acknowledgments}

Our thanks are addressed to BMELV (Bundesministeriums für Ernährung, Landwirtschaft und Verbraucherschutz) for financing this research.

\section{References}

Andrews, D. J., B. Kiula, and J. F. Rajewski, 1993. The Use of Protogeny to Make Hybrids in Pearl Millet. In: New Crops, J. Janick and J. E. Simon (eds.), Wiley, New York, pp. 122-126.

Becker, H. C., and G. Engqevist, 1999. Competition among genotypes in oilseed rape (Brassica napus L.). $10^{\text {th }}$ international rapeseed congress Canberra Australia. GCIRC Bull. (France) 1999.

Bond, D. A., J. L. Fyfe, and G. Toynbee-Clarke, 1966. Yields of mixtures of single -cross hybrid field beans (Vicia faba L.) with one of the parental inbred lines. Agric. Sci., Camb. 67: 235-237.

Bond, D. A. and M. H. Poulsen, 1983. Pollination. In: The Faba Bean (Vicia faba L.), P. D. Hebblethwaite (ed.), pp. 77-101. Butterworths, London.

Burton, G. W., 1948. The performance of various mixtures of hybrid and parent inbred pearl millet, Pennisetum glaucum (L.). R. Br. J. Amer. Soc. Agron. 40: $908-915$.

Burton, G. W., 1989. Composition and forage yield of hybrid-inbred mixtures of pearl millet. Crop Sci. 29: 252-255.

Clements, F. E., J. E. Weaver and H. C. Hanson, 1929. Plant competition- an analysis of community function. Publ. No. 398. Carnegie Institute, Wash., D.C. pp. 340.

Cochran, W. G. and G. M. Cox, 1992. Experimental Designs. Second edition. John Wiley and Sons (eds.), Inc. New York. 
Donald, C. M., 1958. The interaction of competition for lightand nutrients. Aust. J. Agric. Res. 9: 421-435.

Ederer, E., and W. Link, 1992. The polycross-test as a step in breeding partially allogamous crops. Theoretical considerations . Proc . XIIlth EUCARPIA Congress, 6-11 July, Angers, France, Book of Poster Abstracts, pp. 543544.

Goldberg, D. E., and K. Landa, 1991. Competitive effect and response: hierarchies and correlated traits in the early stages of competition. J. Ecol. 79: 1013-1030.

Grabiec, G. J., and J. Krzymanski, 1984. Attempts of heterosis use to improve winter rape yield in Poland. GCIRC Bull. (France). 1: 14-16.

Kelly, J. K., and S. Williamson, 2000. Predicting response to selection on a quantitative trait: A comparaison between models for mixed-mating populations. J. Theor. Biol. 207: 37-56.

Léon, J., 1991. Heterosis and mixing effects in winter oilseed rape. Crop Sci. 31: 281-284.

Léon, L., and Diepenbrock, 1987. Yielding ability of pure stands and equal proportions blends of rapeseed (Brassica napus L.) with double-low quality. J. Agron. Crop Sci. 159: 82-89.

Link, W., 1990. Autofertility and rate of cross-fertilization: crucial characters for breeding synthetic varieties in faba bean (Vicia faba L.). Theor. Appl. Genet. 79: 713-717.

Link, W., and W. Ederer, 1994. Das Paarungssystem von Vicia faba L. führt zu einem höheren unmittelbaren als langfristig realisierten Selektiongewinn. Vorträge für Pflanzenzüchtung 28: 280-282.

Link, W., D. Stelling, and E. Ebmeyer, 1994. Factors determining the performance of synthetics in Vicia faba L. 1. Heterogeneity, heterozygosity, and degree of cross fertilization. Euphytica 75: 77-84. 
Mumaw, C. R. and C. R. Weber, 1957. Competition and natural selection in soybean varietal composites. Agron. J. 49: 154-60.

Piepho, H. P., A. Büchse, and K. Emrich, 2003. A hitchhiker's guide to mixed models for randomized experiments. Agron. Crop Sci. 189: 310-322.

Sakai, K. I., 1955. Competition in plants and its relation to selection. Cold Spring Harbor Symp. Quant. Biol. 20: 137-57.

Sakai, K. I., 1961. Competitive ability in plants: its inheritance and some related problems. Symp. Soc. Exp. Biol. 15: 245-63.

Sammeta, K. P. V. and R. Levins, 1970: Genetics and Ecology. Annu. Rev. Gen. Downloaded from arjournals. annualreviews.org by Deutsche Forschungsgemeinschaft. 4, 469-488.

Schuster, W., and W. Friedt, 1985. Die Nutzung von Heterosiseffekten mit synthetischen Sorten bei Cruciferen. In: Bericht über die Arbeitstagung der Saatzuchtleiter in Gumpenstein, pp. 187-201, Verlag der Bundesanstalt für Alpenländische Landwirtschaft, Gumpenstein, Austria.

Snaydon, R. W., 1991. Replacement or additive designs for competition studies? J. Appl. Ecol. 28: 930-946.

Steel, R. G .D., and J. H. Torrie, 1981. Principles and Procedures of Statistics, International Student ed., McGraw-Hill, New York.

Stelling, D., W. Link, and E. Ebmeyer, 1994. Factors determining the performance of synthetics in Vicia faba L. 2. Syn-generation. Euphytica. 75: 85-93.

Wright, A. J., and C. C. Cockerham, 1985. Selection with partial selfing. I. Mass selection. Genetics. 109: 585-587. 
Table 1. Mean performance of the pure inbred line plots and the pure hybrid plots for grain yield, thousand grain weight and plant height.

\begin{tabular}{|c|c|c|c|c|}
\hline & Genotypes & $\mathrm{YCH}$ (t/ha) & TGW $(\mathrm{g})$ & $\mathrm{HEI}(\mathrm{cm})$ \\
\hline \multirow{2}{*}{$\stackrel{\mathscr{\infty}}{\stackrel{\mathscr{J}}{\Xi}}$} & MER & $4.15^{\mathrm{a}}$ & $409.52^{a}$ & $112.91^{\mathrm{a}}$ \\
\hline & TRO & $4.00^{a}$ & $384.56^{a}$ & $88.91^{b}$ \\
\hline \multirow{3}{*}{$\begin{array}{l}\frac{0}{0} \\
\frac{0}{0} \\
\text { 존 }\end{array}$} & $\mathrm{TH}$ & $5.87^{b}$ & $431.30^{b}$ & $131.37^{c}$ \\
\hline & THB & $5.51^{b}$ & $412.89^{b}$ & $136.87^{c}$ \\
\hline & SHB & $5.70^{b}$ & $500.12^{c}$ & $117.23^{a}$ \\
\hline
\end{tabular}

Table 2. Analysis of the variance for the combine harvest yield $(\mathrm{YCH})$ across both units, the three combinations and all mixtures.

\begin{tabular}{llrc}
\hline Sources of variation $(\mathrm{SV})$ & $\mathrm{DF}$ & $\mathrm{MS}\left(\mathrm{t}^{2} / \mathrm{ha}^{2} ; \times 10^{3}\right)$ & $\mathrm{F}$ \\
\hline $\mathrm{U}$ & 1 & 1401.04 & 2.58 \\
$\mathrm{M}$ & 2 & 1237.52 & 0.89 \\
$\mathrm{CU}$ & 4 & 3944.29 & $6.35^{\star}$ \\
$\mathrm{MU}$ & 2 & 650.89 & $4.70^{\star}$ \\
$\mathrm{MC}$ & 4 & 31.14 & 1.29 \\
\hline
\end{tabular}

Total 88

* Significant at $\alpha=5 \%$.

Table 3. Influence of the five proportions of the hybrids in the mixtures on the combine harvested yield in each mixture.

\begin{tabular}{lccc}
\hline \multicolumn{1}{l}{ H proportion } & YCH (t/ha) & Percentage $(\%) \S$ \\
\hline 0.000 & M1 & 4.10 & 100.00 \\
0.500 & M2 & 4.99 & 121.87 \\
0.667 & M3 & 5.29 & 129.18 \\
0.833 & M4 & 5.64 & 137.60 \\
1.000 & M5 & 5.69 & 138.94 \\
\hline LSD (5\%) & 0.84 & \\
\hline
\end{tabular}

$\S$ Relative to the pure inbred line stands.

Table 4. Inbred line components' analysis of variance across the units, the combinations (C1, C2 and $\mathrm{C} 3$ ) and the mixtures for relevant agronomic traits.

\begin{tabular}{|c|c|c|c|c|c|c|c|c|c|}
\hline Traits & & Ypl (g/pl) & & PMS & & $\mathrm{HEI}(\mathrm{cm})$ & & SSA & $\left.m^{2}\right)$ \\
\hline SV & DF & MS & $\mathrm{F}$ & MS & $\mathrm{F}$ & MS & $\mathrm{F}$ & MS & $\mathrm{F}$ \\
\hline$U$ & 1 & 90.54 & 0.88 & 279.14 & 5.60 & 41817.78 & 10.98 & 0.17 & 0.50 \\
\hline C & 2 & 395.93 & $6.74^{*}$ & 260.84 & $8.03^{*}$ & 255.61 & 0.79 & 0.23 & 3.14 \\
\hline M & 3 & 2893.12 & $17.15^{\star \star}$ & 1428.2 & $42.61^{* *}$ & 2260.07 & $13.93^{\star \star}$ & 1.76 & $35.56^{\star *}$ \\
\hline $\mathrm{CU}$ & 2 & 13.88 & 0. & 01 & 1.29 & 348.52 & 1.07 & 0.06 & 0.78 \\
\hline MU & 3 & 1.63 & 0.08 & 10.97 & 1.45 & 122.73 & $6.04^{*}$ & 0.01 & 0.09 \\
\hline MC & 6 & 10.43 & 0.29 & 8.76 & 0.22 & 121.88 & 1.32 & 0.07 & 1.36 \\
\hline
\end{tabular}

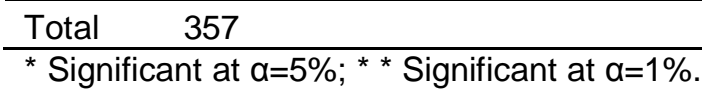


Table 5. Influence of the hybrid combiners on plant yield and number of pods per main stem of the single inbred line components across the combinations (C1, $\mathrm{C} 2$ and $\mathrm{C} 3$ ).

\begin{tabular}{lcc}
\hline & \multicolumn{2}{c}{ Inbred line components performance } \\
\hline Combiners & Ypl $(\mathrm{g} / \mathrm{pl})$ & $\mathrm{PMS}$ \\
\hline TH & $10.86^{\mathrm{a}}$ & $10.81^{\mathrm{a}}$ \\
THB & $10.00^{\mathrm{a}}$ & $10.31^{\mathrm{a}}$ \\
SHB & $13.49^{\mathrm{b}}$ & $13.07^{\mathrm{b}}$ \\
\hline Mean & 11.45 & 11.40 \\
\hline LSD $(5 \%)$ & 1.69 & 1.61
\end{tabular}

${ }^{a, b}$ Values with same letters are not significantly different $(\alpha=5 \%)$.

Table 6. Hybrid genotypes analysis of variance across the units, the combinations (C1, C2 and C3) and the mixtures for relevant agronomic traits.

\begin{tabular}{|c|c|c|c|c|c|c|c|c|c|}
\hline \multicolumn{2}{|c|}{ Traits } & \multicolumn{2}{|l|}{ Ypl (g/pl) } & \multicolumn{2}{|l|}{ PMS } & \multicolumn{2}{|l|}{$\mathrm{HEI}(\mathrm{cm})$} & \multicolumn{2}{|c|}{$\mathrm{SSA}\left(\mathrm{cm}^{2}\right)$} \\
\hline SV & DF & MS & $\mathrm{F}$ & MS & $\mathrm{F}$ & MS & $\mathrm{F}$ & MS & $\mathrm{F}$ \\
\hline$U$ & 1 & 21.06 & 0.15 & 18.23 & 0.14 & 457.88 & 9.96 & 0.29 & 4.62 \\
\hline C & 2 & 36.73 & 0.35 & 1178.72 & $12.48^{* *}$ & 8046.89 & $49.01^{* *}$ & 0.27 & 0.43 \\
\hline M & 3 & 2001.26 & $26.12^{\star *}$ & 575.37 & $9.13^{*}$ & 2018.47 & $6.42^{*}$ & 1.62 & $16.92^{* *}$ \\
\hline $\mathrm{CU}$ & 2 & 11.74 & 0.11 & 88.11 & 0.93 & 1120.72 & $6.83^{*}$ & 0.02 & 0.023 \\
\hline MU & 3 & 76.07 & 2.29 & 21.03 & 0.79 & 71.41 & 1.36 & 0.13 & 0.98 \\
\hline $\mathrm{MC}$ & 6 & 23.18 & 0.43 & 65.09 & 1.03 & 27.74 & 0.19 & 0.12 & 1.30 \\
\hline
\end{tabular}

Total 359

* Significant at $\alpha=5 \%$; * Significant at $\alpha=1 \%$.

Table 7. Influence of the five proportions of the hybrids on the agronomic performance of the hybrid components $(\mathrm{H})$ and inbred line components $(\mathrm{L})$ within each mixture.

\begin{tabular}{|c|c|c|c|c|c|c|c|c|c|}
\hline \multirow{2}{*}{\multicolumn{2}{|c|}{$\begin{array}{l}\text { Traits } \\
\mathrm{H} \text { proportion }\end{array}$}} & \multicolumn{2}{|c|}{ Ypl (g/pl) } & \multicolumn{2}{|l|}{ PMS } & \multicolumn{2}{|l|}{$\mathrm{HEI}(\mathrm{cm})$} & \multicolumn{2}{|c|}{$\mathrm{SSA}\left(\mathrm{cm}^{2}\right)$} \\
\hline & & $\mathrm{H}$ & $L$ & $\mathrm{H}$ & L & $\mathrm{H}$ & $L$ & $\mathrm{H}$ & L \\
\hline 0.000 & M1 & - & 19.74 & - & 17.21 & - & 100.91 & - & 0.72 \\
\hline 0.500 & M2 & 38.70 & 10.38 & 24.13 & 10.68 & 117.54 & 106.34 & 1.32 & 0.50 \\
\hline 0.667 & M3 & 35.39 & 8.21 & 21.80 & 9.24 & 121.31 & 110.29 & 1.21 & 0.44 \\
\hline 0.833 & M4 & 32.30 & 7.40 & 20.09 & 8.46 & 125.14 & 112.52 & 1.15 & 0.40 \\
\hline 1.000 & M5 & 27.62 & - & 18.00 & - & 128.49 & - & 1.00 & - \\
\hline \multicolumn{2}{|c|}{ LSD(5\%) } & 3.19 & 4.74 & 2.90 & 2.11 & 6.47 & 4.65 & 0.11 & 0.08 \\
\hline
\end{tabular}

Table 8. Gain in yield performance of hybrid components and loss in yield performance of inbred line components in mixed stands compared to pure stands (M1 or M5); at the plant level (a) and at the plot level (b).

\begin{tabular}{|c|c|c|c|c|c|c|c|c|}
\hline \multirow{2}{*}{\multicolumn{2}{|c|}{$\begin{array}{l}\text { a. Plant level } \\
\text { H proportion }\end{array}$}} & \multicolumn{3}{|c|}{ Hybrids $(\mathrm{H})$} & \multicolumn{3}{|c|}{ Inbred lines (L) } & \multirow{2}{*}{$\begin{array}{c}\text { Gain + Loss } \\
\text { (g) }\end{array}$} \\
\hline & & Ypl (g) & M5 (g) & Gain (g) & $\mathrm{Ypl}(\mathrm{g})$ & M1 (g) & Loss $(g)$ & \\
\hline 0.500 & M2 & 38.70 & 27.62 & 11.08 & 10.38 & 19.74 & -9.36 & 1.73 \\
\hline 0.667 & M3 & 35.39 & 27.62 & 7.77 & 8.21 & 19.74 & -11.53 & -3.76 \\
\hline 0.833 & M4 & 32.30 & 27.62 & 4.68 & 7.40 & 19.74 & -12.34 & -7.66 \\
\hline
\end{tabular}

Gain= Ypl - M5; Loss $=$ Ypl - M1. 


\begin{tabular}{|c|c|c|c|c|c|c|c|}
\hline \multirow{2}{*}{$\frac{\text { b. Plot level }}{\text { H proportion }}$} & \multicolumn{3}{|c|}{ Hybrids $(\mathrm{H})$} & \multicolumn{3}{|c|}{ Inbred lines $(L)$} & \multirow{2}{*}{$\begin{array}{c}\text { W Gain + W Loss } \\
(\mathrm{g})\end{array}$} \\
\hline & Gain $(g)$ & Proportion & W Gain $(g)$ & Loss $(\mathrm{g})$ & Proportion & W Loss (g) & \\
\hline $0.500 \quad \mathrm{M} 2$ & 11.08 & 0.500 & 5.54 & -9.36 & 0.500 & -4.68 & 0.86 \\
\hline 0.667 & 7.77 & 0.667 & 5.18 & -11.53 & 0.333 & -3.84 & 1.34 \\
\hline 0.833 & 4.68 & 0.833 & 3.90 & -12.34 & 0.167 & -2.06 & 1.84 \\
\hline
\end{tabular}

W Gain: Weighted gain (Gain $\times$ Proportion); W Loss: Weighted loss (Loss $\times$ Proportion).

Table 9. Influence of the five proportions of the hybrids on the weighted average performance of single plant performance in each mixture (cf. text).

\begin{tabular}{lccccc}
\hline $\mathrm{H}$ proportion & $\mathrm{Ypl}(\mathrm{g} / \mathrm{pl})$ & $\mathrm{PMS}$ & $\mathrm{HEl}(\mathrm{cm})$ & $\mathrm{SSA}\left(\mathrm{cm}^{2}\right)$ \\
\hline 0.000 & M1 & 19.74 & 17.07 & 100.91 & 0.72 \\
0.500 & M2 & 24.54 & 17.41 & 111.94 & 0.91 \\
0.667 & M3 & 26.33 & 17.61 & 117.60 & 0.95 \\
0.833 & M4 & 28.15 & 18.15 & 123.04 & 1.03 \\
1.000 & M5 & 27.62 & 18.00 & 128.49 & 1.00 \\
\hline
\end{tabular}

Table 10. Influence of the five proportions of the short inbred line combiner (TRO) on the performance of the tall inbred line (MER) and short inbred lines (TRO) within each mixture.

\begin{tabular}{|c|c|c|c|c|c|c|c|c|c|}
\hline \multirow{2}{*}{\multicolumn{2}{|c|}{$\begin{array}{l}\text { Combiner (TRO) } \\
\text { proportion }\end{array}$}} & \multicolumn{2}{|c|}{ Ypl (g/pl) } & \multicolumn{2}{|l|}{ PMS } & \multicolumn{2}{|c|}{$\mathrm{HEI}(\mathrm{cm})$} & \multicolumn{2}{|c|}{$\mathrm{SSA}\left(\mathrm{cm}^{2}\right)$} \\
\hline & & TRO & MER & TRO & MER & TRO & MER & TRO & MER \\
\hline 0.000 & M1 & - & 20.50 & - & 18.53 & - & 113.53 & & 0.74 \\
\hline 0.500 & M2 & 13.80 & 20.52 & 13.40 & 20.70 & 94.60 & 108.93 & 0.63 & 0.76 \\
\hline 0.670 & M3 & 13.72 & 20.55 & 14.93 & 20.33 & 91.60 & 106.53 & 0.64 & 0.77 \\
\hline 0.830 & M4 & 14.76 & 23.57 & 14.40 & 19.93 & 87.67 & 105.73 & 0.66 & 0.79 \\
\hline 1.000 & M5 & 20.44 & - & 16.20 & & 87.53 & - & 0.69 & - \\
\hline \multicolumn{2}{|c|}{ F significance } & ** & ns & * & ns & ** & ** & * & $\mathrm{ns}$ \\
\hline \multicolumn{2}{|c|}{ LSD(5\%) } & 3.80 & - & 2.98 & - & 3.76 & 3.10 & 0.05 & - \\
\hline
\end{tabular}

ns Not significant; ${ }^{*}$ Significant at $\alpha=5 \% ;{ }^{*}$ * Significant at $\alpha=1 \%$.

Table 11. Influence of the five proportions of the tall inbred line combiner (MER) on the performance of the tall inbred line (MER) and short inbred lines (TRO) within each mixture.

\begin{tabular}{|c|c|c|c|c|c|c|c|c|c|}
\hline \multirow{2}{*}{\multicolumn{2}{|c|}{$\begin{array}{l}\text { Combiner (MER) } \\
\text { proportion }\end{array}$}} & \multicolumn{2}{|c|}{ Ypl (g/pl) } & \multicolumn{2}{|l|}{ PMS } & \multicolumn{2}{|c|}{$\mathrm{HEI}(\mathrm{cm})$} & \multicolumn{2}{|c|}{ SSA $\left(\mathrm{cm}^{2}\right)$} \\
\hline & & TRO & MER & TRO & MER & TRO & MER & TRO & MER \\
\hline 0.000 & M1 & 20.41 & - & 15.73 & - & 88.93 & - & 0.70 & - \\
\hline 0.500 & M2 & 16.44 & 20.89 & 13.90 & 18.13 & 94.53 & 109.67 & 0.64 & 0.74 \\
\hline 0.670 & M3 & 12.96 & 20.40 & 13.13 & 16.80 & 98.53 & 108.07 & 0.62 & 0.74 \\
\hline 0.830 & M4 & 12.38 & 19.63 & 12.27 & 17.73 & 102.60 & 112.47 & 0.58 & 0.76 \\
\hline 1.000 & M5 & - & 21.53 & - & 18.80 & - & 115.33 & - & 0.76 \\
\hline \multicolumn{2}{|c|}{ F significance } & $\star *$ & ns & ** & ns & ** & $\star \star$ & * & ns \\
\hline \multicolumn{2}{|c|}{$\operatorname{LSD}(5 \%)$} & 3.32 & - & 2.45 & - & 1.55 & 4.00 & 0.10 & - \\
\hline
\end{tabular}

ns Not significant * Significant at $\alpha=5 \% ;{ }^{*}$ Significant at $\alpha=1 \%$. 
Units $(U)=2$ Combinations $(C)=4$; covered by five combiners

(Hybrid combiners $=3$; inbred line combiners $=2$ )

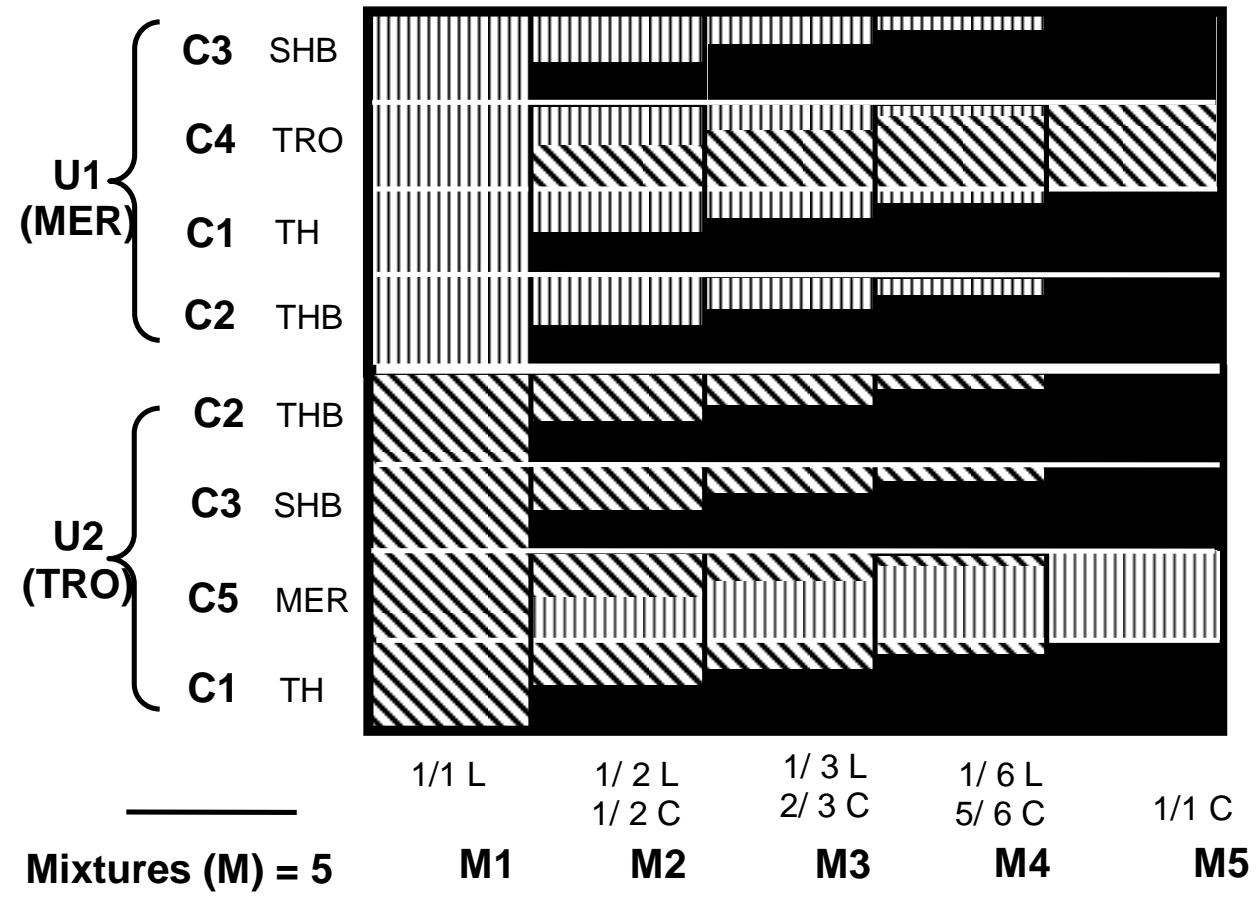

Dashed: inbred lines; Black: hybrids

Figure 1. Field layout (2005); Mixtures (M1 to M5) are crossed with the combinations (C1 to C3; $\mathrm{C} 4$ or $\mathrm{C} 5$ ) and with the units (U1 and U2). L: inbred line; H: hybrid.

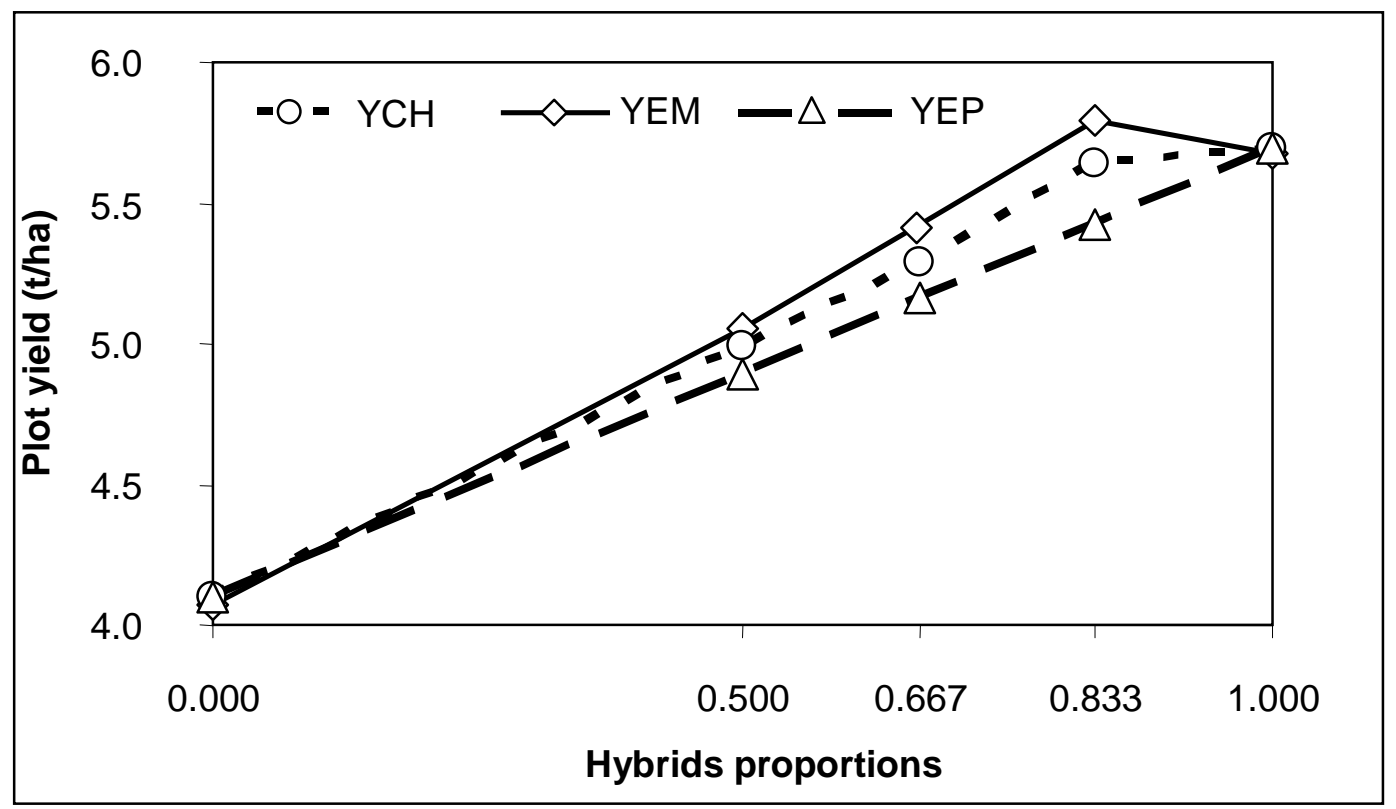


Figure 2. Comparison between the observed yield $\mathrm{YCH}$ and the two expected yield $\mathrm{YEM}$ and YEP. 


\title{
Chapter IV. Effect of competition between Vicia faba L. and Camelina sativa as a model weed in breeding for organic conditions
}

\author{
L. Ghaouti and W. Link
}

Key words: Faba bean, competitive ability, weed stress, heterozygosity

\begin{abstract}
Effect of weeds is detrimental to faba bean cropping in organic farming. Breeding for competitive cultivars is one option for weed control in organic conditions. The aim of the present study was to test the competitive ability of faba bean genotypes contrasting in their heterozygosity and heterogeneity level and in their plant height in order to determine the most weed competitive type of cultivar. A set of 24 genotypes composed from different genotypic structures: eight inbred lines, eight polycross progenies, two inbred line blends, two hybrid blends and four checks were tested under two treatments, with and without weeds, using a split plot design. Each genotypic structure was composed equally from tall and short genotypes. The competitive ability of faba bean genotypes was tested with a model weed Camelina sativa in two locations during two years (2005 and 2006). Yield loss recorded by faba bean genotypes due to weed competition was distinct according to the average yield of the genotypic structures. Hybrid blends were the most competitive genotypes with $6 \%$ average loss of yield, whereas inbred lines were the least competitive genotypic structure and recorded on average $35 \%$ yield loss. However, within the genotypic structures, no correlation was found between the yield performance of genotypes and their competitive response. Competitive ability against weeds was positively correlated with heterozygosity, early flowering and great plant height.
\end{abstract}

\section{Introduction}

Weeds compete with the crops for light, nutrients and soil moisture. Weed competition is among the major biotic stress that can reduce drastically crop yield. In faba bean (Vicia faba L.), yield losses amounted to $35 \%$ (ICARDA, 
1980). The critical period for weed-crop competition in faba bean was reported to begin six weeks from sowing (Zahran, 1981).

In organic farming where the use of herbicides is not approved, crop competitiveness can be utilized as a major tool in a weed regulation strategy (Richard and Heppel, 1990; Gooding et al., 1993; Eisele and Köpke, 1997). The potential to generate a high grain yield despite a significant weed pressure is an attribute of competitive genotypes. Through their ability to reduce weed infestation, such genotypes are reducing as well the input of weed seeds to the soil seed bank (Didon and Boström, 2003).

The competitive ability of a genotype has two aspects: (1) the competitive effect being the ability to suppress weeds and (2) the competitive response being the ability to avoid being suppressed by weeds (Goldberg and Landa, 1991).

Heterosis, the effect of heterozygosity was reported to increase in stress environments compared to optimum environments in many crops such as peas (Sarawat et al., 1994) and barley (Einfeldt et al., 2005). Faba bean is a partially allogamous crop with a degree of cross-fertilization averaging 30\% to $60 \%$ (Bond and Poulsen, 1983; Link, 1990). Both line and population cultivars are possible to be bred in faba bean. Hence, it is of interest to compare the competitive ability of faba bean genotypes with contrasting levels of heterozygosity and heterogeneity and of plant height. The results help to make the adequate choice of cultivars when breeding for organic conditions. The diversity of weed species and degree of infestation usually varies between sites and years. One way to standardize weed competition is to use a given species as a model weed. In the present study, Camelina sativa termed commonly false flax was used for that purpose.

\section{Material and Methods}

\section{Study sites}

The trials were conducted in four environments (E) including two locations in Göttingen (Reinshof and Deppoldshausen) and two years (2005 and 2006). Both 
sites are located in the center of Germany $\left(51 \mathrm{~N}, 9^{\circ} \mathrm{E}\right)$. Although Reinshof and Deppoldshausen have the same geographical position, they are very different for their "Ackerzahl" and their altitude. "Ackerzahl" is the German soil quality index varying from: $0=$ minimum soil quality to $100=$ maximum soil quality. Deppoldshausen has a high altitude (330 m) and has a low "Ackerzahl" (46); whereas Reinshof has a relatively low altitude $(150 \mathrm{~m})$ and a high "Ackerzahl" (83). Temperature and rainfall data for both years are shown in Figure 1.

\section{Breeding material and experimental design}

Faba bean material consisted of 24 entries contrasting in their genotypic structure (heterozygosity and heterogeneity level) and in their plant height (Table 1). The inbred lines were derived from eight old and new European cultivars (Herz Freya, Maya, Merkur, Music, Pistache, Scirocco, Styria, and Troy). They were developed via single seed descent for at least six generations. The eight polycross progenies were derived from natural mating (i.e. partially allogamous) of the eight inbred lines with a tester composed of 18 inbred lines including these eight inbred lines. The short inbred lines blend was created by blending equal numbers of seed from each short inbred line and correspondingly the tall inbred line blend was constituted. The tall hybrid blend was composed from eight tall F1 hybrids derived from crosses among the four tall inbred lines as parents and correspondingly, the short hybrid blend was composed from eight short F1 crosses. Checks encompassed two European cultivars: Espresso and Bilbo. For Camelina sativa, a locally propagated, adapted population has been used. The experimental design was split-plot in which faba bean genotype $(G=24)$ is the main plot and the weed treatment $(\mathrm{TO}=$ no weed; $\mathrm{T} 1=$ with weed) is the sub-plot. The size of the main plot was $10 \mathrm{~m}^{2}$ and the size of the sub-plot was $5 \mathrm{~m}^{2}$. Additionally, eight pure plots of Camelina sativa were sown adjacent to the trial. In both mixtures and pure plots, the sowing density of faba bean was about 35 seeds $/ \mathrm{m}^{2}$ and the sowing density of Camelina sativa was 350 seeds $/ \mathrm{m}^{2}$. The design of the mixture used is "additive mixture" (Snaydon, 1991) where faba bean and Camelina sativa were grown in mixtures using the densities intended 
for pure stands. The trials were altogether sown in the end of March and harvested in the end of August. In the trials, all plots were regularly weeded in order to avoid the interactions with other weeds.

\section{Measurements and statistical analysis}

Agromorphological traits were recorded for faba bean genotypes in both treatments and encompassed: flowering time (FLW, days), plant height (HEI, $\mathrm{cm}$ ), lodging (LOD, score 1-9; 1: fully upright, $9=$ totally lodging), maturity (MAT, days), grain yield (Y, t/ha) and thousand grain weight (TGW, g). Additionally, a measurement of the chlorophyll $(\mathrm{CH})$ was made for each genotype in both treatments. The measurement was made on the leaf of the second youngest inflorescence of a sample of 10 individuals per plot. The device used was "Chlorophyll meterspad-502 (Minolta)". The measurements have no dimension but could be transformed in "Chlorophyll content (\%)" which was not done in this study.

Concerning Camelina sativa, plant height (HEI weeds, $\mathrm{cm}$ ) and grain yield $(\mathrm{Y}$ weeds, t/ha) were as well recorded.

Traits recorded on faba bean genotypes were analyzed using the split plot model as described by Cochran and Cox (1992). Analyses of variance were conducted with the factor environment considered as random and the factors genotypes and treatments as fixed. The statistical analysis was carried out with PLABSTAT (Utz, 1991). Data presented below are averaged across the four environments. For statistical significance, ${ }^{*}$ is used to indicate significances at $5 \%$ level of error probability and ${ }^{* *}$ at $1 \%$ level of error probability.

The yield loss (Yloss) recorded by faba bean genotypes due to their competition with Camelina sativa was expressed as follows:

Yloss $=\frac{(\mathrm{YT0}-\mathrm{YT} 1)}{\mathrm{YT0}} \times 100$ [Eq. 1], where $\mathrm{YT}_{0}$ is the yield of faba bean genotypes in the treatment $T_{0}$ without weeds and $\mathrm{YT}_{1}$ is the yield of faba bean genotypes in the treatment $\mathrm{T} 1$ with weeds. 


\section{Results and discussion}

The monthly average temperature and sum of precipitation followed the same general pattern in 2005 and 2006 as shown in Figure 1. The average temperature in the month of June and July were slightly higher in the 2006. Generally, both growing season did not constitute a stress for the growing of both Camelina sativa and faba bean. The analysis of variance across environments, genotypes and treatments (Table 2) showed that the genotypes $(G)$ and treatments $(T)$ were significantly different for flowering time, height, chlorophyll content, yield and thousand grain weight. The other measured traits did not show any significance between the treatments. The set of genotypes used in this experiment was already tested in the frame of another study and significant differences between these genotypes were as well found (Ghaouti and Link, 2007a). In the presence of competition with Camelina sativa, faba bean genotypes were on average earlier flowering by about one day, shorter in plant height by about $5 \%$ and less yielding by about $25 \%$ although the thousand grain weight increased (Table 3). Apparently, other yield components were responsible for the reduction of yield in faba bean genotypes. The yield of Camelina sativa also decreased significantly by about $56 \%$ due to the competition with faba bean, whereas its plant height increased significantly by $24 \%$. Since in pure plots, the average height of faba bean was higher than the average plant height of Camelina sativa, in mixed plots, probably Camelina was the weaker competitor for light and its competition response resulted in an increase in its plant height. At the opposite, faba bean was the stronger competitor for light and was hence shorter when surrounded by Camelina than when surrounded by other faba bean individuals. Such effect of competition between short and tall individuals was as well shown by a study on intra-specific competition of faba bean (Ghaouti and Link, 2007b). Under competition with Camelina, faba bean genotypes had lower chlorophyll content in the leaves. Low chlorophyll content was found to be correlated with a deficiency in nitrogen uptake and with low protein content. In winter rapeseed, furthermore chlorophyll content was found to be significantly 
and positively correlated with seed protein content (Kessel, 2000). Apparently, faba bean competed strongly with Camelina sativa for the mineral nitrogen in the soil although faba bean as legume is using both the nitrogen in the soil and the atmospheric nitrogen fixed by the rhizobia. A study showed that legumes competing with grasses had lower protein concentrations in vegetative part due to lower nitrogen uptake than those growing in pure plots (Damião et al., 2004). Kitamura et al. (1991) found that rhizobia tend to be less active as nitrogen fixers when legumes are mixed with grass. It is possible that the same phenomenon happened in mixed stands of faba bean with Camelina sativa and that legumes in pure stands may have maintained more active nodule. Further or additional aspects like competition for water and allelopathic interactions can however not be ruled out.

The interaction between the treatment and faba bean genotypes $(T \times G)$ was significant for grain yield. The response to the presence of weeds was different between the genotypes tested. This is of great interest in breeding for competitive genotypes.

Yield of faba bean genotypes in absence of weeds was markedly and positively correlated $\left(r=0.84^{\star *}\right)$ with their yield in presence of competition with weeds (Figure 2). The distribution of genotypes for yield in both treatments was distinct according to the genotypic structures. In absence of weed competition, hybrid blends were the best yielding genotypic structure $(4.91 \mathrm{t} / \mathrm{ha})$, whereas the inbred lines were the lowest yielding genotypic structure $(3.63 \mathrm{t} / \mathrm{ha})$. Polycross progenies (3.93 $\mathrm{t} / \mathrm{ha}$ ) were yielding higher than the inbred lines and lower than the hybrid blends. Heterozygosity seemed to be the main factor influencing the yield performance in faba bean. Although all genotypes yielded lower under competition with weeds, the pattern of the distribution was the same as in the case of absence of weeds. In both cases of presence or absence of weeds, heterozygosity promoted the highest yield performance. Yield loss recorded by faba bean genotypes due to the competition with weeds (see [Eq. 1]) was negatively correlated with the yield performance of faba bean genotypes in absence of weeds $\left(r=-0.54^{* *}\right)$. The competitive response of faba bean genotypes 
to the weed stress was distinct according to the genotypic structure. The inbred lines recorded the highest yield loss (35\%); the polycross progenies lost $23 \%$ of their yield whereas the hybrid blends recorded the lowest yield loss (6\%). Under stress, heterozygosity provided the highest competitiveness. This result corroborated the findings on the competitive response of faba bean to other stresses such as frost stress (Arbaoui, 2007) and drought stress (Abdelmula et al., 1999). However, it is essential to note that the variance among inbred lines was higher than the variance among polycross progenies for yield in both treatments as well as for yield loss. For the trait yield loss, the standard deviation of inbred lines was $13.04 \%$ whereas the standard deviation of polycross progenies was markedly lower $(7.67 \%)$. Therefore, although the inbred lines suffered more from weed stress than their polycross progenies, some inbred lines were found to be as much competitive as the best polycross progenies such as the inbred line Scirocco/069. Besides being the most stable inbred line, Scirocco/069 is as well among the best yielding inbred lines. A study on the competitive ability of barley cultivars showed that no relationship existed between the grain yield and weed suppression ability (Didon and Boström, 2003). It is worthwhile to mention that the cultivars tested were all homozygous. In our case as well, the competitive response of genotypes in the same genotypic structure was not correlated with their grain yield (data not shown). For instance, considering the inbred lines group, the highest yielding inbred line Music/1 and the lowest yielding inbred line Herz Freya/22 in absence of weed were both recording the highest yield loss (Figure 3). The inbred line blends (ILB) were yielding on average higher than the average of the inbred lines in the presence of weeds and recorded a lower yield loss (details not shown). Heterogeneity seemed to provide a higher competitive response for faba bean genotypes to weed stress. Checks were comparable in their competitive response to polycross progenies. This is to be expected since the checks were as well partly heterozygous and heterogeneous.

The loss in yield recorded by faba bean genotypes was translated into a higher yield for the weeds $\left(r=0.55^{* *}\right.$; Figure 4). Competitive effect of faba bean 
genotypes on the yield of weeds (Camelina sativa) was different among the genotypic structures. Hybrid blends had the highest competitive effect on the yield of weeds and inbred lines on average allowed the highest yield of weeds. The yield of the weed was highly variable among the inbred lines compared to the other genotypic structures. There was no obvious relationship between the yield loss of faba bean genotypes in a given genotypic structure and the yield of weeds. Considering the inbred lines, although Music/1 recorded the highest yield loss, it did not allow the highest yield of Camelina. Although there is an evidence of heterozygosity effect on the competitive ability of faba bean genotypes for weed stress, the interaction between faba bean genotypes and weeds appear to be complex and is certainly depending on several other factors.

The interaction of the plant height group with the treatment $(T \times H)$ was significant for plant height, yield and thousand grain weight (Table 4). Both groups did not differ significantly for yield and thousand grain weight (details not shown).Tall genotypes were taller in both treatments. Concerning yield, tall genotypes appeared as more stable across the treatments than short genotypes; they were more competitive than short genotypes. Other studies have shown that plant height is among the factors that are related to the competitive ability of cultivars (Christensen, 1995).

Assuming $50 \%$ cross fertilization, the heterotic increment of faba bean in both treatments can be estimated. The average $F 1$ performance $\mu(F 1)$ is deduced from the following formula: $\mu(\mathrm{F} 1)=2[\mu(\mathrm{PP})-0.5 \mu(\mathrm{IL})]$;

where $\mu(I L)$ is the average performance of the inbred lines and $\mu(P P)$ is the average performance of the polycross progenies. Heterotic increment is estimated through the difference between the $\mathrm{F} 1$ and the inbred line parental value which is expressed as follows:

Heterotic increment $(\mathrm{HI})=\mu(\mathrm{F} 1)-\mu(\mathrm{IL})$.

The amount of $\mathrm{HI}$ expressed in faba bean under weed competition (T1) was 1.23 $\mathrm{t} /$ ha, whereas in non stress conditions (TO) $\mathrm{HI}$ amounted to $0.60 \mathrm{t} / \mathrm{ha}$. The expression of $\mathrm{HI}$ in faba bean under weed stress conditions was twice the 
amount of $\mathrm{HI}$ under optimum environment. Several studies reported a tendency to higher heterosis under stress conditions in different crops such as pea (Sarawat et al., 1994) and barley (Einfeldt et al., 2005). For grain yield, the relative effect of heterozygosity was even found to increase substantially with increasing levels of stress (Finlay, 1964). In faba bean, Bond et al. (1994) stated that most competitive cultivars are heterotic.

The outcome of this study would require the exploitation of maximum heterosis in faba bean to improve the competitive ability to weeds. However, the commercial production of hybrid cultivars is not possible, as no existing system for cytoplasmic male sterility proved to be stable enough in faba bean (Bond, 1987). The alternative type of cultivar is the synthetic cultivar which is exploiting a part of the heterosis in faba bean. Another advantage of synthetic cultivars is the heterogeneity which has proven to be advantageous in weed stress conditions. Nevertheless, line breeding is not excluded as promising since a high intensity of selection could be applied (only one line is needed to establish the entire cultivar) and the genetic variance among lines is very large. Several inbred lines were found here to reach the level of open pollinated checks and polycross progenies.

The present study did not cover a wide range of environments and was not conducted over a long time period. The composition of natural population of weeds is complex and varies over space and time. Hence the weeds-crop interaction is more complex than the interaction with a model weed. However, as confirmed by other studies, heterozygosity and high plant height are certainly among the characteristics of a faba bean cultivar that is competitive referring to weed and that are to be adopted for organic conditions.

\section{Acknowledgements}

Our thanks are addressed to BMELV (Bundesministeriums für Ernährung, Landwirtschaft und Verbraucherschutz) for financing this research. 


\section{References}

Abdelmula, A. A., W. Link, E. von Kittlitz, and D. Stelling, 1999. Heterosis and inheritance of drought tolerance in faba bean (Vicia faba L.). Plant Breeding 118: $485-490$.

Arbaoui, M., 2007. Detailed genetic analysis of faba bean (Vicia faba L.) winterhardiness and its related traits. PhD Diss. Georg-August University, Göttingen, Germany.

Bond, D. A., 1987. Recent developments in breeding faba beans (Vicia faba L.). Plant Breeding. 99: 1-26.

Bond, D. A., and M. H. Poulsen, 1983. Pollination. In: The Faba Bean (Vicia faba L.). P. D. Hebblethwaite (ed.), pp. 77-101. Butterworths, London.

Bond, D. A., G.J. jellis, G. G. Rowland, J. Le Guen, L. D. Robertson, S. A. Khalil, and L. Li-Juan., 1994. Present status and future strategy in breeding faba beans (Vicia faba L.) for resistance to biotic and abiotic stresses. In: Expanding the Production and Use of Cool Season Food Legumes. F. J. Muhlbauer and W. J. Kaiser (eds.), pp 592-616. Netherlands.

Christensen, S., 1995. Weed suppression ability of spring barley cultivar. Weed Res. 35: 241-247.

Cochran, W. G. and G. M. Cox, 1992. Experimental Designs. Second edition. John Wiley and Sons (eds.), Inc. New York. 
Damião W. N., J.P. Muir, R. Wittie, R. Rosiere, and T. J. Butler, 2004. Yield and nutritive value of summer legumes as influenced by dairy manure compost and competition with crabgrass. Agron. J. 96: 812-817.

Didon U. M. E. and U. Boström, 2003. Growth and development of six Barley (Hordeum vulgare ssp. vulgare L.) cultivars in response to a model weed (Sinapis alba L.). J. Agron. Crop Sci. 189: 409-417.

DWD (Deutscher Wetterdienst), 2006. http://www.dwd.de

Einfeldt C. H. P., S. Ceccarelli, S. Grando, A. Gland-Zwerger and H. H. Geiger, 2005. Heterosis and mixing effect in Barley under drought stress. Plant Breeding. 124: 350- 355.

Eisele, J. A., and U. Köpke, 1997. Choice of cultivars in organic farming: new criteria for winter wheat ideotypes. Pflanzenbauwissenschaften. 2: 84-89.

Finlay, K. W., 1964. Adaptation, its measurement and significance in barley breeding. Proc. First Intl. Barley Gen. Symp. 26-31 August, 1964, 351-359. Wageningen, the Netherlands.

Ghaouti, L., and W. Link, 2007b. Relevance of competition effects among genotypes in breeding faba bean (Vicia faba L.). in preparation.

Ghaouti, L., and W. Link, 2007a. Comparison between local vs. formal breeding and inbred line vs. synthetic cultivars for organic farming. Case of Vicia faba L. in preparation. 
Goldberg, D. E. and K. Landa, 1991. Competitive effect and response: hierarchies and correlated traits in the early stages of competition. J. Ecol. 79: $1013-1030$.

Gooding, M. J., A. J. Thompson, and W. P. Davies, 1993. Interception of photosynthetically active radiation, competitive ability and yield of organically grown wheat varieties. Aspects Appl. Biol. 34: 355-362.

ICARDA, 1980. Weed control research in Northern Syria 1978-1979. ICARDA project Report No. 5, pp. 43.

Kessel, B., 2000. Genetische Variation und Vererbung der Stickstoff-Effizienz bei Winterraps (Brassica napus L.). PhD Diss. Georg-August University, Göttingen, Germany.

Kitamura, Y., A. S. Whitney, and A. B. Guevarra, 1991. Legume growth and nitrogen fixation as affected by plant competition for light and soil nutrients. Agronomy J. 73:395-398.

Link, W., 1990. Autofertility and rate of cross-fertilization: crucial characters for breeding synthetic varieties in faba bean (Vicia faba L.). Theor. Appl. Genet. 79: 713-717.

Richard, M. C., and V. Heppel, 1990. Cereal varieties for the organic and low input grower. In: Proceedings Brighton Crop Protection Conference-Weeds, pp.147-154. Brighton.

Sarawat, P., F. L. Stoddard, D. R. Marshall, and S. M. Ali, 1994. Heterosis for yield and related characters in peas. Euphytica. 80: 39-48. 
Snaydon, R.W., 1991. Replacement or additive designs for competition studies?. J.Appl. Ecol. 28: 930-946.

Utz, H. F. 1991. A computer program for statistical analysis of plant breeding experiments. Institute of Plant Breeding, Seed Science and Population Genetics. University of Hohenheim.

Zahran, M. K., 1981. Weed and Orobanche Control in Egypt. In: Faba bean Improvement. pp. 191-198. G. Hawtin and C. Webb (eds). 
Table 1. Genotypic structure and plant height of the 24 genotypes tested.

\begin{tabular}{lcccccc}
\hline \multicolumn{7}{c}{ Genotypic structure } \\
$\begin{array}{l}\text { Plant height } \\
\text { group }\end{array}$ & $\begin{array}{c}\text { Inbred Line } \\
\text { (IL) }\end{array}$ & $\begin{array}{c}\text { Polycross Progenies } \\
\text { (PP) }\end{array}$ & $\begin{array}{c}\text { Inbred line blend } \\
\text { (ILB) }\end{array}$ & $\begin{array}{c}\text { Hybrid blend } \\
\text { (HB) }\end{array}$ & $\begin{array}{c}\text { Check } \\
\text { (CK) }\end{array}$ & Total \\
\hline Tall & 4 & 4 & 1 & 1 & 2 & 12 \\
Short & 4 & 4 & 1 & 1 & 2 & 12 \\
\hline Total & 8 & 8 & 2 & 2 & 4 & 24 \\
\hline
\end{tabular}

Table 2. Sources of variation and expected mean squares for flowering time, height, chlorophyll content, yield and thousand grain weight of faba bean genotypes evaluated in the split plot design.

\begin{tabular}{|c|c|c|c|c|c|c|}
\hline Source & DF & FLW(days ${ }^{2}$ ) & $\mathrm{HEI}\left(\mathrm{cm}^{2}\right)$ & $\mathrm{CH}$ & $\mathrm{Y}\left(\mathrm{t}^{2} / \mathrm{ha}^{2}\right)$ & $\operatorname{TGW}\left(\mathrm{g}^{2}\right)$ \\
\hline $\mathrm{E}$ & 3 & $1322.2^{\star *}$ & $7838.21^{* *}$ & $407.24^{\star *}$ & $11.20^{* *}$ & $79268.51^{\star \star}$ \\
\hline G & 23 & $38.72^{* *}$ & $944.81^{* *}$ & $31.40^{\star *}$ & $2.70^{* *}$ & $24567.54^{\star *}$ \\
\hline$G \times E$ & 69 & $7.71^{\star *}$ & $97.81^{\star *}$ & $10.82^{\star *}$ & $0.63^{\star *}$ & $4925.53^{\star \star}$ \\
\hline $\mathrm{T}$ & 1 & $0.58^{\star}$ & $1402^{\star *}$ & $627.56^{\star \star}$ & $46.64^{* *}$ & $16237.02^{\star *}$ \\
\hline$T \times G$ & 23 & 0.14 & 16.27 & 5.46 & $0.34^{*}$ & 696.55 \\
\hline$T \times G \times E$ & 72 & 0.13 & 18.39 & 4.62 & 0.20 & 753.81 \\
\hline
\end{tabular}

Table 3. Average performance of faba bean and Camelina sativa in both pure plots and mixtures.

\begin{tabular}{|c|c|c|c|c|c|}
\hline Traits & FLW (days) & $\mathrm{HEI}(\mathrm{cm})$ & $\mathrm{CH}$ & $\mathrm{Y}(\mathrm{t} / \mathrm{ha})$ & TGW $(\mathrm{g})$ \\
\hline \multicolumn{6}{|l|}{ Faba bean } \\
\hline Pure stands (T0) & 162.61 & 105.63 & 43.03 & 3.87 & 460.38 \\
\hline Mixture (T1) & 161.52 & 100.23 & 39.39 & 2.88 & 478.77 \\
\hline Significance & $* *$ & $* *$ & $* *$ & $* *$ & $\star \star *$ \\
\hline \multicolumn{6}{|l|}{ Camelina sativa } \\
\hline Pure stands & - & 73.59 & - & 1.16 & - \\
\hline Mixture & - & 91.35 & - & 0.496 & - \\
\hline Significance & - & $* *$ & - & $\star *$ & - \\
\hline
\end{tabular}

Table 4. Performance of the short genotypes and tall genotypes in absence of weeds (T0) and in the presence of weeds (T1) and significance of the interaction $\mathrm{T} \times \mathrm{H}$.

\begin{tabular}{llrcc}
\hline Treatment & Height group & HEI $(\mathrm{CM})$ & $\mathrm{Y}(\mathrm{t} / \mathrm{ha})$ & $\mathrm{TGW}(\mathrm{g})$ \\
\hline T0 & Short & 100.57 & 3.63 & 469.13 \\
T0 & Tall & 111.35 & 3.43 & 453.10 \\
\hline T1 & Short & 93.76 & 3.18 & 493.88 \\
T1 & Tall & 106.04 & 3.26 & 479.84 \\
\hline Significance T×H & & $* *$ & $* *$ & $* *$ \\
\hline
\end{tabular}




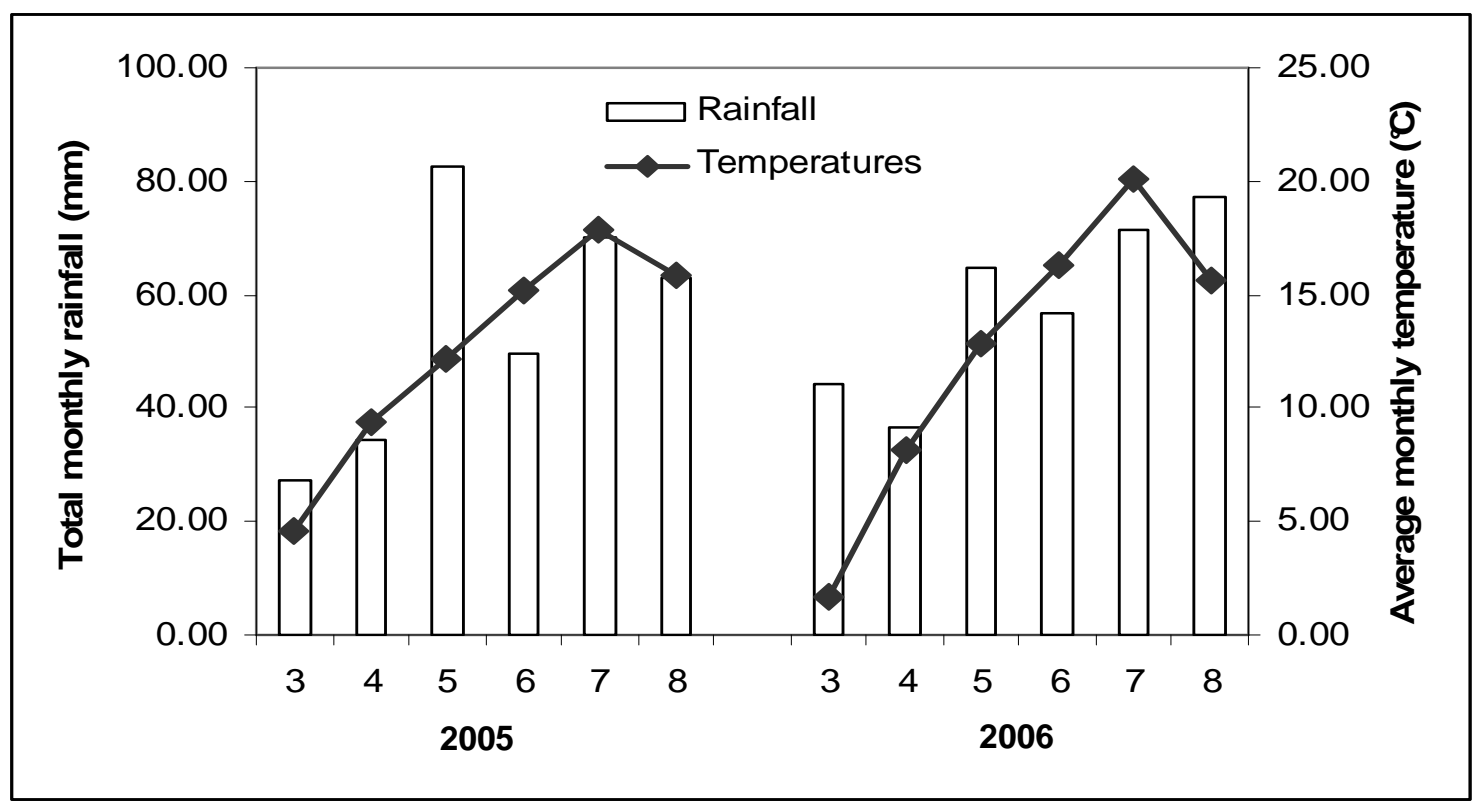

Figure 1. Average monthly temperature and total monthly rainfall in spring bean growing season for the duration of the experiment (Source: DWD, 2006).

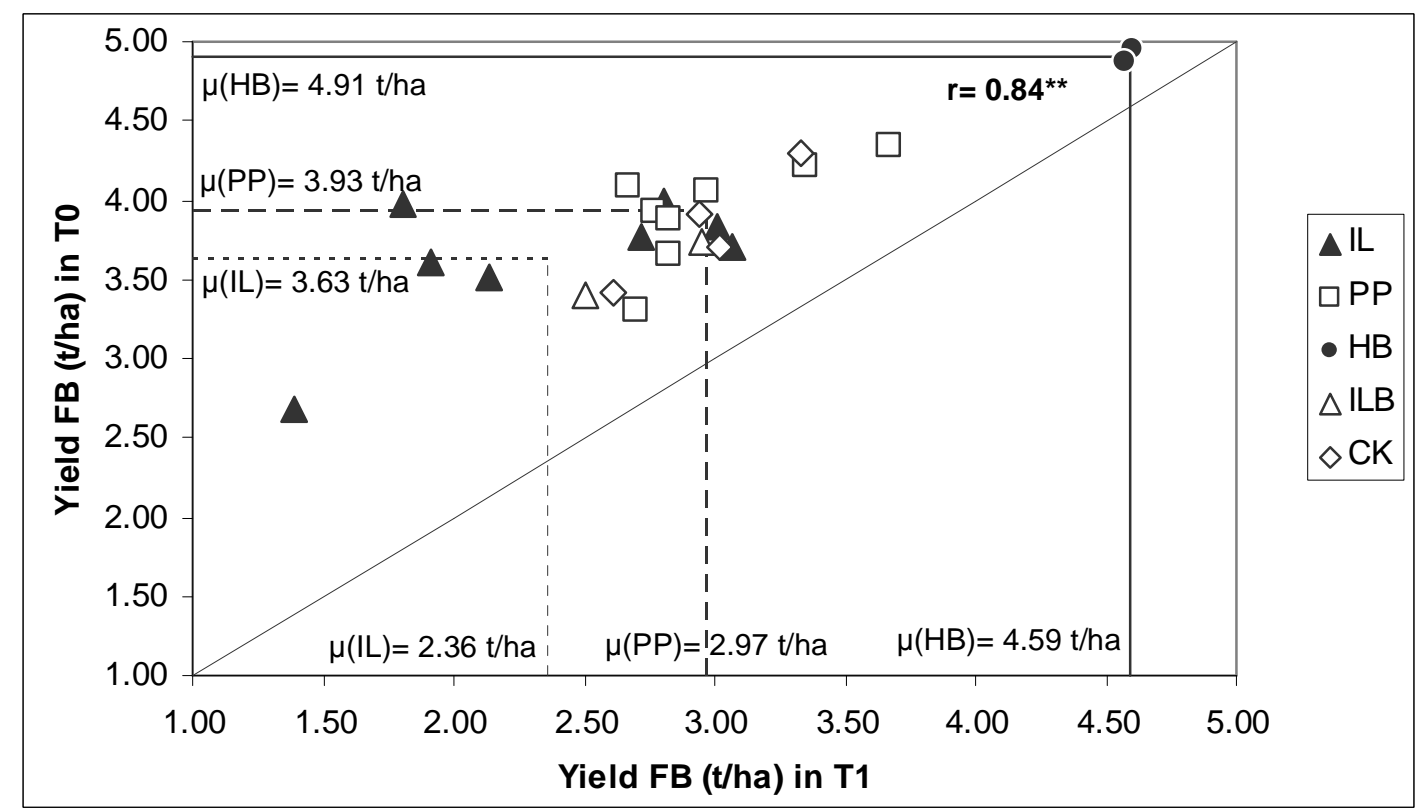

Figure 2. Relationship between the yield of faba bean with weeds (T1) and without weeds (T0) for the different genotypic structures. 


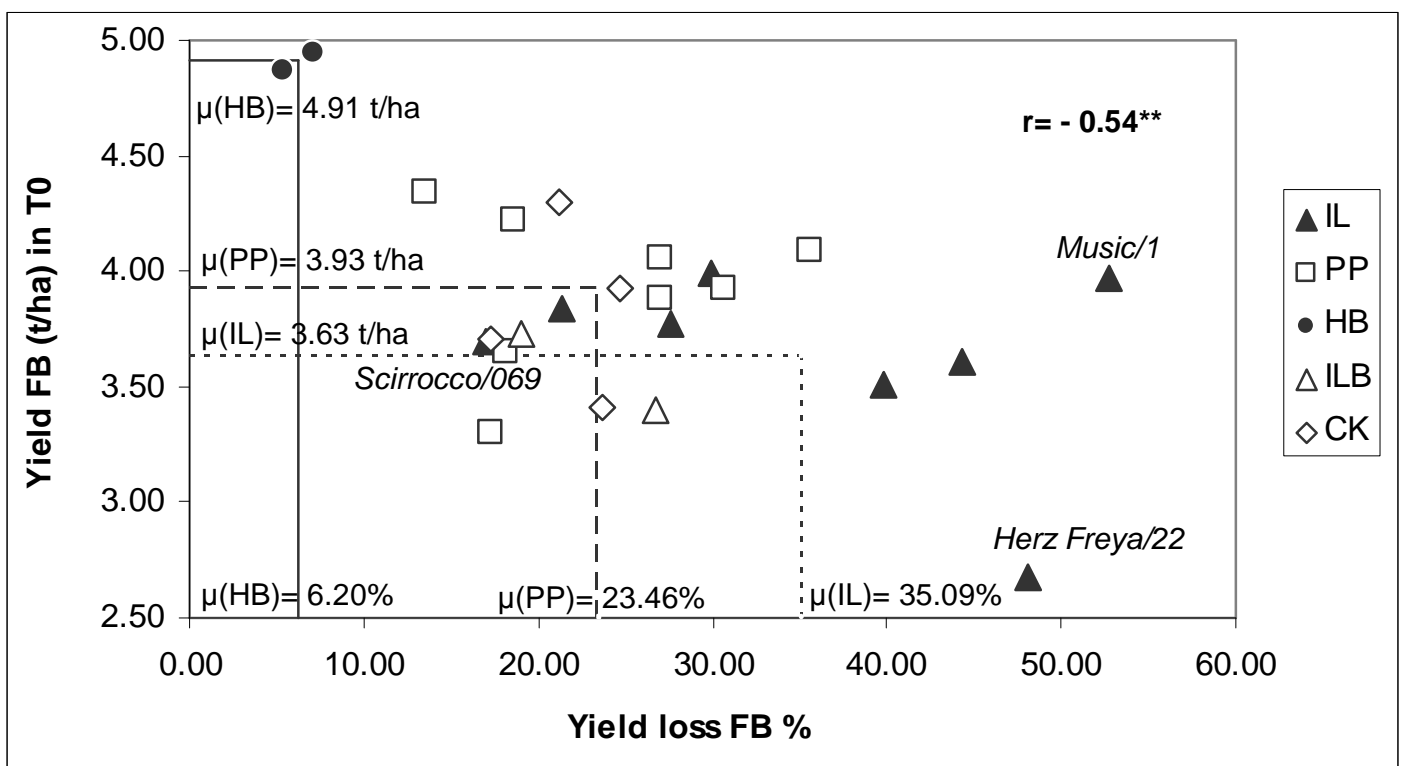

Figure 3. Relationship between yield loss (\%) in faba bean due to competition with weeds and the yield of faba bean in absence of weeds ( $t / h a)$ for the different genotypic structures.

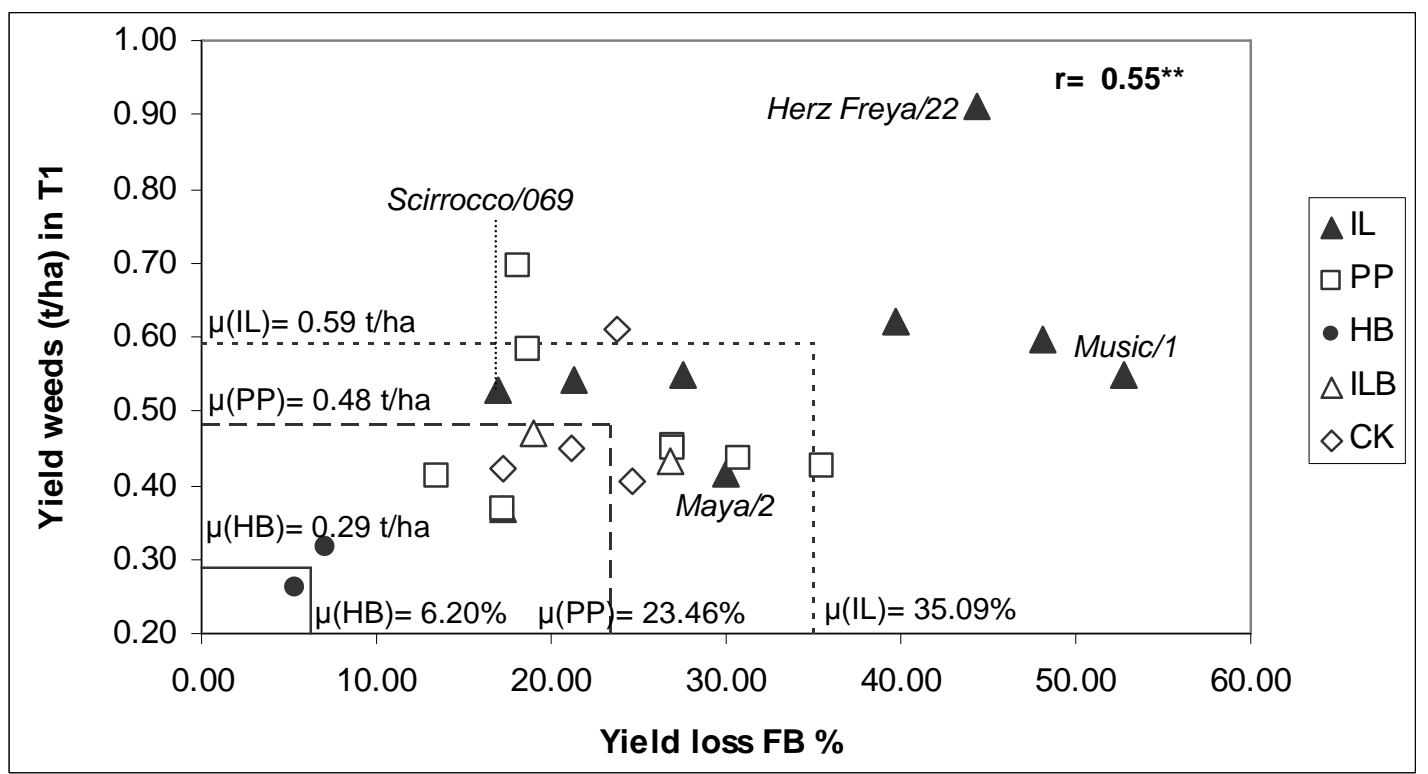

Figure 4. Relationship between yield loss (\%) in faba bean due to competition with weeds and the yield of weeds (t/ha) for the different genotypic structures. 


\section{General discussion}

In comparison to spring beans, winter beans were found to be on average earlier flowering and maturing (Table 1). The reproductive stage (duration between the beginning of flowering and maturity) was longer by 19 days in the case of winter beans, which may have contributed to the better performance of winter beans over spring beans. When they survived the winter at $70 \%$ or more, winter beans outyielded spring beans by more than one $t /$ ha. Winter bean genotypes were on average taller and more lodging than spring bean genotypes, they still resemble the outdated ideotype of faba bean, when instead of combine harvesting farmers did first swath and threshed later on, hence lodging was a minor problem. Grains of spring bean genotypes were more infested by diseases and pests than grains of winter genotypes. As spring bean flower and mature later than winter beans, they are more subject to disease and pest attacks such as aphids.

The genotype $\times$ location interactions were marked and highly significant for both spring bean and winter bean genotypes (Chapter I and II). Genotypes were displaying a specific adaptation and mis-adaptations to locations. Through the analysis of additive main effects and multiplicative interaction (AMMI), a detailed analysis of the genotype $\times$ location interactions was performed for grain yield in both spring beans and winter beans. In spring beans, data across three years (2004, 2005 and 2006) were used whereas only one year data (2005) were used for winter beans. The AMMI approach is based on the analysis of variance of the main effects of the genotypes and the environments (here location) combined with a principal component analysis of the genotype $\times$ location interactions (Gauch and Zobel, 1996).

In spring beans, the two first AMMI axes were highly significant and explained $73 \%$ of the total variability of the trait. The first interaction principal component axis (IPCA 1) was largely explained by the locations Deppoldshausen, Willmering and Ramsthal. According to their coordinates in the main biplot (Figure 1), Willmering and Ramsthal were, as expected from their narrow geographical distance, positively correlated for their $G \times L$ interaction; they were both 
negatively correlated to Deppoldshausen. The second axis (IPCA 2) was mainly explained by Tröndel and Reinshof whose interaction pattern displayed a negative correlation (Figure 1). The inbred lines Maya/2 and Music/1 were specifically adapted to the location Willmering. Indeed Music/1 was the highest yielding inbred line in this location and both inbred lines were parental components of the best synthetic in Willmering (Chapter I). To test genotype's stability and specific adaptation, the AMMI stability value (ASV) was estimated (Purchase, 1997). Adugna and Tlabuschagne (2002) found in a linseed data set the highest rank correlations among the ASV and the deviations from regression $\left.\left(s^{2} d\right) ; r=0.794^{* *}\right)$; the second highest correlation was with Shukla's stability variance, which is equivalent to ecovalence $\left(r=0.721^{* *}\right)$. These findings illustrate the operation mode of ASV in detecting stable and specifically adapted genotypes.

Most inbred lines were markedly adapted or mis-adapted to the locations since as group they displayed high interactions with the locations (mean ASV=0.46); whereas the polycross progenies were less specifically adapted (mean $\mathrm{ASV}=0.37$ ). Checks (mean $\mathrm{ASV}=0.32$ ) behaved similar to the polycross progenies which is to be expected since they were constituted as well from partly heterozygous and heterogeneous cultivars.

Especially in the case of inbred lines, local breeding is advantageous as compared to formal breeding since local breeding approach allows using the specific adaptation of particular genotypes to specific locations.

Based on the main effects of the locations for grain yield, it seemed that this effect in organic locations was either low (Deppoldshausen and Tröndel) or negative (Ramsthal and Willmering). Only the non-organic location Reinshof had a high positive main effect, i.e., a high average performance (Figure 2). It is worth to stress that this high performance in Reinshof was not mainly due to the conventional farming practices but was essentially due to the favorable agroecological conditions in this location. It is expected to find such favorable location as well in organic areas. Concerning the genotypes, inbred lines displayed on 
average a negative main effect $(-0.39 \mathrm{t} / \mathrm{ha})$, the polycross progenies a positive main effect $(0.28 \mathrm{t} / \mathrm{ha})$ and the hybrid blend had the highest main effect $(1.22$ t/ha; Figure 2).

The correlation coefficient between the IPCA1-score of the 18 inbred lines with the IPCA1-score of their polycross-progenies was highly significant $\left(r=0.73^{\star \star}\right)$ which showed that $G \times L$ interactions of the polycross progenies are to some extent inherited from the lines.

Among genotypes having a positive main effect, the two inbred lines Maya/2 and Scirocco/096 were positively interacting with unfavorable environments (Ramsthal and Willmering). These inbred lines were specifically adapted to these locations. The polycross progenies displayed in general no or negative interactions with the unfavorable environments. The hybrid was specifically adapted to Reinshof and displayed as well negative interactions with these unfavorable environments (Figure 2).

In winter beans, only the first axis was significant and explained $61 \%$ of yield variation (Figure 3). Based on this axis, apart from Tröndel, all locations were positively correlated. The interaction pattern was largely determined by the polycross progeny Avrissot/1 showing an IPCA1 score of 1.25. The polycross progeny of Avrissot/1 displayed a very marked, positive interaction with Tröndel and marked, negative interactions with the other locations. The polycross of Avrissot/1 was among the least winter-hardy genotypes, thus explaining its specific adaptation to this mild site at the Baltic Sea coast.

Similarly to the spring beans, grain yield main effect of Reinshof was the highest (1.68 t/ha) and the lowest in Ramsthal (-1.49 t/ha) and Willmering (-1.67 t/ha) (Figure 4). Ramsthal and Willmering were unfavorable locations for both spring and winter beans. As for spring bean, winter inbred lines had a negative main effect $(-0.64 \mathrm{t} / \mathrm{ha})$, whereas polycross progenies had a positive one $(0.63 \mathrm{t} / \mathrm{ha})$. Unlike spring beans, no inbred line with positive main effect was found to positively interact with the two unfavorable locations. The outcome of the comparison between the homogeneous homozygous and the heterozygous 
heterogeneous genotypes such as synthetics for the organic locations showed that heterozygous and heterogeneous genotypes were the best yielding genotypes. Inbred lines on the other side were the most specifically adapted or mis-adapted to the locations since their interactions with the locations were the highest. In unfavorable locations (Ramsthal and Willmering), a high intensity of selection allowed the best inbred lines to show up among the best genotypes. Considering biotic stress, heterozygous genotypes were the most competitive cultivars against weed stress which is a detrimental biotic stress in organic farming (Chapter IV). Heterogeneity in synthetic cultivars is also expected to have a positive effect on their yield performance (Chapter III). Hence, synthetic cultivars through their high yield, high yield stability, high competitive ability against weeds and their option to buffer the environmental changes realize many aspects that favor their adoption in organic farming. As the locations were markedly different and the genotype $\times$ location interaction was displaying a large variance, local breeding is likely to be more efficient than formal breeding. It is obvious that the local breeding is more efficient than formal breeding in the case of inbred line breeding than in the case of synthetic breeding since the inbred lines displayed much higher interactions with the locations. The yield of the best expected inbred line although lower than the yield of the best expected synthetic is still high and some inbred lines were found as well to be very competitive to weed stress. The adoption of inbred line cultivars bred locally in organic conditions is also a reasonable alternative when uniformity in certain characters is required, as for example in vegetable beans or when quality aspects are important such as zero tannin or low vicine convicine.

Due to its partial allogamy, the case of faba bean is very instructive. The analyses of line and synthetic cultivars, contrasting in heterozygosity and heterogeneity and of formal vs. local breeding for organic farming showed that the findings were critical and could not be predicted unless valid experimental data are available. In allogamous crops where the degree of cross fertilization is about $100 \%$ such as in maize, inbreeding depression and heterosis are very high. Therefore, inbred lines in maize (being homogenous) are out of discussion 
as type of cultivar. Hybrid cultivars, being as well homogenous, suffer as well from heavy inbreeding depression if multiplied inter se, and moreover loose their homogeneity. Thus, no option for a homogeneous type of cultivar that is relatively good performing and could be grown successively over time is available. For a cross-fertilizing crop, the population cultivar is the only type that fits the requirement of a good performance plus the option to be locally reproduced and evolve. Since population cultivars show small $G \times L$ interactions, the difference between local breeding and formal breeding to achieve the best gains of selection would be weak.

In fully self fertilizing crops, a comparison between two contrasting cultivars in heterogeneity is possible: the homogeneous inbred line cultivars and the heterogeneous inbred lines mixture cultivars (multiline variety). In a specific location, only one given inbred line could be best adapted. The inclusion of further inbred lines to build a line mixture cultivar would inevitably decrease the performance. Considering yield performance, the best inbred line is expected to win in both breeding approaches and local breeding is expected to be more efficient than formal breeding. However, considering disease and pest management as well as yield stability, inbred lines mixture cultivars could be privileged over a line cultivar (Finckh et al., 2000).

\section{References}


Adugna, W., and M. Tlabouschagne, 2002. Genotype-environment interactions and phenotypic stability analyses of linseed in Ethiopia. Plant Breeding. 121: 66-71.

Finckh, M. R., et al., 2000. Cereal variety and species mixtures in practice, with emphasis on disease resistance. Agronomie. 20: 813-837.

Gauch, H. G., and R. W. Zobel. 1996. AMMI Analysis of Yield Trials. In: Genotype by environment interaction. M. S. Kang and H. G. Gauch (eds.). pp 85-122. CRC Press, Boca Raton, FL.

Purchase, J. L. 1997. Parametric analysis to describe genotype $x$ environment interaction and yield stability in winter wheat. PhD Thesis. Department of Agronomy, Faculty of Agriculture of the University of the Free state, Bloemfontein, South Africa. 
General discussion

\begin{tabular}{lllllll}
\hline Crop & $\begin{array}{l}\text { Flowering time } \\
\text { days }\end{array}$ & $\begin{array}{l}\text { Height } \\
\mathrm{cm}\end{array}$ & $\begin{array}{l}\text { Lodging } \\
\text { score }\end{array}$ & $\begin{array}{l}\text { Maturity } \\
\text { days }\end{array}$ & $\begin{array}{l}\text { Grain status } \\
\text { score }\end{array}$ & $\begin{array}{l}\text { Yield } \\
\text { t/ha }\end{array}$ \\
\hline Winter bean & 141.0 & 112.5 & 3.24 & 220.4 & 2.60 & $4.53 \S$ \\
Spring bean & 165.3 & 107.4 & 2.72 & 225.7 & 3.76 & 3.38 \\
\hline
\end{tabular}

$\S$ Yield of winter genotypes with an overwintering equal or more than $70 \%$.

Lodging (score 1-9; 1: fully upright, $9=$ totally lodging) and grains status (score 1-9; 1: healthy, 9: fully infested).

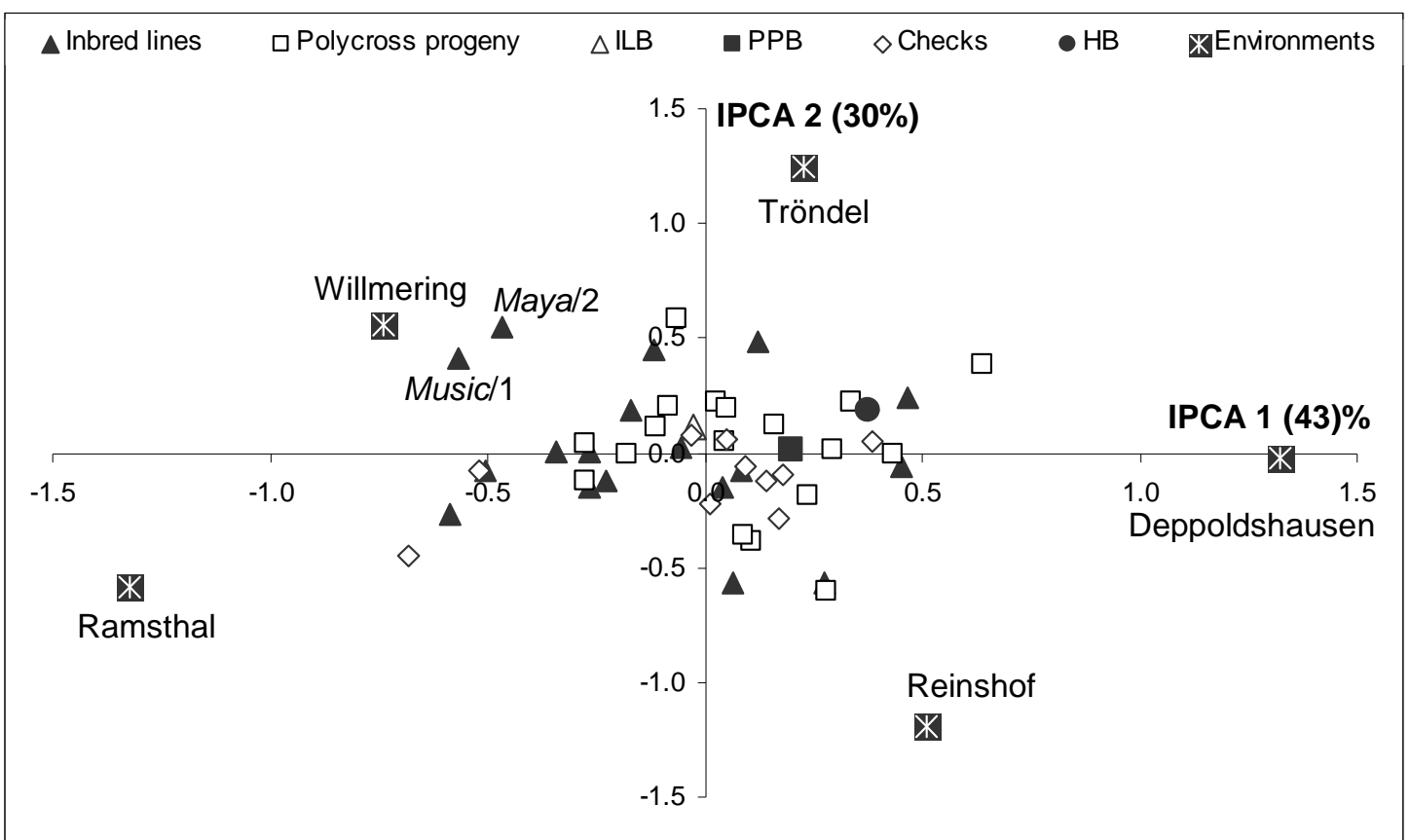

Figure 1. AMMI main biplot for grain yield ( $t /$ ha) performance of 49 spring bean genotypes (mean across three years) and five locations. 


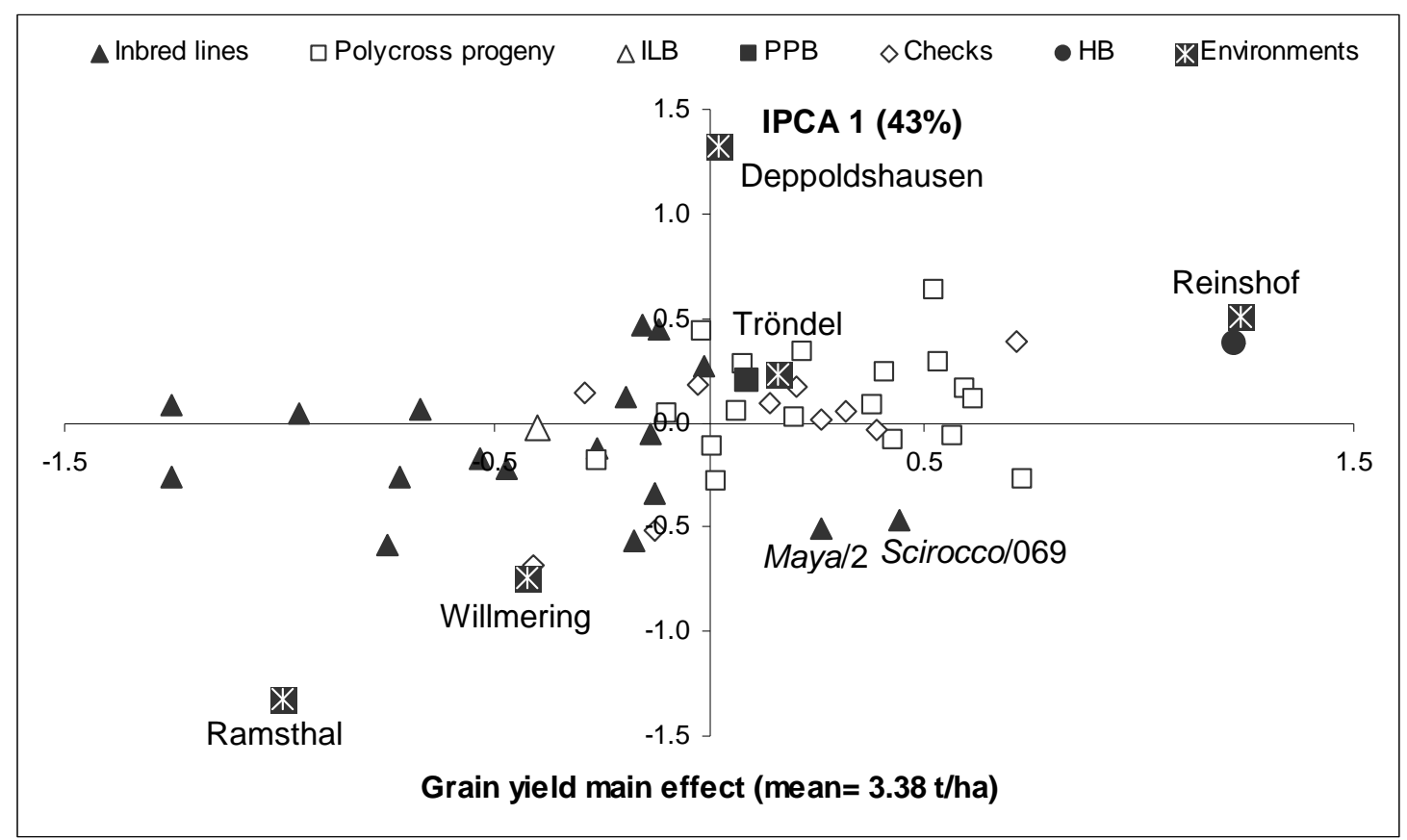

Figure 2. AMMI biplot of the first principal component axis and grain yield main effect (t/ha) of 49 spring bean genotypes (mean across three years) and five locations.

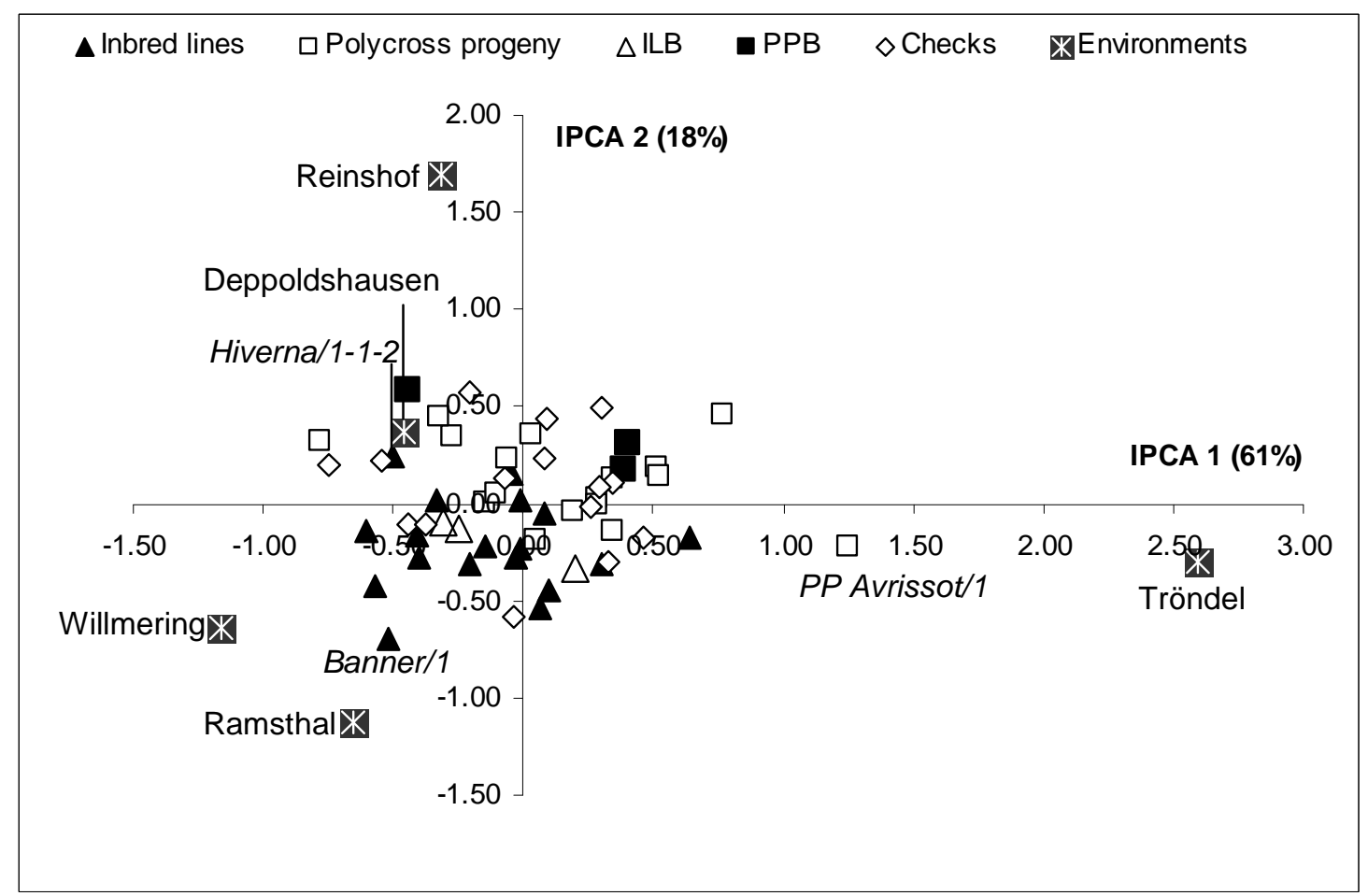

Figure 3. AMMI main biplot for grain yield ( $\mathrm{t} / \mathrm{ha}$ ) performance of 56 winter bean genotypes (year 2005) and five locations. 
General discussion

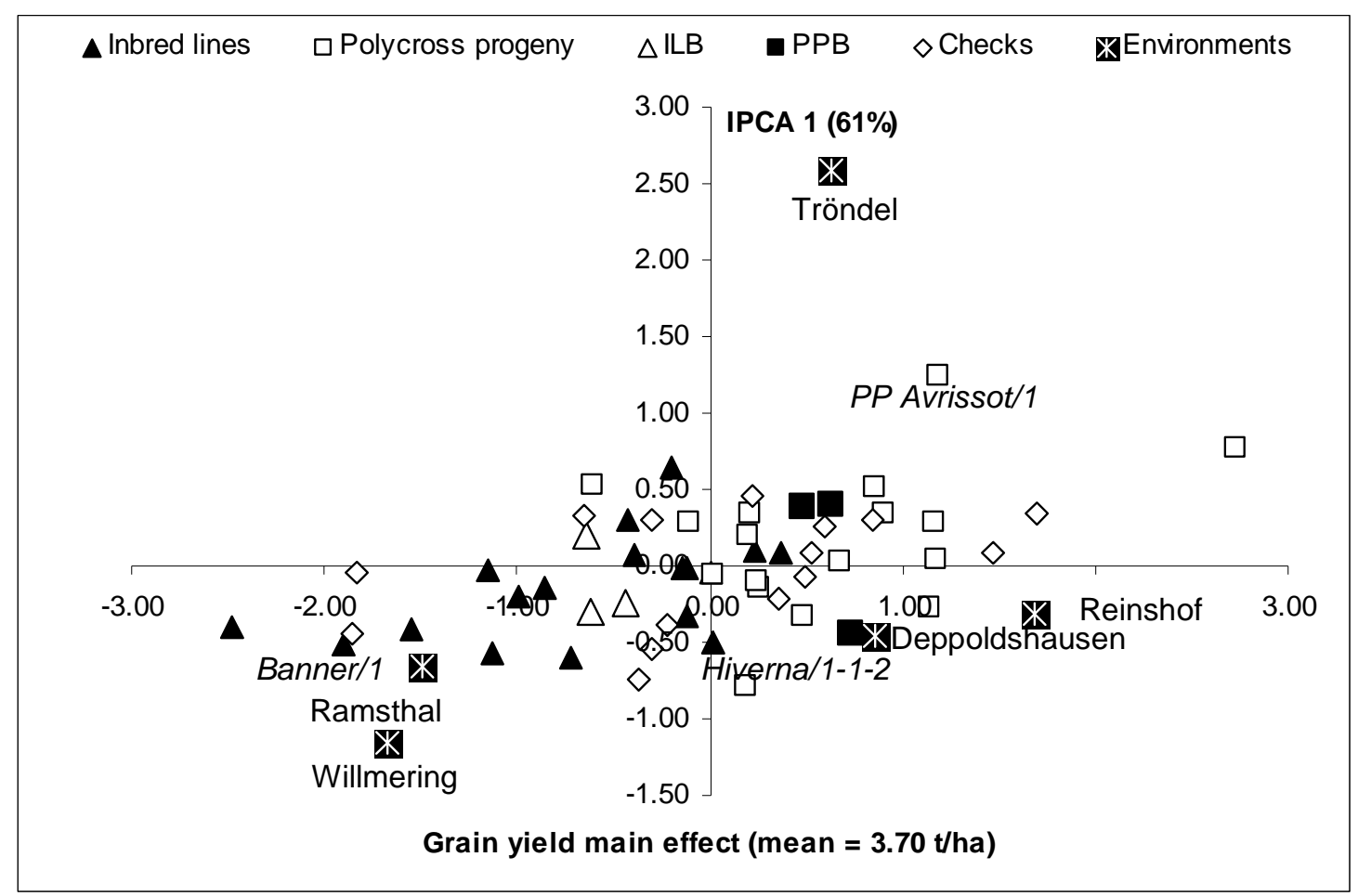

Figure 4. AMMI biplot of the first principal component axis and grain yield main effect (t/ha) of 56 winter bean genotypes (year 2005) and five locations. 
Appendices

Appendix I.

Spring bean genotypes used in this study.

\begin{tabular}{|c|c|c|c|c|c|}
\hline Material & Genotypic structure & Chapter I & Chapter II & Chapter III & Chapter IV \\
\hline Maya/2 & Inbred line & $\sqrt{ }$ & $\sqrt{ }$ & & $\sqrt{ }$ \\
\hline Merkur/2 & Inbred line & $\sqrt{ }$ & $\sqrt{ }$ & $\sqrt{ }$ & $\sqrt{ }$ \\
\hline Scirocco/069 & Inbred line & $\sqrt{ }$ & $\sqrt{ }$ & & $\sqrt{ }$ \\
\hline Styria 343 & Inbred line & $\sqrt{ }$ & $\sqrt{ }$ & & $\sqrt{ }$ \\
\hline Alfred/9 & Inbred line & $\sqrt{ }$ & $\sqrt{ }$ & & \\
\hline Gloria/5 & Inbred line & $\sqrt{ }$ & $\sqrt{ }$ & & \\
\hline Gobo/1 & Inbred line & $\sqrt{ }$ & $\sqrt{ }$ & & \\
\hline Herz Freya/22 & Inbred line & $\sqrt{ }$ & $\sqrt{ }$ & & $\sqrt{ }$ \\
\hline Karna/2 & Inbred line & $\sqrt{ }$ & $\sqrt{ }$ & & \\
\hline L1_MxCEx/19 & Inbred line & $\sqrt{ }$ & $\sqrt{ }$ & & \\
\hline L2_MxCEx/25 & Inbred line & $\sqrt{ }$ & $\sqrt{ }$ & & \\
\hline MarisBead/1 & Inbred line & $\sqrt{ }$ & $\sqrt{ }$ & & \\
\hline Mars/2 & Inbred line & $\sqrt{ }$ & $\sqrt{ }$ & & \\
\hline Music/1 & Inbred line & $\sqrt{ }$ & $\sqrt{ }$ & & $\sqrt{ }$ \\
\hline Peleponnes & Inbred line & $\sqrt{ }$ & $\sqrt{ }$ & & \\
\hline Pistache/4 & Inbred line & $\sqrt{ }$ & $\sqrt{ }$ & & $\sqrt{ }$ \\
\hline Troy/1 & Inbred line & $\sqrt{ }$ & $\sqrt{ }$ & $\sqrt{ }$ & $\sqrt{ }$ \\
\hline Viktor/2 & Inbred line & $\sqrt{ }$ & $\sqrt{ }$ & & \\
\hline Basic Population & Cultivar & $\sqrt{ }$ & & & \\
\hline Basic Population Elite & Cultivar & $\sqrt{ }$ & & & $\sqrt{ }$ \\
\hline Divine & Cultivar & $\sqrt{ }$ & & & \\
\hline Syn-3 & Cultivar & $\sqrt{ }$ & & & $\sqrt{ }$ \\
\hline Mélodie & Cultivar & $\sqrt{ }$ & & & \\
\hline Limbo & Cultivar & $\sqrt{ }$ & & & \\
\hline Samba & Cultivar & $\sqrt{ }$ & & & \\
\hline Syncro & Cultivar & $\sqrt{ }$ & & & \\
\hline Bilbo & Cultivar & $\sqrt{ }$ & & & $\sqrt{ }$ \\
\hline Espresso & Cultivar & $\sqrt{ }$ & & & $\sqrt{ }$ \\
\hline
\end{tabular}

Polycross progenies derived from the inbred lines and inbred lines blends were used in Chapters I and IV. Polycross progenies blend was used in Chapter I. Hybrids blends were used in Chapters I, III and IV. 
Appendices

\section{Appendix II.}

Winter bean genotypes used in this study.

\begin{tabular}{|c|c|c|}
\hline Material & Genotypic structure & Chapter I \\
\hline Arrissot/1 & Inbred line & $\sqrt{ }$ \\
\hline Banner/1 & Inbred line & $\sqrt{ }$ \\
\hline Bourdon/1 & Inbred line & $\sqrt{ }$ \\
\hline Bulldog/1-4 & Inbred line & $\sqrt{ }$ \\
\hline Côte d' Or/2-4 & Inbred line & $\sqrt{ }$ \\
\hline Hiverna/1-1-2 & Inbred line & $\sqrt{ }$ \\
\hline L79/79/1 & Inbred line & $\sqrt{ }$ \\
\hline L977/88/S1wn & Inbred line & $\sqrt{ }$ \\
\hline L979/S1/1/1sn & Inbred line & $\sqrt{ }$ \\
\hline Webo/1-1-1 & Inbred line & $\sqrt{ }$ \\
\hline Wibo/1 & Inbred line & $\sqrt{ }$ \\
\hline S4-25 & Inbred line & $\sqrt{ }$ \\
\hline S4-30 & Inbred line & $\sqrt{ }$ \\
\hline S4-45 & Inbred line & $\sqrt{ }$ \\
\hline S4-227 & Inbred line & $\sqrt{ }$ \\
\hline S4-241 & Inbred line & $\sqrt{ }$ \\
\hline S4-280 & Inbred line & $\sqrt{ }$ \\
\hline S4-324 & Inbred line & $\sqrt{ }$ \\
\hline Wab 98-267 & Cultivar & $\sqrt{ }$ \\
\hline Target & Cultivar & $\sqrt{ }$ \\
\hline Clipper & Cultivar & $\sqrt{ }$ \\
\hline Striker & Cultivar & $\sqrt{ }$ \\
\hline Irena & Cultivar & $\sqrt{ }$ \\
\hline Diva & Cultivar & $\sqrt{ }$ \\
\hline D_461 & Cultivar & $\sqrt{ }$ \\
\hline Pōp. Gleisdorf & Cultivar & $\sqrt{ }$ \\
\hline Population selbst & Cultivar & $\sqrt{ }$ \\
\hline
\end{tabular}

Polycross progenies derived from the inbred lines, inbred lines blends and polycross progenies blends were used in Chapter I. 
Summary

\section{Summary}

Faba bean (Vicia faba L.) as a grain legume is a low input crop that fits well to the organic farming and provides the organic cropping system with a number of advantages (e.g., break crop, positive N-balance, weed suppression). The use of chemical inputs in conventional farming partially buffers the effects of environmental variation on crops. In organic farming the use of genetic variation as a way to cope with agro-ecological, environmental variation and to reduce the risks of crop failure is of high importance. Therefore, organic farming requires cultivars that are specifically adapted to organic conditions. The main objectives of the present study were: (1) to develop locally adapted cultivars in faba bean for a set of organic farms in Germany through a participatory breeding approach, (2) to compare local versus formal breeding, and inbred line versus synthetic cultivars for organic farming, (3) to assess the effect of heterogeneity for inbreeding status and plant height on competition among faba bean genotypes and finally (4) to test the competitive ability against weeds of faba bean genotypes contrasting in their heterozygosity and heterogeneity and in their plant height.

To fulfill the first objective, 49 spring bean genotypes and 56 winter genotypes with different genotypic structures (more or less heterozygous and heterogeneous), were tested in field trials across four organic farms and one conventional site in Germany across 2004, 2005 and 2006. The material involved in case of spring beans as well as for winter beans, was composed from 18 inbred lines, their 18 polycross progenies, polycross progenies blends, inbred lines blends, one hybrids blend (spring beans) and checks. Yield performance of synthetic cultivars was predicted through the yield performance of inbred lines and their polycross progenies. For the second objective, data of the genotypic performance of inbred lines and polycross progenies of spring bean genotypes over the five locations across the three years were considered. For the third objective, an experiment across three years (2004, 2005 and 2006) was conducted in one location where a tall hybrid, a tall hybrid blend, a short hybrid blend, a tall and a short inbred line were tested in all possible two component 
Summary

"line plus hybrid" and "line plus line" combinations. A sequence of five proportions of the two components was established per combination. Competition effects were recorded at both plot level and at the individual component level. Concerning the fourth objective, a set of 24 genotypes composed from different genotypic structures: eight inbred lines, eight polycross progenies, two inbred line blends, two hybrid blends and four checks were tested under two treatments with weeds and without weeds. The competitive ability of these faba bean genotypes against weeds was tested with a model weed Camelina sativa in two locations during two years (2005 and 2006).

The outcome of these experiments showed that farmer's criteria of selection were strongly influenced by biotic and abiotic constraints faced by the crop in each location. Yield constituted for all partners an important trait for the evaluation of the genotypes. Unexpectedly, uniform rather than diverse genotypes were apparently appreciated by organic farmers. Due to the large genotype $\times$ location interaction in organic locations, local breeding proved to generate higher gains from selection and was obviously more efficient than formal breeding. Despite the large variance among inbred lines available in local breeding which allowed a high gain from selection, highest yielding synthetics were superior in both breeding strategies to highest yielding inbred lines due to their partially expressed heterosis. Through their heterogeneity and heterozygosity, synthetic cultivars have the advantage to be more stable and adaptable across years to a given environment. Besides, heterogeneity for inbreeding status, a characteristic of faba bean synthetic cultivars, proved to be advantageous and led to an increase in yield performance. Heterogeneity in plant height in the case of inbred lines was not found to be favorable for yield performance. As heterozygosity increased in the genotypes, the competitive ability against weeds increased, shown by the hybrid blends which were the most competitive genotypes, whereas inbred lines were least competitive. No correlation was found between the yield performance of genotypes and their competitive response within the genotypic structures (e.g., within lines). Competitive ability against weeds was improved by heterozygosity and high plant 
height, although some inbred lines were found to be as competitive to weed stress as the partially heterozygous and heterogeneous polycross progenies and checks.

However, through the different aspects of this study, generally heterozygosity and heterogeneity appeared to be the required characteristics in a cultivar in order to match the conditions and constraints of organic farming. Hence, the synthetic cultivar seemed to be the adequate type of cultivar fitting the requirement of organic farming. 


\section{Zusammenfassung}

Die Fababohne (Vicia faba L.) ist als Körnerleguminose eine 'low input'-Frucht, die gut zur ökologischen Landwirtschaft passt und die dem ökologischen Anbausystem eine Reihe von Vorteilen gibt (z.B. ,break crop', positive N-Bilanz, Unkraut-Unterdrückung). Der Einsatz von Chemikalien in der konventionellen Landwirtschaft mildert dort teilweise die Auswirkungen von Umweltschwankungen auf die Feldfrucht. In der ökologischen Landwirtschaft ist es sehr wichtig, genetische Variation zu nutzen als Mittel, um mit den agroökologischen und umweltbedingten Schwankungen umzugehen, um das Risiko eines Anbau-Misserfolges zu vermindern. Deswegen benötigt die ökologische Landwirtschaft Sorten, die besonders an die ökologischen Bedingungen angepasst sind.

Die hauptsächlichen Ziele dieser Studie waren: (1) lokal angepasste Fababohnen-Sorten für einige ökologische Bauernhöfe in Deutschland zu entwickeln, und dazu den partizipativen Ansatz zu wählen, (2) eine lokale mit der üblichen, überregionalen Pflanzenzüchtung zu vergleichen, und Inzuchtlinien mit synthetischen Sorten als Sortentyp für die ökologische Landwirtschaft zu vergleichen, (3) die Wirkung von Heterogenität des Inzuchtstatus und der Wuchshöhe auf die Konkurrenz zwischen Fababohnen-Genotypen abzuschätzen und schließlich (4) die Konkurrenzkraft zwischen Unkraut und AckerbohnenGenotypen zu prüfen, wenn die Bohnen sich in ihrer Heterozygotie, Heterogenität und Wuchshöhe kontrastierend unterscheiden.

Für das erste Ziel wurden 49 Sommerbohnen-Genotypen und 56 WinterbohnenGenotypen mit unterschiedlicher genotypischer Struktur (hoch und niedrig heterozygot bzw. heterogen) in Feldversuchen über vier ökologische Standorte und einen konventionellen Standort in Deutschland über die Jahre 2004, 2005 und 2006 geprüft. Das Material umfasste sowohl bei Winterbohnen als auch bei Sommerbohnen 18 Inzuchtlinien, ihre 18 Polycross-Nachkommenschaften, Polycross-Nachkommenschafts-Mischungen, Inzuchtlinien-Mischungen, eine F1Hybriden-Mischung (Sommerbohnen) und Kontroll-Genotypen. Der Ertrag von synthetischen Sorten wurde aus dem Ertrag von Inzuchtlinien und ihren 
Polycross-Nachkommenschaften vorhergesagt. Für das zweite Ziel wurden die Resultate der genotypischen Leistung von Inzuchtlinien und PolycrossNachkommenschaften von Sommerbohnen-Genotypen über diese fünf Orte und diese drei Jahre betrachtet. Für das dritte Ziel wurde ein Experiment über drei Jahre $(2004,2005,2006)$ an einem Ort durchgeführt, wo geprüft wurden: eine hochwüchsige Hybride, eine hochwüchsige Hybriden-Mischung, eine kurze Hybriden-Mischen, eine hoch- und eine kurzwüchsige Inzuchtlinie, dieses in allen möglichen Zwei-Komponenten-Kombinationen des Typs „Linie plus Hybride“ und „Linie plus Linie“. Für jede Kombination wurde eine Serie von fünf MischungsAnteilen der je zwei Komponenten aufgestellt. Effekte aufgrund von Konkurrenz zwischen den Komponenten wurden auf der Ebene der Parzellen und auf der Ebene der einzelnen Komponenten erfasst. Was das vierte Ziel betrifft, so wurde ein Satz von 24 Genotypen, der aus verschiedenen genotypischen Strukturen zusammengesetzt wurde (acht Inzuchtlinien, acht PolycrossNachkommenschaften, zwei Inzuchtlinien-Mischungen, zwei F1-HybridenMischungen, vier Kontroll-Genotypen) unter zwei Behandlungen geprüft: mit Unkraut und ohne Unkraut. Die Konkurrenzkraft dieser Fababohnen-Genotypen gegenüber dem Unkraut wurden mit dem Modell-Unkraut Camelina sativa in zwei Orten in den Jahren 2005 und 2006 geprüft.

Die Resultate dieser Versuche zeigten, dass die Kriterien der Landwirte bei der züchterischen Auslese stark durch die biotischen und abiotischen Bedingungen beeinflusst war, denen die Ackerfrucht an dem jeweiligen Ort ausgesetzt war. Der Ertrag bildete für alle Partner ein wichtiges Merkmal für die Einschätzung der Genotypen. Unerwarteterweise wurden anscheinend eher homogene Genotypen als heterogene Genotypen von den Landwirten wertgeschätzt. Aufgrund der großen Genotyp x Orts-Interaktionen der ökologischen Anbauorte versprach eine lokale Züchtung höhere Selektionsgewinne und wäre offensichtlich effizienter als die überregionale Züchtung. Trotz der großen Varianz zwischen Inzuchtlinien, die einer lokalen Züchtung zur Verfügung steht und die einen hohen Auslesegewinn erlaubt, waren die Synthetiks mit dem höchsten Ertrag in beiden Züchtungsstrategien aufgrund ihrer partiell genutzten 
Heterosis den Linien mit dem höchsten Ertrag überlegen. Durch ihre Heterogenität und Heterozygotie haben synthetische Sorten den Vorteil, an einem gegebenen Anbauort über die Jahre stabiler und auch anpassungsfähig zu sein. Außerdem zeigte sich klar, dass Heterogenität für den Inzuchtstatut, eine Eigentümlichkeit von Fababohnen-Synthetiks, ein Vorteil ist und zu einer Erhöhung der Ertragsleistung führt. Heterogenität der Wuchshöhe im Fall von Inzuchtlinien wurde nicht als Vorteil für die Ertragsleistung gefunden. Mit der Heterozygotie der Genotypen stieg die Konkurrenzkraft gegenüber Unkräutern, was durch die Hybriden-Mischungen gezeigt wurde, die die höchste Konkurrenzkraft hatten, wohingegen Inzuchtlinien am konkurrenzschwächsten waren. Es wurde innerhalb einer genotypischen Struktur (z.B. innerhalb der Gruppe der Inzuchtlinien) keine Korrelation zwischen der Ertragsleistung von Genotypen und ihrer Konkurrenz-Reaktion gefunden. Die Konkurrenzkraft gegen Unkräuter wurde durch frühe Blüte, hohen Wuchs und hohe Heterozygotie verbessert, obwohl einige Inzuchtlinien gefunden wurden, die gegen den Unkrautstress ebenso konkurrenzkräftig waren wie die teilweise heterozygoten und heterogenen Polycross-Nachkommenschaften und Kontroll-Genotypen.

Dennoch, über all die verschiedenen Aspekte dieser Studie erschien generell Heterozygotie und Heterogenität als notwendiges Charakteristikum einer Sorte, um zu den Bedingungen und Auflagen der ökologischen Landwirtschaft zu passen. Somit scheint die synthetische Sorte der angemessene Sortentyp zu sein, der den Erfordernissen der ökologischen Landwirtschaft entspricht. 
Résumé

\section{Résumé}

En tant que légumineuse, la féverole (Vicia faba L.) nécessite peu d'intrants et se trouve par conséquent appropriée pour l'agriculture biologique. La féverole fournit au système organique divers avantages: elle constitue un bon précédent cultural et approvisionne le sol en azote.

L'utilisation des intrants agrochimiques dans le cadre de l'agriculture conventionnelle permet de tamponner partiellement les effets de la variation environnementale sur les cultures. Par ailleurs, au sein de l'agriculture biologique, l'exploitation de la variation génétique est d'une grande importance, car elle permet de tamponner les variations agroécologiques et environnementales. Par conséquent, des variétés spécifiquement adaptées aux contraintes de l'agriculture biologique sont requises. Les principaux objectifs de la présente étude étaient de: (1) développer des variétés de féverole locallement adaptées pour une série de fermes biologiques en Allemagne tout en moyennant une approche participative (2) comparer dans un premier temps le système d'amélioration locale avec le système d'amélioration formelle et dans un second temps les variétés lignées avec les variétés synthétiques dans le cadre de l'agriculture biologique (3) évaluer l'effet de l'hétérogénéité du degré de consanguinité et la hauteur de la plante sur la compétition entre les génotypes de la féverole et enfin (4) tester la capacité compétitive contre les mauvaises herbes des génotypes de féveroles qui différent pour leur degré d'hétérozygotie et d'hétérogénéité ainsi que leur hauteur de la plante.

Afin de répondre au premier objectif, 49 génotypes de féverole de printemps et 56 génotypes de féverole d'hiver avec différentes structures génotypiques (plus ou moins hétérozygotes et hétérogènes) ont été testés au champ sur quatre fermes en agriculture biologique et sur une ferme en conventionnel en Allemagne durant les années 2004, 2005 et 2006. Le matériel testé comprenait 18 lignées fixes, leurs 18 progénitures issues du polycross, une mixture des lignées fixes, une mixture des progénitures issues du polycross, une mixture d'hybrides (féverole de printemps) et des contrôles. La performance en rendement des variétés synthétiques a été prédite dépendamment du rendement 
des lignées fixes et des 18 progénitures issues du polycross. Concernant le second objectif, les données de la performance génotypique des lignées et des polycross de la féverole de printemps dans les cinq localités durant les trois années d'études ont été considérées. Pour répondre au troisième objectif de cette étude, une expérience a été conduite dans une localité durant les trois années (2004, 2005 et 2006) où un hybride haut, une mixture d'hybrides hauts, un hybride court, une mixture d'hybrides courts, une lignée haute et une lignée courte ont été testés dans toutes les combinaisons á deux composantes possibles du type «lignée - hybride » et «lignée - lignée ». Au sein de chaque combinaison, une série de cinq proportions par composante a été adoptée. L'effet de la compétition a été enregistré au niveau de la parcelle aussi bien qu'au niveau individuel des composantes. Enfin, l'expérience conduite pour le quatrième objectif comprenait une série de 24 génotypes composés de différentes structures génotypiques: huit lignées, leurs huit polycross respectifs, deux mixtures de lignées, deux mixtures d'hybrides et quatre contrôles. Ces génotypes ont été testés sous deux différents traitements: avec mauvaises herbes et sans mauvaises herbes. La capacité compétitive des génotypes de féverole contre les mauvaises herbes a été étudiée avec Camelina sativa utilisée en tant que mauvaise herbe modèle dans deux localités durant deux années (2005 et 2006).

Les résultats de ces expériences ont démontrés que les critères de sélection des agriculteurs étaient fortement influencés par les contraintes biotiques et abiotiques présentes dans chaque localité. Le rendement en grain a constitué pour tous les partenaires un trait important dans l'évaluation des génotypes. Les génotypes uniformes comparativement aux génotypes hétérogènes ont été les plus appréciés par les agriculteurs. Considérant l'importance de l'interaction génotype $\times$ localité existant dans les localités en agriculture biologique, le système d'amélioration locale est supposé générer de meilleurs gains de sélection et être plus efficace que le système d'amélioration formelle. Dans le système d'amélioration locale, bien que la variance exhibée au sein des lignées était large, permettant ainsi de meilleurs gains de sélection, les synthétiques 
avec les meilleurs rendements se sont révélées plus performantes que les lignées avec les meilleurs rendements. Ce résultat qui s'explique par l'heterosis partiellement exprimé chez les synthétiques était aussi bien valable dans le système d'amélioration locale que formelle. A travers leur hétérogénéité et leurs hétérozygotie, les variétés synthétiques ont l'avantage d'être plus stable et adaptable au cours du temps dans un environnement donné. Par ailleurs, l'hétérogénéité dans le degré de consanguinité qui constitue un trait des variétés synthétiques, s'est révélée avantageuse puisqu'elle a mené à une augmentation du rendement en grain. L'augmentation du degré d'hétérozygotie dans les génotypes a entraîné une augmentation de leur capacité compétitive contre les mauvaises herbes. Les mixtures des hybrides possédaient la meilleure capacité compétitive contre les mauvaises herbes alors que les lignées étaient les moins compétitives. Au sein des structures génotypiques, aucune corrélation n'a été trouvée entre la performance en rendement et la compétitivité contre les mauvaises herbes. La compétitivité contre les mauvaises herbes dépendait essentiellement de I hétérozygotie et de la hauteur des génotypes.

Les différents aspects traités dans cette étude révèlent que les variétés synthétiques semblent être les plus adéquates qui satisfont les exigences de l'agriculture biologique de la féverole. 


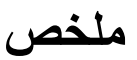

تعتبر زراعة الفول زراعة ذات إحتباجات محدودة، وبذلك فهي زراعة جد ملائمة للزراعة العضوية. إضافة لذلك، نزود زراعة الفول نظام الزراعة العضوية بامتياز ات عديدة خاصة في الزراعة الدورية وتوفير عنصر النيتروجين. استعمال المواد الكيميائية في إطار الزر اعة التقليدية يمكن جزئيا من تخفيف تأثير التغيرات البيئية. أما في إطار الزراعة العضوية، يشكل استعمال التغير ات الور اثية عنصر ا أساسيا للتغلب على التغيرات البيئية و التقليل من خطر ضياع الزر اعة. بالتالي، تتطلب الزراعة العضوية أصنافا متكيفة بصورة خاصة مع الظروف العضوية. ترتكز الأهداف الرئيسية لهذه الدراسة في:

أو لا، تطوير أصناف من الفول متكيفة محليا لمجموعة من المزارع العضوية بألمانيا. ثانيا، مقارنة نظام التربية النباتية المحلي والرسمي إلى جانب مقارنة أصناف السلالة النقيه والأصناف التركيبية (synthetic variety) في إطار الزر اعة العضوية. ثالتا، تقدير تأثير درجة التجانس، درجة الإضواء وطول النبات على التنافس بين أصناف الفول. رابعا، فحص القدرة التنافية ضد الأعشاب الضارة لأصناف من الفول مختلفة من حيث درجة التجانس، درجة الهجن (heterozygosity) وطول النبات. للإجابة على الهدفين الأولين، تم إستعمال 9؛ صنفا من الفول الربيعي و 9 ه صنفا من الفول الثتوي. تختلف هذه الأصناف من حيث درجة التجانس و درجة الهجن (heterozygosity) وتتقسم إلى: ^/ سلالة نقية، 1/ (polycross progeny) مستنبطة من السلالات النقية، مزيج من السلالات النقية، مزيج من polycross progeny) مزيج من عدة أهجنة (hybrids) وشواهد. تمت التجارب الحقلية في أربعة مزارع عضوية وموقع تقلبدي بألمانيا خلال ثلاث

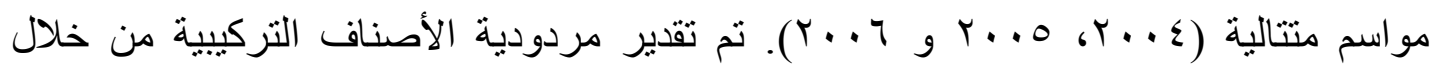
مردودية السلالات النقية إلى جانب مردودية polycross progeny م 


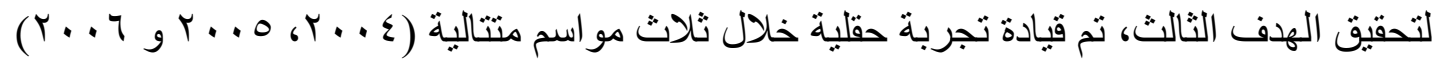
في موقع واحد. ارتكزت التجربة على تحليل مجموعة من التركيبات من نوع "سلالة نقية ـ هجين" و "سلالة نقية - سلالة نقية" ثم سجل تأثير التنافس على مستوى المزيج و على مستوى الصنف. في إطار تحقيق الهدف الرابع، ثم فحص مجموعة من \& ب صنف من الفول الربيعي مختلفة في درجة التجانس والهجن. زرعت هذه الأصناف في غياب و حضور الأعشاب الضارة. أرشدت نتائج التجارب أن معايير الانتقاء المستعملة من طرف المزارعين تأثرت بشكل كبير بالظروف البيئية التي واجهتها الزراعة في كل موقع. شكلت المردودية بشكل عام معيار أساسيا لتقييم الأصناف وفضل المزارعون الأصناف المتجانسة. نظر ا للتفاعل الكبير بين الأصناف والموقع، خاصة في المواقع العضوية، حقق نظام تربية النبات المحلي ارتفاعا في المردودية أعلى مقارنة مع نظام تربية النبات الرسمي. فاق الصنف التركيبي ذا أعلى مردودية السلالة النقية ذات أعلى مردودية باعتبار نظام تربية النبات المحلي وكذا الرسمي. تعود هاته النتيجة أساسيا للتعبير الجزئي للهجن في الصنف التركيبي. أدى التغاير في مستوى الإضواء و هي خاصية من خواص الصنف التركيبي، إلى تزايد المردودية. أدى ارتفاع مستوى الهجن إلى ارتفاع مقرة النبات في التنافس ضد الأعثاب الضارة، بينما لم يظهر أي ارتباط بين المردودية في غياب الأعثاب الضارة، والقدرة التنافسية داخل مجموعة معينة من الأصناف (كالسلالات النقية). تعتمد القدرة التنافية للنبات ضد الأعثاب الضارة على درجة

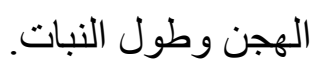
وضحت مجمو عة نتائج هذه الدراسة، أن الصنف التركيبي يمثل الصنف الملائم للزر اعة العضوية لفصيلة الفول. 


\section{Acknowledgment}

$$
\text { الحمد لله }
$$

I am very grateful to Prof. Dr. Wolfgang Link for his very valuable supervision and excellent guidance throughout the study period. I owe him for a large extent the knowledge I acquired during my PhD work. Beyond the perfect relationship with the Professor, I thank Wolfgang for the very pleasant conversations we had and his advices and help throughout those three years.

I express my sincere thanks to Prof. Dr. Heicko C. Becker for his helpful comments and suggestions regarding the analysis of the data.

My thanks are addressed to Prof. Dr. Mohammed Sadiki for his willingness to take the role of co-referee and to Prof. Dr. Johannes Isselstein for kindly consenting to be a member of the examination committee.

I am very grateful to the organic farmers: Alex Hausladen, Günter Neder and Henning Untiedt for conducting managing and scoring the trials in their farms. I also thank Werner Vogt-Kaute from Naturland-Verband for keeping the constant contact between us and the farmers.

The financial support of BMLEV (Bundesministerium für Landwirtschaft, Ernährung und Verbrauchschutz) is thankfully acknowledged.

My warmest gratitude is due to Regina Martsch for the excellent work achieved in the field experiments and for her kindness and the warm relationship we had at the private level.

My special thanks extend to my colleague and husband Mustapha Arbaoui for his never ending support and his valuable help for the achievement of this PhD work.

I thank Dr. Hans Weber for accepting to receive me so kindly in his laboratory in Gatersleben for the achievement of the protein analysis.

I am thankful to Dr. Sabine von-Witzke Ehbrecht, Dr. Friedrich Kopish O'Buch, Dr. Christian Möllers, Dr. Wolfgang Ecke and all the colleagues of the Crop Sciences Department for their kindness, help and the interesting discussions we had. 
I thank especially Mladen and Suzanne for being beyond the colleagues, very nice friends and for sharing a great time together.

Finally, I am indebt to my parents for allowing me to reach this level of education and for being simply "the perfect parents". 


\section{Curriculum Vitae}

\section{Lamiae Ghaouti}

Date of birth: 09.05.1979

Marital Status: Married

Nationality: Moroccan

Von-Siebold-Str 8, 37075, Göttingen, Germany

Tel: (0049)551.39.43.55

E-Mail: lamiaeghaouti@hotmail.com

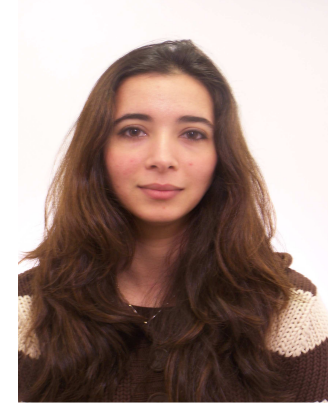

\section{Education}

2007: PhD Diploma, specialized in Plant Breeding at the Crop Sciences Department (GeorgAugust University, Göttingen, Germany) and supervised by Prof. Dr. Wolfgang Link. The chief aim of this German project was to combine the efforts of organic farmers and scientists in a participatory breeding approach to develop region specific cultivars of spring and winter bean.

2003: Master Diploma, engineer in agronomy specialized in plant breeding at the Agronomic and Veterinary Institute, Rabat, Morocco. First in the master class. The research part was supervised by Prof. Mohamed Sadiki and was led in the frame of IPGRI project (International Plant Genetic Resources Institute) aiming to develop in-situ conservation of faba bean in North Morocco.

2001: Diploma of General Agronomy at the Agronomic and Veterinary Institute, Rabat, Morocco.

1997: Diploma of Scientific Baccalaureate at "Omar El Khayam” in Rabat, Morocco.

\section{Trainings}

2000: Training for one month in a Moroccan farm to analyse the management of its agricultural system for vegetal as well as animal production.

1999: Training for three weeks in the north of Morocco to discover the nature and rural areas.

1998: Training as a worker in a French farm near to Montellimar for two months and half.

\section{Professional experience}

Since 2004: Assistant to the scientific research at the Crop Sciences Department of Göttingen, (Georg-August University) in Germany. Tasks assigned encompassed the project 
management, trials planning and data analysis as well as the contribution to national and international scientific meetings.

\section{Informatics and statistical knowledge}

- Excel, Word and Power Point : very good

- Statistical software (STATITCF and PLABSTAT): very good

\section{Languages knowledge}

- Arabic : mother tongue

- French : very good

- English : good

- German : average

\section{Publications}

- Sadiki M., M. Arbaoui, L. Ghaouti, D. Jarvis, 2004. Seed exchanges and supply systems and on farm maintenance of crop genetic diversity. A case study: faba bean in Morocco. In 'Seed System and Crop Genetic Diversity on Farm' Jarvis D.I., R. Sevilla Panizo, J.L. ChavezServia, and T. Hodgkin, Editors.

- Ghaouti L., W. Vogt-Kaute, W. Link, 2005. Development of region-specific organic cultivars in faba bean, pp 61-62. In 'Ende der Nische'. 8. Wissenschaftstagung Ökologisher Landbau, 1-4 March 2005, Kassel, Germany. J.Heß and G.Rahman, Editors.

- Ghaouti L., W. Vogt-Kaute, W. Link, 2006. A Participatory Breeding Approach to develop locally adapted cultivars in winter and spring faba bean (Vicia faba L.). In 'Participatory Plant Breeding: Relevance for Organic Agriculture?', pp 58-64. Proceeding of the ECO-PB Workshop, 11-13 June 2006, La Besse, France. D. Desclaux and M. Hédont, Editors.

- Ghaouti L., W. Vogt-Kaute, W. Link, 2006. Region specific breeding for organic conditions in winter and spring faba bean. In 'International Workshop on Faba Bean Breeding and Agronomy' pp 87-89. 25-27 October 2006, Cordoba, Spain. Junta de Andalucia, Editors.

- Ghaouti L., W. Vogt-Kaute, W. Link, 2007. Genotype $\times$ location interactions are advantageous for local breeding of faba bean (Vicia faba L.). In 'Zwischen tradition und Globalisierung'. 9. Wissenschaftstagung Ökologisher Landbau, Universität Hohenheim, Germany, 23-27 March 2007.

\section{In the process of publication:}

- Ghaouti L., W. Vogt-Kaute, W. Link, 2007. Development of locally-adapted faba bean cultivars for organic conditions in Germany through a participatory breeding approach. Submitted to "Euphytica".

- Ghaouti L., and W. Link, 2007. Comparison between local vs. formal breeding and inbred line vs. synthetic cultivars for organic farming. Case of Vicia faba L. submitted to "Crop Science".

- Ghaouti L., and W. Link, 2007. Relevance of competition effects among genotypes in breeding faba bean (Vicia faba L.). Submitted to "J. of Agronomy and Crop Science".

- Ghaouti L., and W. Link, 2007. Effect of competition between Vicia faba L. and Camelina sativa as a model weed in breeding for organic conditions. Submitted to Weed research 